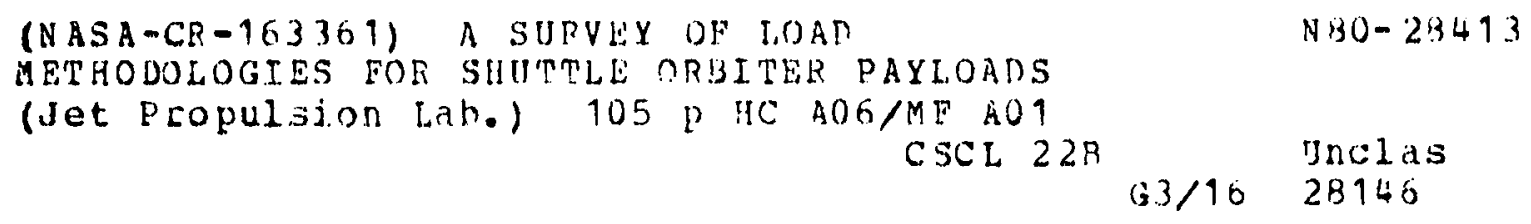

\title{
A Survey of Load Methodologies For Shuttle Orbiter Payloads
}

\author{
J.C. Chen \\ J.A. Garba \\ M. Salama \\ M. Trubert
}

June 15,1980

National Aeronautics and Space Administration

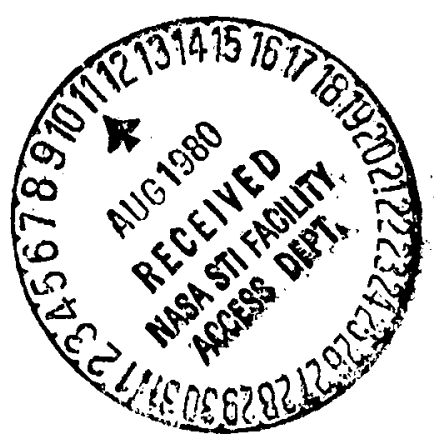

Jet Propulsion Laboratory

California Institute of Technology

Pasadena, California 


\title{
A Survey of Load Methodologies For Shuttle Orbiter Payloads
}

\author{
J.C. Chen \\ J.A. Garba \\ M. Salama \\ M. Trubert
}

June 15,1980

National Aeronautics and

Space Administration

Jet Propulsion Laboratory

California Institute of Technology

Pasadena, California 


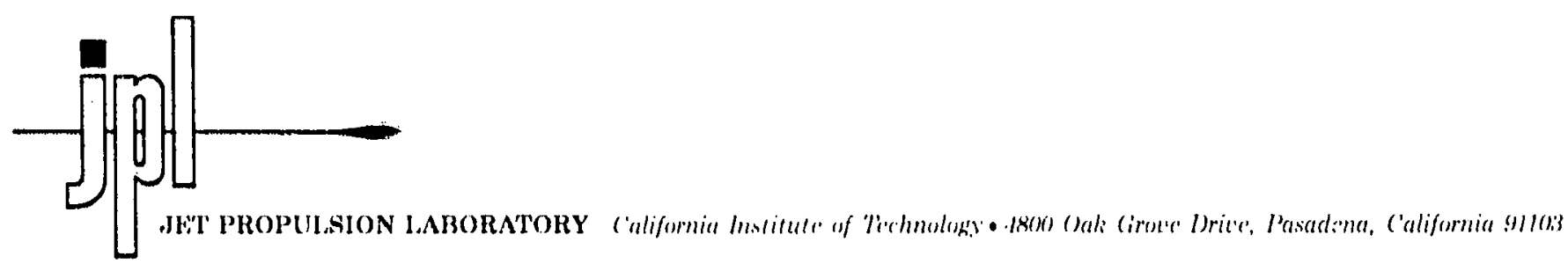

July 15,1980

Recipients of Jet Propulsion Laboratory

Publication 80-37

\section{SUBJECT: Errata}

Please note the following corrections to JPL Publication 80-37, A Survey of Load Methodologies for Shuttle Orbiter Payloads, by J.C. Chen, J.A. Garba, M. Salama, and M. Trubert, dated June 15, 1980:

Page 63, Eq. IV-53 should read as:

$$
[G]=\left[\left[\bar{\phi}_{I}\right]^{\mathrm{T}}\left(\left[\overline{\mathrm{m}}_{\mathrm{er}}\right]^{\mathrm{T}}-\left[\overline{\mathrm{m}}_{\mathrm{rr}}\right]\left[\phi_{I}\right]\right)-\left[\bar{\psi}_{\mathrm{P}}\right]^{\mathrm{T}}\left[\overline{\overline{\mathrm{m}}}_{\mathrm{er}}\right]\left[\phi_{I}\right]\right]
$$

Page 63, Eq. IV-54. The last line of the equation should be:

$$
\left.\left.=\left(\left[\bar{\phi}_{\mathrm{R}}\right]\left[\phi_{\mathrm{OI}}\right]\left[\bar{\psi}_{\ell}\right]+\left[\phi_{2}\right]\left[\bar{\psi}_{\mathrm{p}}\right]\right) \mid \ddot{\bar{q}}_{(t)}\right\}+\left[\bar{\phi}_{\mathrm{R}}\right] \mid \ddot{\mathrm{x}}_{\mathrm{I}}\right\}
$$

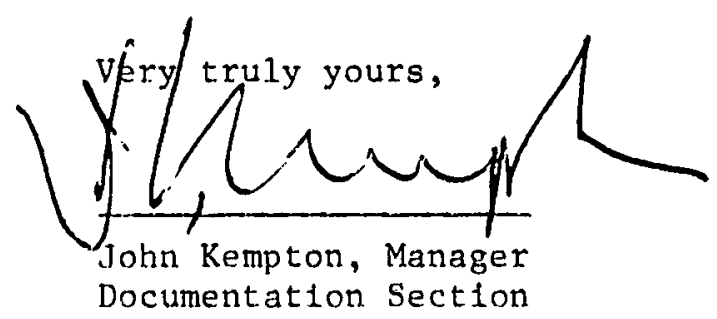


This report summarizes past experiences in payloads analys is methods as well as proposed future methods. As such, it includes direct or indirect contribution by a large number of individuals within the aerospace community, as well as at the Jet Propulsion Laboratory. All of the contributions are too numerous to mention. Specific thanks and acknowledgements are extended to Dr. Ted Nishimoto, Rockwell International, Messrs. Robert Dyrdahl and Steve Church, both of Boeing Aerospace Company, Dr. George Morosow of Mart in Marietta Aerospace Division, and Messrs. R. Herzberg, C. Coale and R. Dotson of Lockheed Missile and Space Company.

The original work on the shock spectra impedance method has been pioneered by Mr. Robert Bamford, JPL. The Viking Orbiter Loads Analysis effort was directed by Mr. Ber Wada of JPL. The International Solar Polar Mission Spacecraft Loads Analysis was performed by Messrs. R. F. Tillman and K. Zagzebski, both of IPL.

This research effort has also been supported by Mr. R. Goetz and Dr. A. Amos, Materials and Structures Division, Office of Aeronautics and Space Technology, NASA. 
ABSTRACT

Loads methods currently being used to design Shuttle Orbiter payloads are summarized. Methods used for the design of payloads launched by expendable launch vehicles are described in historical perspective. Experiences gained from expendable launch vehicle payloads are used to develop methodologies for the Space Shuttle Orbiter payloads. The objectives for the development of a new metiodology for the Shuttle payloads are to reduce the cost and schedule for the payload load analysis by decoupling the payload analysis from the launch vehicle to the maximum extent possible. Methods are described for payload member load estimation or obtaining upper bounds for dynamic loads, as well as load prediction or calculating actual transient member load time histories. 
I. INTRODUCTION

II. EARLY LOADS METHODOLOGY FOR EXPENDABLE BOOSTERS 5

A. - The Ranger Lunar Spacecraft 5

B. The Surveyor Lunar Spacecraft 7

C. The Mariner Interplanetary Spacecraft 10

III. SPACE VEHICLE SYSTEM TRANSIENT LOADS ANALYSES

A. Viking Orbiter Structural Design Criteria 16

B. Viking Orbiter Dynamic Analyses 16

C. Structural Testing 24

D. Flight Instrumentation 27

E. Summary of Experiences Gained From Viking 27

IV. LOADS PREDICTION METHODS FOR SHUTTLE PAYLOADS 29

A. Loads Estimation Techniques 29

B. Transient Load Analysis Techniques 44

C. Comparison of Load Estimation Methods to
Transient Loads Methods

$\begin{array}{ll}V . & \text { OTHER METHODS } \\ \text { V. }\end{array}$

A. Time Uncorrelated Maxima and Minima 70

B. Impedance Technique for Determining Low-Frequency
Payload Environments

C. Coupled Base Motion Response Analys is of Payload
Structural Systems

D. Modification of Flight Vehicle Vibration Modes to
Account for Design Changes 
APPENDIXES

A. COMPARISON OF MEASURED AND ANALYTICALLY PREDICTED MEMBER FORCES FOR VIKING ORBITER

B. COMPARISON OF MEASURED AND ANALYTICALLY PREDICTED MEMBER FORCES FOR VOYAGER SPACECRAFT

C. COMPARISON OF ACCELERATION LEVELS OBTAINED USING THE GENERALIZED SHOCK SPECTRA METHOD TO THOSE OBTAINED FROM THE MASS ACCELERATION CURVE

D. A SAMPLE PROBLEM FOR THE RECOVERED TRANSIENT ANALYSIS

\section{Figures}

III-1. Viking Spacecraft

-II-2. Viking Space Vehicle

III-3. Viking Orbiter System Flight Loads and Environnents, $0-450 \mathrm{sec}$

III-4. Viking Orbiter System Flight Loads and Environments, from $450 \mathrm{sec}$

III-5. Daida Flow for Viking Load Analyses

IV-1. Two Degrees of Freedom System Subject to Impulse Function

IV-2. Preliminary Design Limit Loads for Galileo Orbiter 33

[V-3. Idealization of Forcing Function 36

IV-4. Schematic of Launch Vehicle/Payload Composite Systems 46

B-1. Interface Accelerations for Launch 78

B-2. Interface Accelerations for Stage I Burnout 79

C-1. Compariso! of Acceleration Levels 86

D-1. ISPM Spacecraft 87 
D-2. STS/IUS with ISPM Payload

D-3. IUS/Galileo Interface Accelerations

D-4. Load Time History for RCS Thruster Outrigger

$\underline{\text { Tables }}$

I-1. Classification of STS Payloads

III-1. Events for Viking Orbiter System Load Analysis

III-2. Viking Orbiter System Load Analysis

III-3. Error Contributors to Viking Orbiter System Analysis IV-1. Comparison of Shock Spectra and Transient Loads iur'
Two Events

IV-2. Comparison of Shock Spectra and Transient Loads Design Loads for Major Structural Elements

IV-3. Comparison of Generalized Shock Spectra and Recovered Transient l.oads for the International Solar Polar Mission

A-1. Comparison of Viking 1 and Viking 2 Measured VLCA Forces to Preflight Analytical Predictions

B-1. Comparison of Maximum Flight and Shock Spectra Design

B-2. Comparison of Maximum Flight ard Transient Predicted Loads

D-1. International Solar Polar Mission Finite Element Model

D-2. Member Load for NA.SA/ESA Spacecraft Adapter Truss 
I. INTRODUCTION

The advent of the space shuttie as the major transportation system for U.S. space operations in the 1980's and beyond has renewed the interest in developing improved methods for payload dynamic load prediction. Consistent with the objective of the space shuttle system to achieve a low cost launch capability, cost-effective methods for obtaining payload design loads are being sought. To achieve these objectives, the Dynamic, Acoustic, and Thermal Environments (DATE) program has been formed by the NASA Office of Aeronautics and Space Technology (OAST). The DATE working group consists of representatives from NASA centers interested in structures technology and is chaired by the Goddard Space Flight Center (GSFC). The goals of DATE are the develapment and validation of improved technology for the prediction of dynanir, acoustic, and thermal environments and the associated payload responses in cargo areas of large reusable vehicles. To achieve this, extensive research-oriented environmental measurements on early shuttie flights are to be made. These data will then serve as the basis for developing better load prediction methods which are to be confirmed and refined as additional flight data become available. Uitimately these data will lead to improved spacecraft structural design criteria and test criteria [1],[2].

This repoit summarizes the loads methods for the Shuttle Orbiter payloads which are now being priposed for future usage by the payload community. A historic background of payload design methodology for expendable boosters is included for completeness. While this summary emphasizes the experiences at the Jet Propulsion Laboratory (JPL), it is representative of aerospace practice over the last 20 years. In the context of loads analysis, the term "spacecraft" is frequently used in this report to mean the payload structure carried by the launch vehicle or expendable booster.

Extensive experience has been gained in the past ai JPL in the structural design of such spacecraft as Ranger, Mariner, Surveyor, Viking, and Voyager. All these were launched using expendable boosters. 
The Galileo spacecraft currently being developed at JPL is the first interplanetary spacecraft to be launched using the Space Transportation System (STS). Over the years spacecraft structures have been designed to various criteria. In the early days of the space program the structure was typically designed to survive a sine vibration test at input levels prescribed by the environmental requirements engineers. Later as computers and finite element methods became prevalent, structures were designed to survive an analytically predicted flight load. Lately methods were developed at JPL to calculate the expected upper bounds of the member loads.

Since it is anticipated that ultimately the STS is to be used much like a cargo airplane, such that only minimal or no system preflight loads analysis will be required for high reliability missions, it is important to deviop several tools for loads predictions. The methodology to be used for a particular payload will be determined by the size, complexity, and cost of the payload, and thus by the degree of dynamic interaction with the STS. The degree of dynamic interaction between the payload and the launch vehicle is much more important for a reusable launch vehicle due to the emergency landing loads, a condition where in the spacecraft-to-launch vehicle weight ratio is higher than for typical launch events of expendable boosters.

A classification of STS payloads as to cost, size, and criticality as related to the detail of predicted analys is levels is given in Table I- 1 .

The purpose of this report is to summarize the STS loads methodology currently being used by the payload community and the methods under development to simplify the STS loads prediction. Wherever possible, the proposed methodology will be evaluated using actual design loads obtained for the Galileo (GLL) and the International Solar Polar Mission (ISPM) spacecrafts.

This summary is intended as a first step in the development of loads methodology as part of DATE, and will be updated as more experience is 
Table I-1. Classiftcation of STS payloads

\begin{tabular}{|c|c|c|c|}
\hline & Category I & Category II & Category III \\
\hline $\cos t$ & $\begin{array}{l}\text { Low cost, } \\
\text { detalled } \\
\text { transient anal- } \\
\text { ysis too severe } \\
\text { a cost penalty. }\end{array}$ & $\begin{array}{l}\text { Moderate cost, some } \\
\text { loads analysis } \\
\text { justifiable. }\end{array}$ & $\begin{array}{l}\text { Highly expensive, largo } \\
\text { cost penalty for } \\
\text { structural failure, } \\
\text { detalled loads analysis } \\
\text { justified. }\end{array}$ \\
\hline Size & $\begin{array}{l}\text { Sma1l/light, no } \\
\text { significant } \\
\text { effect on } \\
\text { orbiter, can } \\
\text { afford wt. } \\
\text { penalty. }\end{array}$ & $\begin{array}{l}\text { Some impedance } \\
\text { effects at orbiter } \\
\text { interface in low- } \\
\text { frequency range. }\end{array}$ & $\begin{array}{l}\text { Large payload/orbiter } \\
\text { dynamic interactions, } \\
\text { may effect orbiter/ } \\
\text { external tank dynamics } \\
\text { at launch. }\end{array}$ \\
\hline Criticality & $\begin{array}{l}\text { No critical } \\
\text { launch window, } \\
\text { can be } \\
\text { retrieved/ } \\
\text { repaired, } \\
\text { numerous } \\
\text { launches. }\end{array}$ & $\begin{array}{l}\text { Some duplication of } \\
\text { payloads, con- } \\
\text { straints on launch } \\
\text { windows, minimal } \\
\text { repairability }\end{array}$ & $\begin{array}{l}\text { Critical launch win- } \\
\text { dows, no retrieve/ } \\
\text { repair capability, } \\
\text { single backup } \\
\text { spacecraft. }\end{array}$ \\
\hline
\end{tabular}

\section{EXAMPLES}

Communication satellites, small science payloads, earth resources, weather satellites.
High energy/ synchronous, DOD payloads, manned orbital lab., large space telescope.
Planetary missions, comet rendezvous, out-of-ecliptic. 
gained in applying these methods and comparing the results to filight data. This report is mainly concerned with the method of obtaining loads; however, the modelling techniques, analysis/test correlation of the mathematical and test philosophy will be discussed to the extent that they relate to loads methods. 
II. EARLY LOADS METHODOLOGY FOR EXPENDABLE BOOSTERS

The structural analysis and design engineer has been searching for a systematic method to obtain dynamic loads data since the design of Explorer I in 1957, long before spacecraft structural design criteria and spacecraft environmental requirements were formalized. At that time, spacecraft designers lacked the experience and technology of the aircraft industry both in the area of loads prediction and dynamic testing. Thus, the first Explorer was conservatively designed by a combination of engineering judgemeit and requirements to de-couple the spin-frequency from structural frequencies. Structural modeling for the Explorer satelilite was limited to simple back-of-the-envelope type of calculations. The vibration test requirements were derived from existing military specifications for the Sergeant and Corporal Missiles.

As the linar and interplanetary spacecraft became larger and more complex, the design for a dynamic environment became more important.

\section{A. The Ranger Lunar Spacecraft}

Ranger was the first JPL project for which an attempt was made to design a spacecraft for a dynamic environment. The Ranger spacecraft weighed approximately $340 \mathrm{~kg}$ (750 lbs) and were launched using the Atlas/Agena Space Vehicle.

\section{Structural Design Criterion}

Although the fundamentals of the dynamics of space vehicle systems were understood at the commencement of the Ranger project, they were not documented until much later [3]. Since there was a lack of flight data, the structural design philosophy for Ranger was basically governed by an environmental specification for a system vibration test. An implied design goal was a minimum frequency criterion for the cantilevered 
spacecraft which was negotiated with the launch vehicle contractor.

2. Dynamic Analyses

Since the computer tools were limited at the time Ranger was designed, only a limited amount of static and dynamic analyses were performed. The modeling was limited to a finite element representation using truss and beam elements [4]. The dynamic analyses consisted of estimating load factors for various masses and then solving an equivalent static problem. Thus the dynamic analysis relied heavily on engineering judgement, and was mainly aimed at successfully passing the vibration test.

\section{Structural Testing}

Structural testing on Ranger consisted of developmental testing and qualification testing.

\section{a. Developmental Testing}

Extensive modal testing using multiple shakers was performed on the Ranger spacecraft. The data obtained in these tests consisted of frequencies, mode shapes, moda? damping and a limited number of force coefficients. Although data obtained in these early modal tests were not used to correlate with analysis, these data proved very valuable in re-evaluating design load factors and assessing the dynamic responses expected during qualification testing. On later Ranger spacecraft, the modal data was used to redesign the spacecraft to avoid coupling with space vehicle modes. The Ranger modal data proved very useful for the Surveyor spacecraft as will be discussed later. 
b. Onalification Tersting

The qualification test requirements for the oarly Ranger spacecraft prescribed a throe axis system vibration test to a level defined by the project environmental requirements. The input frequency spectrum was flat. This resulted in over sesting and required some redesign at the cost of structural weight. Later in the project, a limitation on the vibration input levels based on the structural capability of the Agena adapter was implemented. The justification was not to test the spacecraft to levels higher than what the support stricture could react, thus ensuring that in flight the launch vehicle support. structure would fail before the spacecraft would.

\section{Flight Instrumentation}

Flight instrumentation on the Ranger program was minimal and was mainly aimed at defining a torsional pulse which had bo: observed in flights of Atlas velicles at the time of Bonster Engine Cutoff (BECO). Two accelerometers were flown on later Ranger spacecraft to define this pulse. These flight measurements did little to affect the design of the Ranger. spacecraft other than to provide frequency inforlation, but proved to be very valuable for the survey, program.

B. The Surveyor Lunar Spacecraft

Surveyor was the first JPL project in which a limited attempt was made to use loads analysis methods to either design the structure [5], [6] or define the qualification testing [7]. The Surveyor Spacecraft weighed approximately $290 \mathrm{~kg}(620 \mathrm{lbs})$ and was launched using the Attas/Centaur Spaco Vehicle. 
1. Structural Design Criteria

The Surveyor structural design requirements were dominated by the expected 30 lunar landing loads. The launch loads were generally expected to be lower. For the launch condition the structure was basically designed to survive a sinusoidal vibration test, the input level of which was intended to envelope the expected launch acceleration. A frequericy criterion was not imposed on the spacecraft design.

2. Dynamic Analyses

Analytical tools for structural design were becoming readily available at the time the Surveyor analysis was performed. Not only were the finite element capabilities increasing [8], but also the computer core availability allowed the solution of larger structural problems.

Dynamic landing simulations were performed for the purpose of assessinq landing stability [9], [10], [11] and landing loads [12]. The landing analyses assumed a rigid spacecraft body using an elastic simulation of the non-linear landing structure. The equations of motion were integrated using a fourth order Runge-Kutta procedure. To ohtain spacecraft landing loads, the interface forces between the landing struts and the spacecraft calculated in a landing simulation were applied to the elastic spacecraft, simulated by experimentally determined normal modes. This procedure was not entirely consistent because the stability simulation program did not account for elastic responses of the spacecraft. However, in this simulation an approximation with deviations generally in the conservative direction was expected. Several redesians, especially in the antenna solar panel positioner, were perforined based on the results of the landing ioad investigation. 
for the simulation of lanch louls, a linilod amount of andysis was performed using forcina functions estimated from flight. data mrasured dering the Atlas/Mana/Ranger boost phase. These analyses wore limited to cstimates of spacecrdft response to a torsional forcing function since that was the only flight data available [6]. Similar types of analyses using the same flight. data were later performed for the GSFC Orbiting Geophysical Observatory (OGO-E) Spacecraft. [13] and the Orbiting Astronomical Observatory (OAO A-?) Spacecraft [14].

\section{Structural Testing}

Two types of structural testing for the Surveyor Spacecraft were performed: developmental testing and qualification testing.

\section{a. Develomental Testina}

Extensive modal testing with multiple shakers was performed both by the Hughes Aircraft Company (HAC) and by JPL. The data obtained in thrse tests were used both for modal correlation and for obtaining dynamic data used directly in the landing loads analysis [1?]. The modal test rosults for the boost configuration wore used directly in the torsion launch load analysis[5], [6]. Structural transfer functions were lieasured for the purnose of assessing flight. stability during the terminal docent phase [ 15$]$.

b. Qual ification Iestiun

Qualification testing was conducted for the landing loads and the launch loads. For the landing loads a prototype spacocraft with all components in flight-like configuration and nemerat inn, including the telomedry link, was type-approvel tested lor lanting in three drop tests. This was dome in onere to retahlish confidence in structural and 
functional survival of the spacecraft when subjected to the dynamic landing environment.

For the launch environment a sinusoidal vibration test on the system level was performed, allowing the input levels to be suppressed or "notched" at frequencies where the response of certain components such as the solar panel positioner exceeded the design loads as determined from a landing loads analysis.

The lack of simulation of the boundary conditions during a sinusoidal vibration test was recognized during both the Ranger and Surveyor Spacecraft [16]. It was shown analytically that severe over- or undertesting can occur. A rocking test table allowing the proper truncation and rotation inputs was proposed. This mode of testing was, however, never implemented due to cost and complexity.

4. Flight Instrumentation

Flight instrumentation on the Surveyor Spacecraft was limited to strain gauges on the landing gear to measure landing forces. Data obtained from these measurements compared favorably to analytical predictions [1]. There was no flight instrumentation flown to measure spacecraft responses during the boost phase.

C. The Mariner Interpianetary Spacecraft

The Mariner Spacecraft series was the first JPL project for which in-house loads analyses were performed for some of those flight events for which flight data was available. The Mariner spacecraft ranged in weight from $245 \mathrm{~kg}(540 \mathrm{lbs})$ to. $980 \mathrm{~kg}(2150 \mathrm{lbs})$ and were launched atop the Atlas/Centaur Space Vehicle. 


\section{Structural Design Criterion} The Mariner Spacecraft were basically designed to survive a of the input levels based on with some allowable suppression from load analysis.

2. Dynamic Analyses

The development of the modal synthesis method [17], [18] was an advancement which was exploited during the Mariner project. This method allowed subsystems to be analyzed, tested, and verified separately and then combined into a system dynamic model to be used in loads analysis or test simulation studies. On-later Mariners the Structural Analys is and Matrix Interpretive System (SAMIS) and modal synthesis was used [19],
[20].

The load analyses performed for the Mariner spacecraft utilized flight accelerometer data from previously flown space vehicles. A detailed description of the method is contained in References [21], [ 22], [23]. The fundamental idea was to use response data from a previously flown space vehicle system to predict the input to a new spacecraft design using response data from a previously flown space vehicle system. The flight data consisted of six acceleration time histories measured at the base of the spacecraft. The spacecraft/launch vehicle interface was assumed to be statically determinate, thus the linear acceleration time histories were transformed into equivalent translation and rotation accelerations at the base of the spacecraft. Furthermore, it was assumed that the equivalent component vector at function can be represented by a six vector was invariant with pays of the launch vehicle and that this system the relationship payload. For any complex structural the forcina-function 


$$
A(\omega)=H(w) F(\omega))
$$

where $A(\omega)$ is the Fourier transform of the response acceleration

$F(\omega)$ is the Fourier transform of the forcing function

$H(w)$ is the complex structural transfer function for the space vehicle, and

$\omega$ is the circular frequency, rad/sec.

It is easily seen that if $A(\omega)$ is obtained from a previous flight and the transfer functions for the previous and the new space vehicle are $H_{0}(\omega)$ and $H_{N}(\omega)$, respectively, the new spacecraft response $A(\omega)$ can be calculated from

$$
A_{N}(\omega)=H_{N}(\omega) H_{0}(\omega)^{-1} A_{0}(\omega)
$$

assuming that $F(\omega)$ is invariant.

The above method was used to estimate Mariner loads from previously flown spacecraft, both Mariner and others. It should be noted that while the method is mathematically exact there are several practical limitations. The accuracy of this method depends on obtaining phase coherent data with a minimum of telemetry noise. Furthermore, the method is inherently sensitive to the fidelity of the structural model. A difference of computed modal properties with the observed frequency response will cause a spurious response in the inverse process of Eq. $(I I-2)$.

The frequency domain approach was used in the Mariner Program both on the digital and analog computer. In addition to flight load estimation, this technique was also used for determining the shaker armature overturning moment during the low frequency 
longitudinal vibration test and for determining the control requirements during the forced vibration test.

\section{Structural Testing}

On Mariner, several unique development tests were conducted in addition to the qualification vibration test.

a. Develcpmental Testing

Frequencies, mode shapes and damping characteristics for the cantilevered Mariner Spacecraft were determined using multiple shaker sine dwell tests. The modal data were used for analytical model correlation. These test data were also used directly in the dynamic analyses. The modal survey showed that the propellant played a very important role in the proper representation of the dynamic model. Hence special dynamic testing using a single tank was performed [24]. The objective of this testing was to study the dynamic behavior of the fluid, specifically the effective weight and the damping.

b. Qualification Testing

The major structural elements of the Mariner Spacecraft were qualified by a static test using strain gauged members. The static loading conditions were determined from a combination of predicted flight loads and expected loads during the qualification vibration tests. Forced vibration testing was performed on the Mariner Spacecraft system to levels specified by the environmental requirement group. The input levels were suppressed in order not $\because$, exceed design levels for primary structure. 
4. Flight Instrumentation

Several of the Mariner Spacecraft were instrumented at the spacecraft/launch vericle interface. The instrumentation consisted of six (6) linear accelerometers placed on the adapter, such that the equivalent translational and rotational accelerations at the base of the spacecraft could be calculated assuming a rigid interface. These flight data proved extreme.y valuable and cost effective in the estimation of launch loads and test criteria for subsequent Mariner Spacecraft. 


\section{SPACE VEHICL.F SYSTEM TRANSIENT LOADS ANALYSES}

Space vehicle system transient load analysis is defined as a process wherein a detailed model of the space vehicle system, a coupled dynamic model of spacecraft and launch vehicle is analytically excited by a set of transient forcing functions to obtain spacecraft loads. The output of such analyses includes detailed member loads which are used directly for the design, and/or acceleration of masses from which member loads can be derived. These analytically determined spacecraft structural loads are used as the basis for the structural design and qualification. This approach was used for the Viking Orbiter System (VOS) which was part of the Viking project managed by the Viking Project office (VPO) at Langley Research Center (LaRC) for NASA.

The project decision to rely almost exclusively on analysis for spacecraft design was a clear technological advancement in spacecraft structural design philosophy, and was an indication that the quality of analytical tools and the understanding of launch vehicle system dynamics had reached appreciable maturity. Further advances in computer technology, the development of versatile finite element programs such as NASTRAN [25], new methods for analyzing large dynamic systems [26], and dedicated anaiyticai tools for booster analyses made a reliance on analysis possitile. The approach selected for Viking was based upon the following corsiderations: (1) requirement for a lightweight structure, (2) high reliability ior two Viking missions, (3) a new, not previously flown launch vehicle system. and (4) availability of launch vehicle engine forcing function data rom provious Titan and Centaur flights. The Viking orbiter design_experience proved extremely valuable both from a technical and organizational point of view. Lessons learned from viking were later used for developing simplified and more efficient methods for loads analysis. The Viking design process has been we11 documented [27], [28], [29], [30]. The Viking experience will be summarized here emphasizing analytical and tost methods used. 
A. Viking Orbiter Structural Design Criteria

1. Primary Structure

Any structural element whose failure would result directly in an overall spacecraft structural failure was classified as primary structure. Early in the program specific hardware items were established to be designed by transient loads analysis. Engineering judgement was used to select hardware with design loads in the low-frequency $(0$ to $30 \mathrm{~Hz}$ ) range. Design loads for the primary structure were obtained from space vehicle system loads analyses not verified by test. Flight load predictions were obtained using mathematical models verified by a test program. The qualification test levels for primary structure were based on predicted flight loads. Wherever statistical information was available the design and flight loads at the $3 \sigma$ level were used.

\section{Secondary Structure}

All other structural parts whose loading was governed by the middle or high frequency range were designated as secondary structure. Secondary structure was designed to specified test levels.

B. Viking Orbiter Dynamic Analyses

As indicated in Figs. III-1 and III-2, upward of nine organizations were responsible on the Viking project for hardware or integration functions which directly affected the evaluation of dynamic transient loads. The significant forcing functions anticipated during the flight are jllustrated in Figures III-3 and III-4. Table III-1 shows the number of forcing functions or conditions for which the space vehicle system had to be designed. A major analytical effort was expended on Viking to obtain design and flight loads both by the 


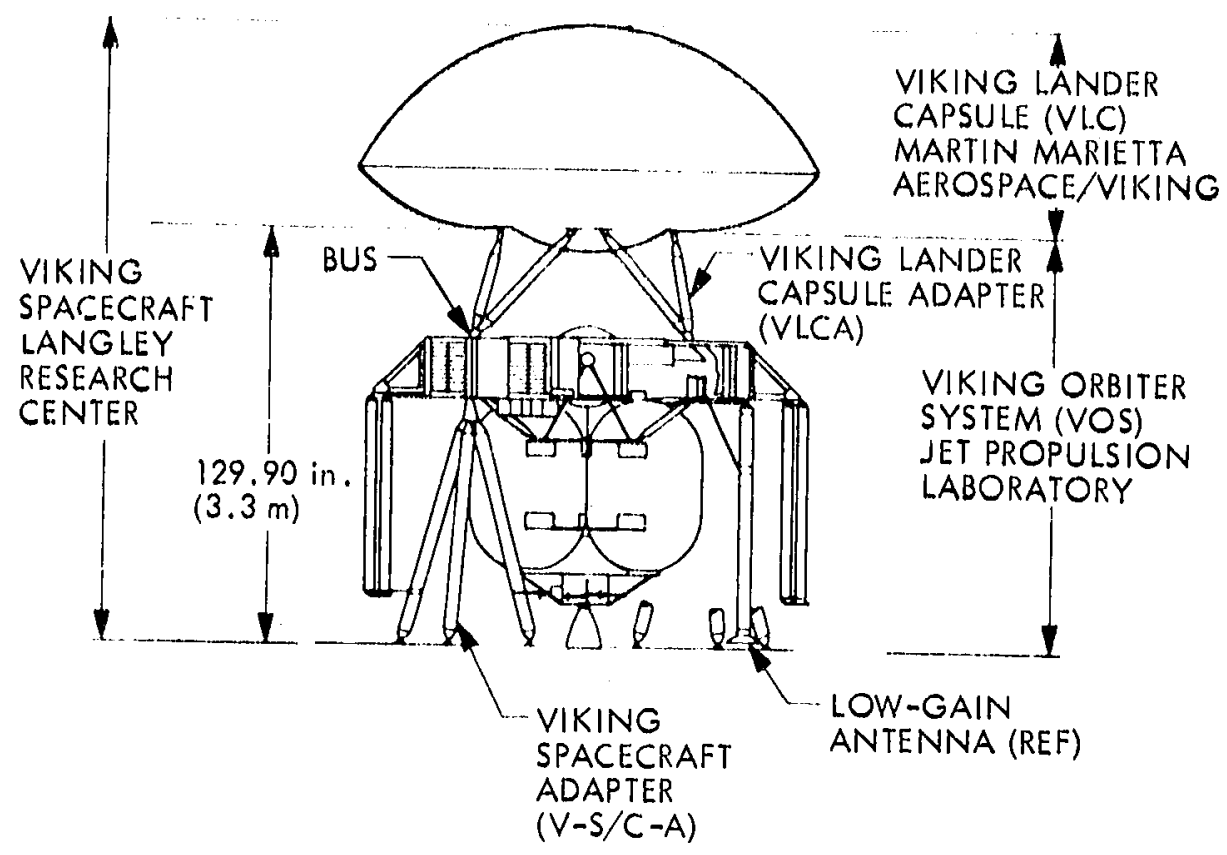

Figure III-1. Viking spacecraft

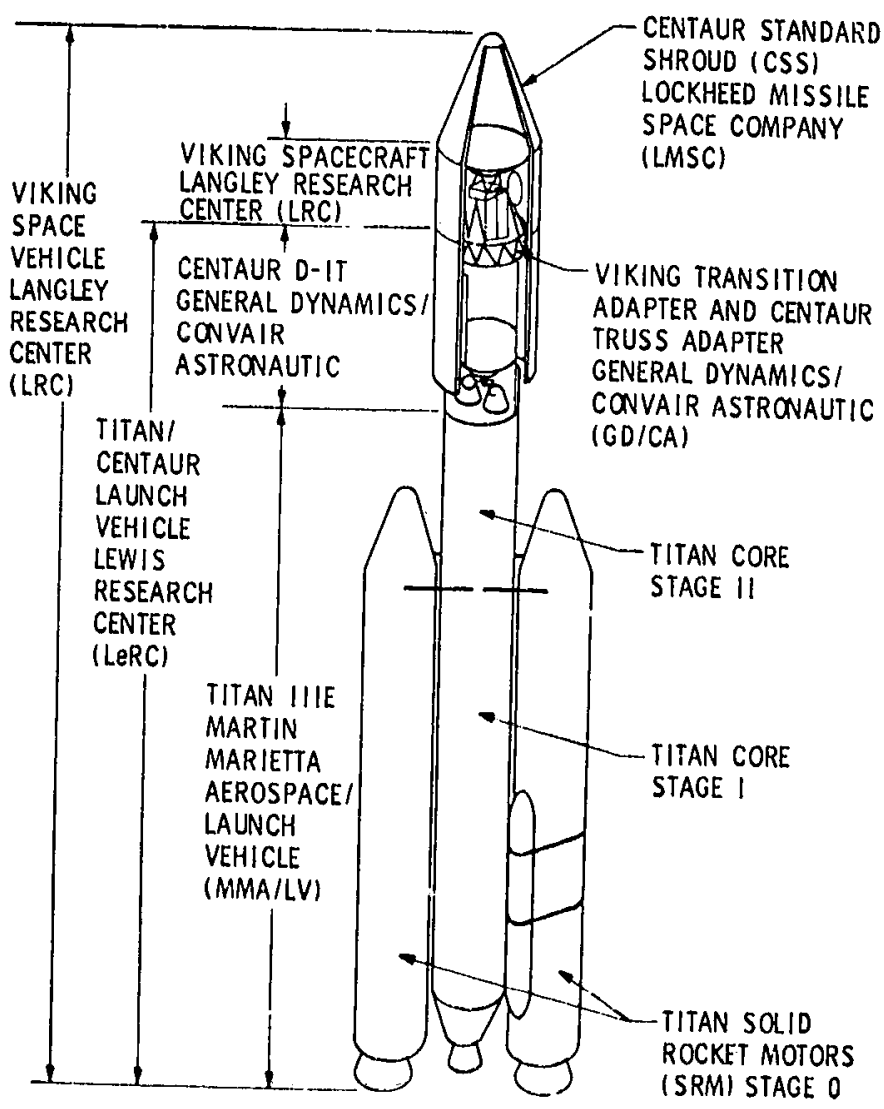

Figure 111-2. Viking space vehicle 


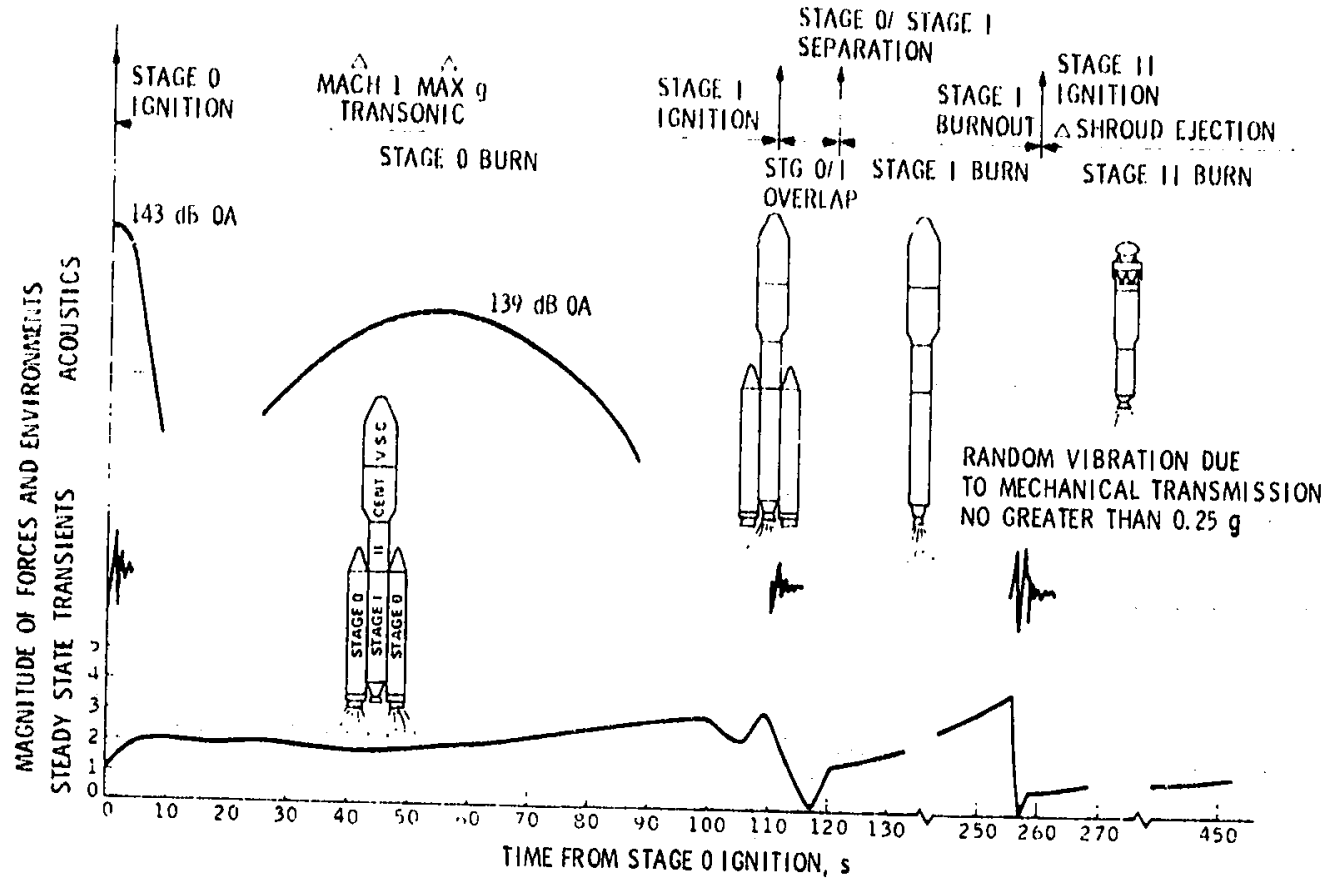

Figure III-3. VOS flight loads and environments, $0-450 \mathrm{sec}$

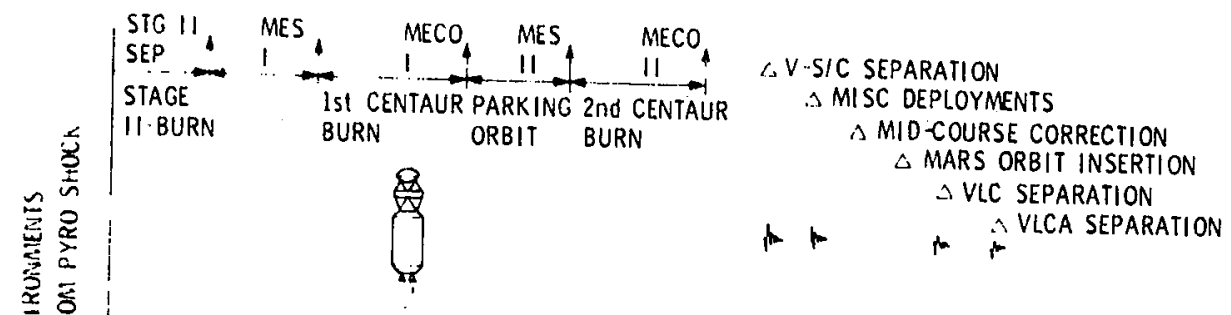

MECHANICAL TRANSMISSION FROM CENTAUR ENGINE - NO "GREATER"

MECHANICAL TRANSMISSION THAN $0.1 \mathrm{~g}$ FROM VOS ENGINE

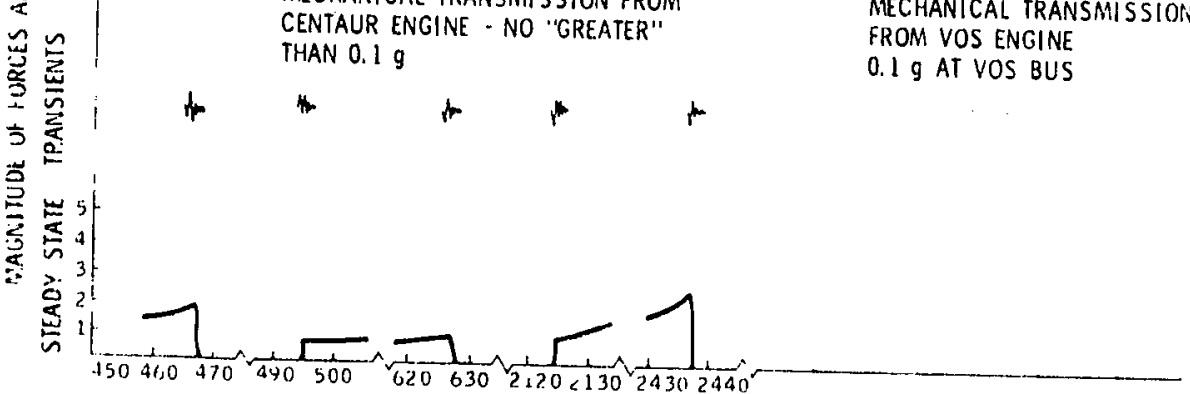
TIME FROM STACE OIGNITION, S

Figure tit-4. Vos flight loads and environments, from $450 \mathrm{sec}$ 
Table IIT-1, Fvents for vos Load Analysis

\begin{tabular}{lc}
\multicolumn{1}{c}{ Events } & $\begin{array}{c}\text { No of forcing } \\
\text { functions } \\
\text { or conditions }\end{array}$ \\
\hline Cround conditions & 6 \\
Stage O ignition & 21 \\
Airloads & 5 \\
Stage O max acceleration & 1 \\
Stage I ignition & 12 \\
SRM separation & 1 \\
Stage I burnout & 29 \\
Stage II ignition & 3 \\
Stage II burnout & 19 \\
Centaur main engine start I (MES I) & 1 \\
Centaur main engine cutoff I (MECO I) & 1 \\
Centaur main engine start II & 1 \\
Centaur main engine cutoff II (MECO II) & 1 \\
\end{tabular}


launch vehicle contractors, Martin Marietta Aerospace (MMA), General Dynamics Convair (GDC), and by JPL. The main load analysis cycles were performed by MMA. JPL performed simplified in-house loads cycles to support certain orbiter design activities using the output from the space vehicle system analysis. It was recognized on Viking from the beginning that the loads analysis process is in iterative one and that as a result the design loads and hence the structural design would be changing between iterations.

1. Dynamic Models

Dynamic modeling for Viking orbiter made extensive use of modal synthes is and substructuring techniques [17], [20], [31]. The Guyan reduction technique [32] was used extensively to obtain reduced mass and stiffness matrices. Modal truncation was performed based on frequency and component effective mass [33], [34]. Using this technique orbiter subsystems having originally up to 4000 static degrees of freedom each were reduced to approximately 300 dynamic degrees of freedom on the orbiter system level. A total of seven (7) subsystems constituted the Orbiter dynamic model [29]. Throughout the dynamic modeling the most important parameter was the Load Transformation Matrix (LTM). A typical Viking orbiter dynamic model required 450 load transformations. Dynamic models were generated in support of the loads analysis cycles as well as for various subsyster: and system test configurations.

2. Loads Analysis Cycles

Load analyses were performed by MMA and GDC, the launch vehicle contractors. Some additional analyses were performed at JPL using the output from the system loads analyses. 
a. System Loads Analyses

There were five (5) major loads cycles as shown in Table III-2. The data flow for these cycles is shown in Figure II[-5. Modal coupling techniques were used for combining the spacecraft and launch vehicle models. Transient responses were obtained by integration in the time domain. Mathematically the solution was straightforward, since the models were linear except for the Stage 0 event during which the system boundary conditions changed from a cantilevered model including the launch complex to a free-free model. Output from these analyses consisted of maximum/minimum data for member loads, accelerations and displacements as well as time history data for selected parameters such as interface accelerations and generalized system coordinates. The latter data were used to perform additional analyses at JPL. Another exception to the linear transient response solution was the calculation of the structural response due to the transonic flight event. Member loads for this event were calculated by adding gust, buffet and quasi-static loading in a statistical marner account ing for dispersions $|35|$.

b. Simplified Spacecraft Loads Analyses

Simplified transient spacecraft loads analyses were performed in-house at JPL to support Orbiter design iterations. Experience with such analyses showed that when the acceleration time history at the spacecraft/launch vehicle interface was assumed invariant from the old to the new spacecraft configuration, small changes in the spacecraft model sometimes produced large and unrealistic member loads. This was attributed to the impedance wismatch at the spacecraft/launch vehicle interface. To 
liable 111-? Vos loid Anilysis

\begin{tabular}{|c|c|c|}
\hline $\begin{array}{l}\text { load } \\
\text { cijele }\end{array}$ & $\begin{array}{l}\text { Approxtmate } \\
\text { date of vos model } \\
\text { dolivery }\end{array}$ & Doscription \\
\hline 1 & $6 / 69$ to $11 / 69$ & $\begin{array}{l}\text { Analysis with a preliminary vos configuration } \\
\text { to establish design loads }\end{array}$ \\
\hline 2 & $7 / 70$ & $\begin{array}{l}\text { Analysis with a final vos configuration to } \\
\text { update dosign loads }\end{array}$ \\
\hline 3 & $11 / 71$ & $\begin{array}{l}\text { Analysis with a vos model based on a firm } \\
\text { design prior to hardware fabrication to con- } \\
\text { firm design loads }\end{array}$ \\
\hline 4 & $7 / 73$ & $\begin{array}{l}\text { Analysis of vos model based on modal test } \\
\text { data to establish flight loads for structural } \\
\text { qualification tests }\end{array}$ \\
\hline 5 & $2 / 74$ & $\begin{array}{l}\text { Analysis of Viking Dynamic simulator to ver = } \\
\text { ify the loid analysis process }\end{array}$ \\
\hline 6 & $10 / 75$ & $\begin{array}{l}\text { Analysis of the two-V-S/C flights to verify } \\
\text { the load analysis process }\end{array}$ \\
\hline
\end{tabular}




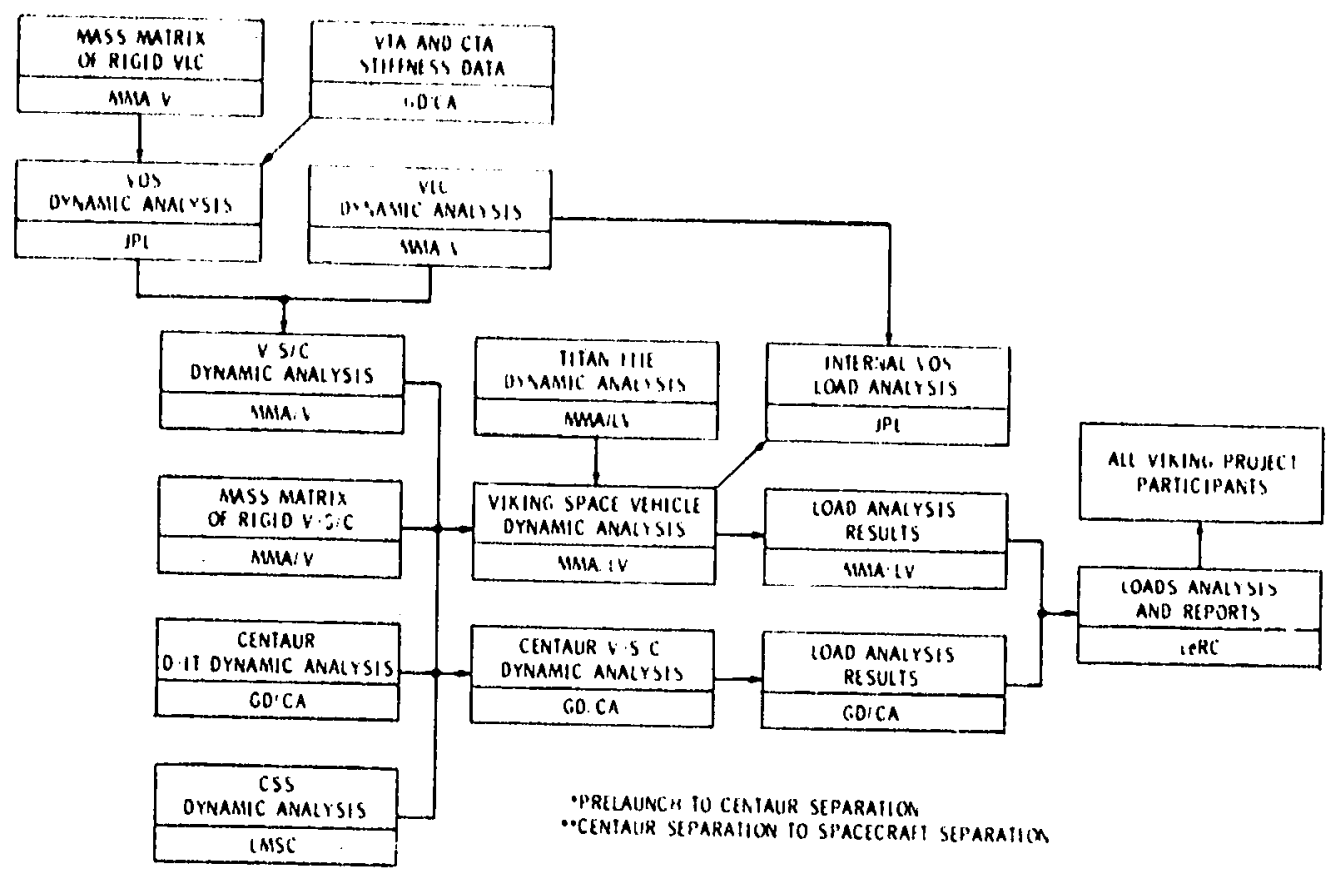

Figure 11t-5. Data flow for viking load analyses

alleviate this problem, part of the launch vehicle was included in the spacecraft model and the acceleration time history at this interface, obtained from the previous analys is was used. This seemed to give much more realistic answers since the assumption of invariance of the acceleration time history had more validity as the point of application for the forcing function was further removed from the changes of the model.

The technique of applying acceleration time histories from a previous analysis to a new model to obtain approximate member loads was called "mini-loads analysis."

3. Error Contributions to the Load Analyses

Since the models and the load analysis process were not perfect, especially for obtaining the design loads which were calculated from a model which had not heen verified by test, a factor of 
safety, referred to as a Loads Analysis Factor (LAF) to account for the uncertainties of Table III-3 was used. The value for this factor was chosen as 1.3 based upon a qualitative evaluation of very limited data comparing available flight data with analytical predictions. The load analysis factor was decreased during the program as the uncertainties of Table III-3 were diminished.

\section{Structural Testing}

As in all other JPL projects two types of structural testing were performed on the Orbiter: developmental testing and qualification testing. In addition the whole launch vehicle system was flight tested using a Viking dynamic simulator as a payload.

\section{Developmental Testing}

The objectives of developmental testing were aimed at the improvement of the mathematical models used for ioads analyses.

\section{a. Modal Tests}

Extensive modal testing of all subsystems as well as the Viking Orbiter System was performed using the Multi-Point Sine (MPS) excitation technique. These tests yielded frequencies, mode shades, and modal damping values as a function of excitation levels [36]. The test results were correlated with analysis [37], and modifications to the analytical models were made.

b. Fluid Dynamic Tests

Since an appreciable fraction of the Viking spacecraft consisted of liquid propellant, the dynamic behavior of the fluid was a very important modelling consideration. Special 
Table III-3. Error Contributors to Vos Load Analysis

Spacecraft mathematical model variation

Launch vehicle mathematteal model variation

Centaur standard shroud mathematical model variation

Definition of the forcing functions

Load analysis process 
fluid dynamic tests to determine the effective mass of the fluid as a function of frequency of excitation and the ullage condition were performed [38]. Analytical methods for obta iing effective fluid mass data from modal tests were derived [39].

2. Qualification Testing

Qualification testing consisted of a static test and a vibration test.

a. Static Test

All primary structure was qualified by a static test [40].

b. Vibration Test

Secondary structure was qualified during a three axis sinusoidal test [41] and an acoustic test. The input to the sinusoidal test was limited so as not to exceed design loads in the primaiy structure. A thorough analys is of the test configuration was performed and excellent correlation of the andytical predictions with test responses was obtained [42].

3. Flight Testing

A Viking Dynamic Simulator (VOS) was used as a payload to test the newly integrated Titan/Centaur launch vehicle system [43]. The objectives were to determine the accuracy of the loads analysis process and to verify the orbiter flight data instrumentation plan [44]. Excellent transient flight load data were obtained from the VDS program which was used to verify the analytical predictions. 
D. Flight Instrunentation

Flight instrumentation played a very important role in the Viking program. As discussed earlier the VDS flight measurements were used to verify the loads analysis process. Flight instrumentation on the Viking spacecraft consisted of strain gauges and accelerometers [45]. inese data were used to assess the margins of safety of the first Viking spacecraft before the second spacecraft was launched. Such response measurements were also used to synthesize launch vehicle forcing functions [46]. The flight measurements obtained from VDS showed an appreciably higher loading than predicted by analysis for the Stage 0 Ignition event. The VDS flight measurements were used to re-evaluate the Stage 0 Ignition forcing function.

\section{E. Summary of Experiences Gained From Viking}

As discussed ahove the Viking spacecraft structural design was an integrated effort both organizationally and analytically. As a result, the Viking spacecraft structure was designed to loads which were very close to those measured in fiight. [47], [48]. Appendix A summarizes the comparison of flight measured data with predictions for various events. This integrated loads analysis approach is technically sound and produces a lightweight highly reliable structure. To achieve this several prerequisites have to be met. In the technical area, reliable, verified launch vehicle models and forcinq functions have to be available. This implies a previously flown launch vehicle system. On the management level this approach requires a commitment both in manpower and resources and the recognition that this is an iterative process.

The riumerous organizational and technical interfaces inherent in the space vehicle system transient loads analys is approach resulted in appreciable elapsed time between the generation of a spacecraft model and the availability of spacecraft lcads. The output of the various load cycles did not always support the spacecraft design effort in a 
timely fashion. Furthermore, it was observed that some member loads were sensitive to small design changes.

These experiences prompled the search for a new methodology to obtain spacecraft member loads. The objectives were to simplify the loads effort by decoupling the procedure as much as possible from the launch vehicle system and to search for methods to determine an upper bound for the loads. This seemed especially appropriate with the advent of the Space Transportation System (STS), a new, and as yet not flown reusable launch vehicle system for which the dynamic model has not been confirmed and the forcing functions have not been measured in flight.

The next few sections will sumarize the methods being proposed. Some of them are currently being used to obtain design loads for payloads to be launched by the STS. 
IV. LOADS PREDICTION METHODS FOR SHUTTLE PAYLOADS

As described in the previous section, payload structural systems are usually designed to withstand the dynamic environments of the launch and exit phase. The exceptions are payloads designed to withstand lunar or planetary landing loads such as the Surveyor spacecraft and the Viking Mars Lander. The design loads for the launch and exit phase are obtained from loads analyses of representative mathematical models subjected to external forcing functions. Since the mathematical model is based on the configuration and the detailed structural properties of the spacecraft the design/analysis approach is an iterative process. Since this process is expensive and time-consuming, it is desirable to develop a more costeffective and simplified loads prediction methodology. The effort at JPL centers around two main objectives. One is developing more effective, less conservative load estimation methods. The other aims at simplification of the load analys is or flight simulation process.

A. Loads Estimation Techniques

Loads estimation assumes worst tuning between the launch vehicle and the payload and seeks an upper bound of the expected loading in flight. As such it is not a flight simulation. It is performed entirely within the payload organization with only a minimum amount of launch vehicle information. The goal is to have a definition of loads early in the project, have a low sensitivity of the loads to design changes, and obtain loads which are only moderately conservative, thereby resulting in a favorable structural weight/analysis cost trade-off. Two load estimation methods are currently being used at JPL. The first one is used for the preliminary sizing of structural members for the spacecraft; it requires no launch vehicle model information. The second is used to obtain upper bound member loads using minimal launch vehicle dynamic model data. In view of the present uncertainties of the STS dynamic models and forcing functions the second method, referred to as the 
generalized shock spectra/impedance method, is being used to obtain design loads for the early STS interplanetary spacecraft.

1. Preliminary Design Loads - The $\sqrt{\bar{\omega}}$ curve and mass acceleration curve

For preliminary design purpose an upper bound of payload dynamic response as a function of payload or component effective weight has been estimated. These semi-empirical estimates are based upon the responses of various spacecraft obtained from experimental, analytical and flight data for a variety of payloads flown on various expendable launch vehicles of the past and from analysis done on the STS.

The purpose of developing simplified rules for estimating preliminary loads is to give the analyst and the designer a "rule of thumb" for sizing of a preliminary structure and to assist load estimation in design studies. These methods are also intended to be used for the design of secondary structure for which the load analysis approach is not applicable.

The preliminary loads are estimated on the basis of a two degrees of freedorn system subjected to an impuise function as shown in Fig. IV-1, where one of the degrees of freedom represents the payload or component weight and the other represents the launch vehicle. It can be shown that the maximum response can be expressed as

$$
\ddot{x}=\frac{C}{\sqrt{\bar{w}}}
$$

where $C=$ constant, $\bar{w}=$ weight (ib) 


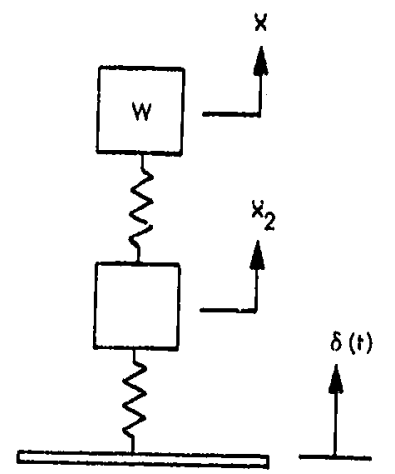

Figure IV-1. Two Degrees of Freedom System Subject to Impujse Function

The constant $C$ depends on the weight of the launch vehicle. Extensive data from previous programs have estimated these constants, $C=185$ for Atlas-type vehicles and $C=220$ for Titan vehicles. Using the shuttle load factors, it was originally estimated that $C=285$ for the shuttle payloads. More recent analysis shows $C=230$ for the shuttle payloads.

A disadvantage of this relationship is that as the component weight tends to zero, the response or load factor terids to infinity. Using the derivation of Ref. 51, it can be shown that in the limit, $\bar{W} \rightarrow 0$, the response can be expressed as

$$
\operatorname{Limit}_{\bar{W} \rightarrow 0} \ddot{x}=\frac{Q}{2.718}\left|x_{2}\right| \max
$$


where

$$
\begin{aligned}
Q= & \text { gain factor }=\frac{1}{2 \alpha} \\
\alpha= & \text { percent critical damping, } C / C_{C} \\
\ddot{x}_{2}= & \text { interface response of launch vehicle } \\
& \begin{array}{l}
\text { carrying no payload (unloaded launch vehicle } \\
\text { response) }
\end{array}
\end{aligned}
$$

Using the outlined approach, a load factor curve can then be constructed such as the one shown in the Fig. IV-2 in which the preliminary upper bound response for the Galileo spacecraft components are plotted as functions of the effective weight. The upper weight range is impedance or weight controlled with very little effect of damping and in the lower weight range it is damping controlled.

Currently, this approach is being used at JPL for preliminary design purposes and for estimating load factors for the design of secondary structures for Galileo and International Solar Polar Mission (ISPM) and other STS launched payloads. Figure IV-2 shows typical results obtained by this approach for the Galileo spacecraft.

\section{Generalized Shock Spectra Method}

A more accurate method for obtaining upper bound loads is the shock spectra method. Estimates of loads are obtained by combining the maximum responses for various combinations of launch vehicle and spacecraft normal modes, and by allowing for impedance effect between launch vehicle and spacecraft and frequency shifts to obtain the most adverse combination of dynamic response. The goal is to develop a cost effective tool for obtaining design loads in a timely fashion. The method is 


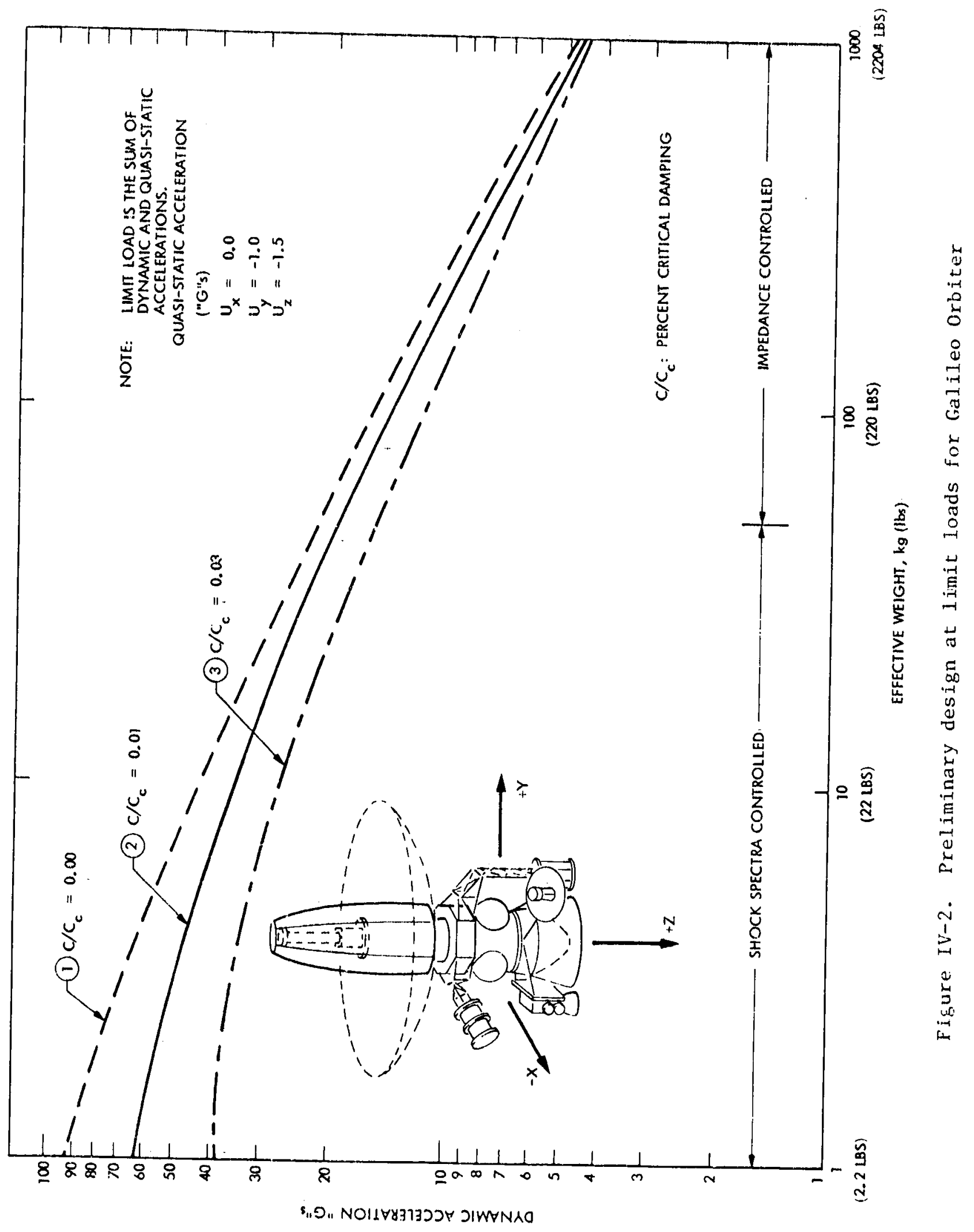


low in cost as compared to a transient load analysis, it is insensitive to design changes, and hopefully moderately conservative in load prediction.

The shock spectra method was originally presented in Reference [49], [50] and later expanded as a generalized shock spectra in Reference [51].

The following general observations are fundamental to understanding the rationale of the shock spectra approaches:

(1) The general objective is to avoid the cost of a launch vehicle/new spacecraft overall transient analysis.

(2) A previous dynamic analysis has been performed for the same launch vehicle with another or a dummy spacecraft, the results of which are used as inputs to the generalized shock spectra method. The method is derived to utilize modes of the launch vehicle loaded by a rigid mass only, or unloaded. If such an analysis is not available, the proper data can be recovered from the analysis of the launch vehicle loaded with a spacecraft having rigid or elastic mass representation.

(3) The structural analyst needs only to determine the worst case load maxima or the bounds, rather than time histories, of the structural response. Since maxima or bounds are the objective of the shock spectra concept, a shock spectra approach is readily applicable to the structural design process.

(4) Any loads analysis - transient, shock spectra, or other - incorporates two basic items: a model idealizing the dynamic environment, i.e., the forcing 
function, and another idealizing the composite structural system. The form of each model is influenced by the selected approach, while its complexity is constrained by cost and time.

(5) The original launch venicle forcing functions, usually unknown to the spacecraft analyst, may be idealized by a simpler form to obtain an explicit closed form solution. A complete definition of this idealization is possible from the previcus analysis of item (1) above, and is tone at the modal level.

Only the highlights of the generalized shock spectra method will be summarized here. The reader is referred to Reference 51 for a detailed derivation of the method.

First, the modal forcing function $F_{\ell}(t)$ corresponding to the modes of the launch vehicle loaded by a rigid mass (or unloaded) at the spacecraft interface and representing the modal contribution of an actual flight event, is modeled, regardless of its physical point. of application, by an equivalent laurich vehicle modal forcing function, $F_{e l}(t)$. Unlike the actual complex transient force, the equivalent forcing function assumes a simple form of variation with time. Here, an impulse delta function $F_{\text {el }}(t)=F_{0 \ell^{\delta}}(t)$ with a yet-unknown magnitude $F_{0 \ell}$, or equivalently a velocity with magnitude $v_{0 \ell}$, is chosen for convenience.

The choice of a simplified forcing function as an impulse emphasizes the view that the shape of the response time-history is of little consequence, and that only the peak or bound of the response is of interest. Therefore, any forcing function that would reproduce a response with the same maximum peak or bound as the actual forcing function is acceptable. The equivalency between the actual forcing function and the idealized one is 
established, not on the basis of producing identical response time histories, but on the basis of producing an identical peak of the shock spectra of each of the launch vehicle modal responso $\ddot{q}_{2}(t)$, Figure IV-3, derived from the previously performed launch vehicle/dummy spacecraft analysis. An alternate to the direct use of $\ddot{q}_{l}(t)$ is discussed later.

The use of modal shock spectra, rather than the interface degrees-of-freedom shock spectra is significant because it automatically accounts for the matching of all interface physical deqrees of freedom, and allows one to determine the inodal maqnitude of the impulse $F_{e l}(t)$ or velocity $v_{0 l}$. It is noteworthy that the above process of establishing the equivalent idealized forcing function requires knowledge of the
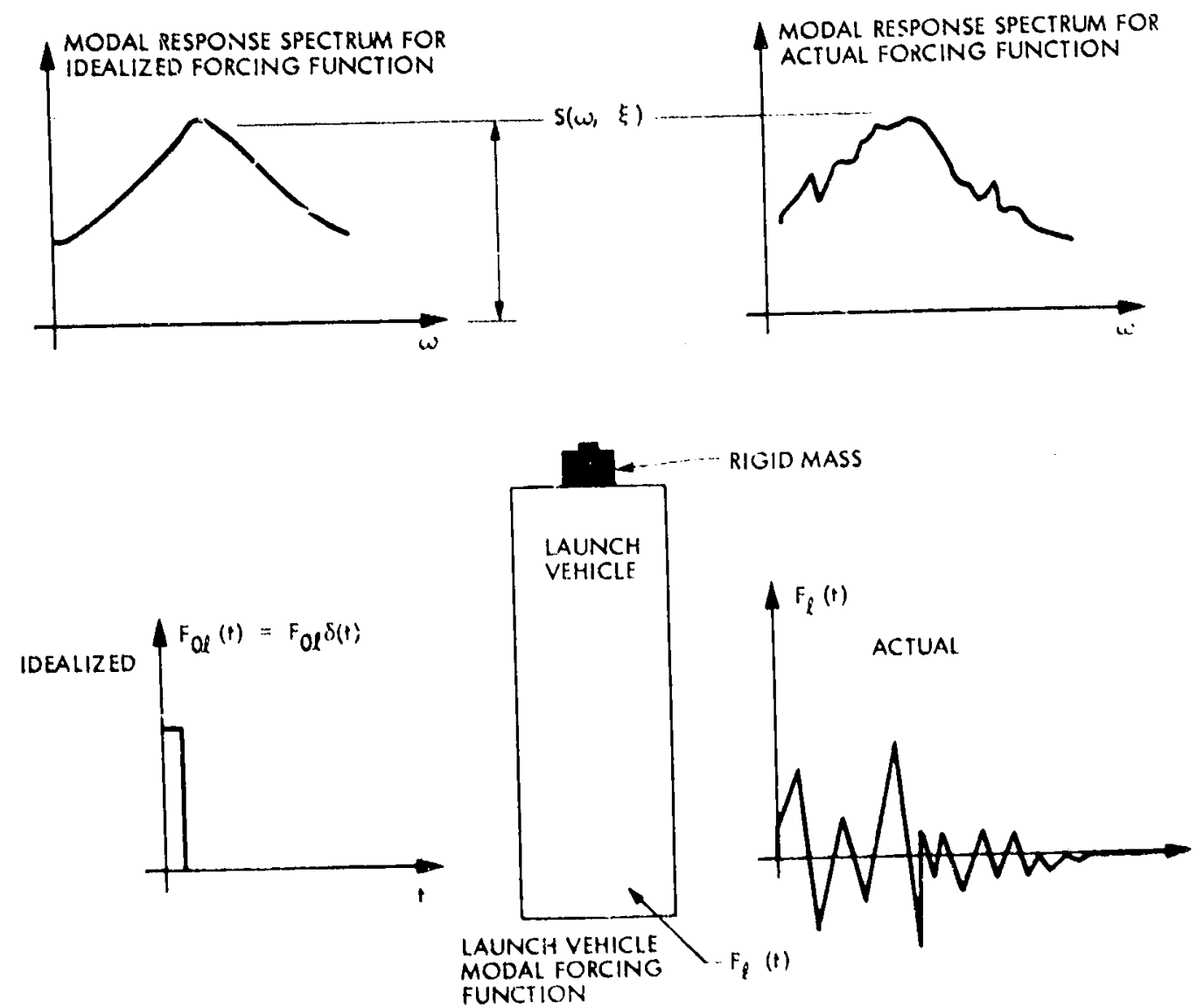

IGID MASS

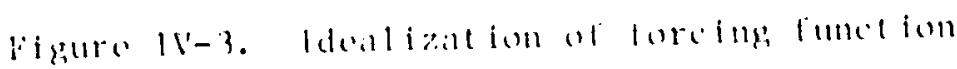


modal properties of the launch vehicle with or without a payload. Such information is usually available from the launch vehicle organization. Also note that the rigid mass at the launch vehicle/spacecraft interface does not have to be the total mass of the spacecraft to be analyzed, but can have any value convenient for purposes of the transient analys is performed earlier on the launch vehicle. This approach does correct for whatever mass value was used previously.

Second, in considering the composite structural system which consists of a spacecraft modeled by $S$-normal modes and a launch vehicle modeled by $L$-normal modes, there will be $(S+L)$ modally coupled equations of motion. The coupling arises because the $S$-spacecraft modes and the $L-l$ aunch vehicle modes are obtained from two separate modal analyses, rather than from an analysis where the two models are integrated. Unlike the transient analysis where the solution is expressed in the complete $(S+L)$ space of modal coordinates and time, a bound on the complete solution is established by:

(1) Idealizing the totality of $(S+L)$ mathematical space of modal coordinates by an array of nested $(S \times L)$ mathematical subspaces, in each of which only one spacecraft mode is individually coupled with one launch vehicle mode. In this fashion, each spacecraft mode is coupled with $L-l$ aunch vehicle modes one at a time. To derive a bound on the total solution in the original $(S+L)$ mathematical space, an explicit solution in the form of spacecraft modal response time history is first derived for the pair of modes in a typical subspace. The explicit form of this solution is based on the idealized modal forcing function just discussed. Furthermore, because the spacecraft member loads are the objective of the analysis, and since these are proportional to the generalized modal 
displacements, the response quantities used here are generalized modal displacements, $q_{s e}(t)$, from which an expression of the bound $Q_{s e}$ of $q_{s e}(t)$ is then derived.

(2) Numerical computations are made first to establish the bounds, $Q_{S e}$, on each of the $(S \times L)$ discrete modal responses. Each bound $Q_{S Q}$ corresponds to one of the $(S \times L)$ subspaces. To account for unknown design tolerances and variations in the structural model idealization, worst cases can be provided by allowing realistic possible tuning between each spacecraft mode and its nearest launch vehicle mode, and by scaling the entire frequency spectrum of the launch vehicle with respect to that of the spacecraft.

(3) Next, a bound on the total spacecraft modal response, $Q_{S}$, is constructed by summation over all the discrete L-bounds for that spacecraft mode. The summation can be over absolute values, or in a root-sum-square sense that can also be weighted to account for phasing.

(4) Finaliy, spacecraft member loads are obtained by adding the contributions of all spacecraft modes, either in absolute value or in a root-sum-square sense.

In the procedure outlined above, steps (1) and (2) derive expressions for bounds on the discrete response, $Q_{S Q}$, in each of the $(S \times L)$ modal subspaces, while steps (3) and (4) construct a bound on, $Q_{S S}$, the complete solution in the total $(S+L)$ space from the discrete $Q_{s e}$ bounds. In this manner, much computational effort is saved over the usual transient analysis. 
Because the spacecraft member loads are the object of the analysis here, and since these are proportional to the generalized modal displacements $Q_{S}$, bounds on the spacecraft member loads are expressed in terms of the bounds, $Q_{s \ell}$, of the generalized modal displacements for each subspace. A typical generalized modal displacement bound, $Q_{\text {si }}$, is derived here for a typical subspace in which one spacecraft mode $q_{s}$ is coupled with one launch vehicle mode $q_{\ell}$. The governing equation is in thie following form [51]

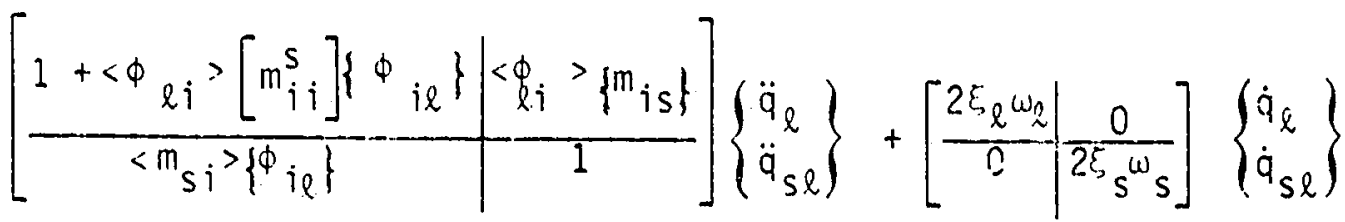

$$
\begin{aligned}
& +\left[\begin{array}{c|c}
\omega_{l}^{2} & 0 \\
\hline 0 & \omega^{2}
\end{array}\right]\left\{\begin{array}{l}
q_{l} \\
q_{s l}
\end{array}\right\}=\left\{\begin{array}{c}
<\phi_{\ell j}>\left\{F_{j}\right\} \\
0
\end{array}\right\}
\end{aligned}
$$

where

$$
\begin{aligned}
u_{\ell}^{2}= & \text { eigenvalue of the launch vericle mode } q_{\ell} \cdot \\
u_{s}^{2}= & \text { eigenvalue of the spacecraft mode } q_{s} \cdot \\
\varepsilon_{\ell}= & \text { percent of critical modal damping for the launch } \\
& \text { vehicle mode } q_{\ell} \cdot \\
\xi_{S}= & \text { percent of critical modal damping for the } \\
& \text { spacecraft mode } q_{s} .
\end{aligned}
$$



$\begin{aligned}\left.\therefore \phi_{\ell j}\right\rangle= & \text { values of the launch vehicle mode } q_{\ell} \text { at the } j^{\text {th }} \\ & \text { degree of freedom. }\end{aligned}$

$\left\{F_{j}\right\}=$ time history vector of forces applied at the launch vehicle degrees-of-freedom.

and $\left[m_{i j}^{s}\right],\left[m_{i s}\right]$ are the mass and the rigid-elastic terms defined in [51].

As mentioned before, the modal forcing function $\left\langle\phi_{\ell j}\right\rangle\left\{F_{j}(t)\right\}$ is modeled by an equivalent impulse delta function having a magnitude $F_{0 \ell}$, or alternatively, an initial velocity with a magnitude $v_{0 \ell}$.

Then the bound, $Q_{S l}$, of the modal response $q_{s}$ of $a$ spacecraft mode can be obtained as

$$
Q_{S}=\frac{\omega_{1} V_{O Q} \sqrt{m} s \ell}{\left(1+M_{s \ell}\right)} D_{\max }
$$

where

$$
w_{1}=\frac{w_{\ell}}{\sqrt{1+M_{S \ell}}}
$$

The definitions for $m_{s \ell}, M_{s \ell}$ and $D_{\max }$ can be found in Reference 51.

During the early stages of the design, the spacecraft and launch vehicle modes and frequencies are obtained from analyses that usually contain a large denree of uncertainty. To account for such uncertainties, one may introduce an artificial tuning between the spacecraft and launch vehicle modes. Two forms of artificial tuning have been identified: global and local. In global tuning, the entire spectrum of launch vehicle frequencies is incrementally scaled in either direction relative to the 
spacecraft frequency spectrum. For each increment, a global response

$$
\bar{Q}=\sqrt{\sum_{s} \sum_{\ell} Q_{s}^{2}}
$$

can be computed and used as a measure for determining the worst case for design purposes. In this scheme, tuning is achieved by finding the amount of relative scaling that maximizes $\bar{Q}$. Clearly, limits on the allowable relative scaling must be selected in advance, and the search for the maximum $\bar{Q}$ conducted within these limits. An alternate is to evaluate member loads or acceleration for each tuning.

In the local tuning, the response is maximized for each spacecraft mode, one at a time. This is achieved by allowing the nearest launch vehicle frequency to coincide with that of the spacecraft frequency under consideration, provided that the two were originally separated by no more than a preselected amount.

Since each $Q_{S \ell}$ results from coupling between a spacecraft mode $s$ and only one $i$ aunch vehicle mode $\ell$, and since a complete representation of the launch vehicle includes more than one mode, say $L$ modes, contributions due to all $L$ modes should be included. The upper bound of the contribution by all the launch vehicle modes can be obtained in the root-sum-square sense. 


$$
Q_{s}=\left[\sum_{l=1}^{L} Q_{s l}^{2}\right]^{1 / 2}
$$

or

$$
Q_{S}=\left\{\sum_{l=1}^{L}\left[w_{l}\left(w_{s}, w_{l}\right) \cdot Q_{s l}\right]^{2}\right\}^{1 / 2}
$$

where $w_{l}\left(\omega_{s}, \omega_{l}\right)$ is a weighting function that can be used to account for time phasing between the launch vehicle modes.

Using Eq. (IV-6a) or $(I V-5 b)$, a bound on the relative displacement $\left\{D_{b}\right\}$ is found from

$$
\left\{D_{b}\right\} \cong \sqrt{\sum_{s}\left\{o_{b s}^{2}\right\}}
$$

or

$$
\left.\left.\mid D_{b}\right\} \cong \sqrt{\sum_{s}\left\{\left[w_{s}\left(\omega_{s}\right) o_{b s}\right]^{2}\right.}\right\}
$$

in which

$$
\begin{aligned}
\left\{D_{b s}\right\}= & \begin{cases}\phi_{b s} & \left.Q_{s}\right\} \\
\left\{\phi_{b s}\right\}= & \begin{array}{l}
\text { spacecraft modal displacement at the } b^{\text {th }} \text { DOF } \\
\text { for the } s-\text { spacecraft mode. }
\end{array} \\
W_{s}\left(u_{s}^{\prime}\right)= & \text { a weighting function dependent upon the } \\
& \text { spacecraft frequency }\end{cases}
\end{aligned}
$$

A bound on the absolute acceleration $\left\{a_{b}\right\}$ for $a$ degree-of-freedom, $b$, on the spacecraft is found from 


$$
\left\{a_{b}\right\}=\|\left[\phi_{b s}\right]\left[\begin{array}{c}
\omega_{s}^{2} \\
s
\end{array}\left\{a_{s}\right\}\|+\|\left(\left[\phi_{b i}\right]-\left[\phi_{b s}\right]\left[m_{s i}\right]\right)\left\{\ddot{R}_{i s}\right\} \|\right.
$$

where

$$
\begin{aligned}
& s=1,2, \ldots, \bar{s} \leq s \\
& \left\{\ddot{R}_{i s}\right\}=\left[\phi_{\ell i}\right]\left\{\omega_{1} v_{0 \ell}\right\}=\text { accelerations at the } \\
& \text { spacecraft mode } s \text {. }
\end{aligned}
$$

In Eq. (IV-8), the $\|\cdots\|$ means that a bound similar to that of Eq. (IV-7a) and (IV-7b) is taken for the enclosed quantities. It is also noted that the underlined term in Eq. $(I V-8)$ is a correction term that accounts for errors introduced if a truncated set of spacecraft modes $\bar{S}$ is used in place of the total S. It can be shown that when all spacecraft modes are considered, i.e. $S=\bar{S}$, the correction term vanishes.

If the modal displacement method is used to calculate the member forces $\left\{F_{a}\right\}$ associated with the $a^{\text {th }}$ force component, one may write

$$
\left\{F_{a}\right\}=\left\|\left[C_{a b}\right]\left[\phi_{b s}\right]\left\{Q_{s}\right\}\right\| s=1,2, \ldots s
$$

where

$$
\begin{aligned}
{\left[{ }^{C} \mathrm{ab}\right]=} & \text { matrix of force coefficients whose elements are } \\
& \text { the } a^{\text {th }} \text { force component associated with } \\
& \text { displacements in the } b^{\text {th }} \text { degree-of-freedom. }
\end{aligned}
$$


Again, if a truncated set of spacecraft modes $\overline{\mathrm{S}}<\mathrm{S}$ are used to compute the forces $\left\{F_{a}\right\}$, the same correction term of Eq. (IV-8) can be introduced to give

$\left\{F_{a}\right\}=\left\|\left[c_{a b}\right]\left[\phi_{b s}\right]\left\{Q_{s}\right\}\right\|+\left\|\left[c_{a b}\right]\left[\omega_{s}^{2}\right]^{-1}\left(\left[\phi_{b i}\right]-\left[\phi_{b s}\right]\left[m_{s i}\right]\right)\left\{\ddot{R}_{i s}\right\}\right\|$

As before, the underlinad term is the member load correction due to mode truncations, and $\|$... $\|$ means that a bound is taken during summation over the spacecraft similar to Eq. (IV-7). Member loads computed by the generalized modal shock spectra method are, by intent more conservative than those calculated by the transient method.

A comparison of acceleration levels obtained by the generalized shock spectra method to those from the mass acceleration curve are contained in Appendix $C$.

B. Transient Load Analys is Techniques

For more accurate loads prediction, the launch vehicle/payload composite model will be subjected to appropriate external forcing functions for the response and member load calculations. These external forcing functions are derived from the relevant dynamic environments representing the launch vehicle thrusts, staging events, aerodynamic loads and others. Since the mathematical model is based on the design of the structures, this design/analysis approach is an iterative process. This design/analysis process involves the integration of the payload model and launch vehicle model and the subsequent transient analysis. Considerable time and cost are required in the integration of the composite model and the response analysis, since typically the payloads and the launch vehicle are developed and designed by separate organizations with their respective mathematical models which involve different computer codes, 
coordinate systems, units and normalization proceciures. In a previous experience, the liking project, as many as ten organizations were involved in generating the composite model and its integration. One design/analysis cycle required up to six months $[281$.

To reduce cost and schedule, several approximation techniques have been developed in the past. One method utilizes the fact that payload design changes during the design/analysis iteration are "smâll", such that a cost effective perturbation procedure can be applied to update the response analys is due to design changes [52]. This method was further extended to estimate the modifications of launch vehicle/payload interface responses due to payload design changes [53]. The modified interface responses can then be applied to the base of the payload to calculate the payload responses and loads. This method is not only cost effective but also can be implemented by the payload organization without interfacing with the launch vehicle organization. However, this method is developed with the assumption that the payload is always much "smaller" than the launch vehicle. For shuttle-launched payloads, the effects of payload dynamics can no longer be considered as "small" for future dynamic events such as the abort landing of a fully loaded shuttle orbiter. In these events, the interaction between the shuttle orbiter and its payload is critical to both the orbiter and payload loads [54]. Therefore it seems that the launch vehicle/payload composite model integration and its transient analysis cannot be avoided.

The simplified loads analysis methods aim at simulating a time response solution within the payload organization with minimal launch vehicle information. The objective is to greatly reduce the interface between the payload and launch vehicle organizatuon. Thus methods to obtain the payload response of a launch vehicle/payload composite system from the results of another launch vehicle/payload composite system under the identical forcing function have been developed. Fig. IV-4 shows two composite systems with identical 

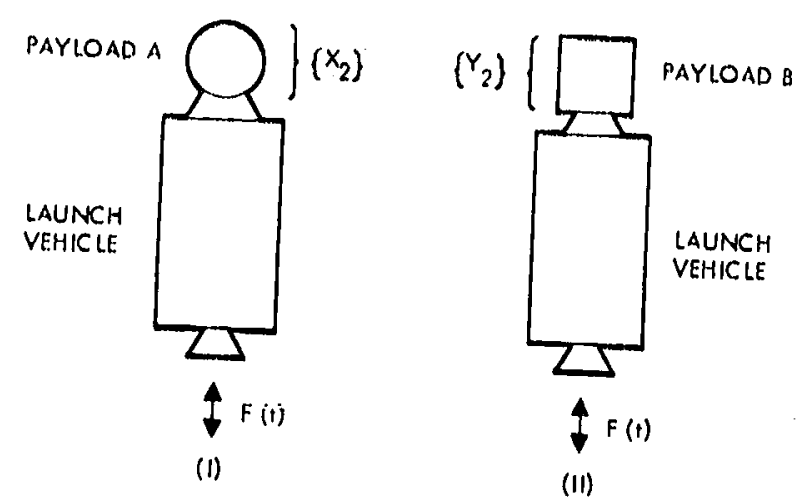

Figure IV-4. Schematic of launch vehicle/payload composite systems

launch vehicle but different payloads. The governing equations for these two systems can be written in the finite-element formulation as

$$
\left[\begin{array}{ll}
m_{1} & 0 \\
0 & m_{2}
\end{array}\right]\left\{\begin{array}{l}
\ddot{x}_{1} \\
\ddot{x}_{2}
\end{array}\right\}+\left(\left[\begin{array}{ll}
k_{1} & 0 \\
0 & 0
\end{array}\right]+\left[\begin{array}{ll}
k_{11} & k_{21} \\
k_{12} & k_{22}
\end{array}\right]\right)\left\{\begin{array}{l}
\left.x_{1}\right) \\
x_{?}
\end{array}\right)\left\{\begin{array}{l}
F(t) \\
0
\end{array}\right\}
$$

and

$$
\left[\begin{array}{cc}
m_{1} & 0 \\
0 & \bar{m}_{2}
\end{array}\right]\left\{\begin{array}{l}
\ddot{y}_{1} \\
\ddot{y}_{2}
\end{array}\right\}+\left(\left[\begin{array}{ll}
k_{1} & 0 \\
0 & 0
\end{array}\right]+\left[\begin{array}{ll}
\bar{k}_{11} & \bar{k}_{21} \\
\bar{k}_{12} & \bar{k}_{2 ?}
\end{array}\right]\right)\left\{\begin{array}{c}
y_{1} \\
y_{2}
\end{array}\right\}=\left\{\begin{array}{c}
F(t) \\
0
\end{array}\right\}
$$

where

$$
\begin{aligned}
\left\{x_{1}\right\},\left\{y_{1}\right\}= & \text { launch vehicle degrees-of-freedom (DOF) of the } \\
& \text { composite system (I) and (II), respectivel.y. }
\end{aligned}
$$


$\left\{x_{2}\right\},\left\{y_{2}\right\}=$ payload DOF of the composite system (I) and (II), respectively.

$\left[m_{1}\right]$ = mass matrix of the launch vehicle.

$\left[k_{l}\right]=$ stiffness matrix of the launch vehicle.

$\left[m_{2}\right],\left[\bar{m}_{2}\right]=$ mass matrix of the payload $A$ and payload $B$ of the system (I) and (II), respectively.

$\left[k_{11}\right],\left[k_{12}\right],\left[k_{21}\right],\left[k_{22}\right]$, sub-matrices of the total payload stiffness partitioned into launch

$\left[\begin{array}{l}k_{11}\end{array}\right],\left[\begin{array}{l}k_{12}\end{array}\right],\left[\bar{k}_{21}\right],\left[{ }^{k_{22}}\right]$, = payload DOF for the system (I) and (II), respectively.

$$
\begin{aligned}
F(t)= & \text { vector representing the external } \\
& \text { forcing functions acting on the } \\
& \text { launch vehicle DOF. }
\end{aligned}
$$

Assuming a "partial" solution of Eq. (IV-11) is available, the objective of the methods is to obtain the payload response $\{y\}$ of Eq. (IV-12) by using the results of Eq. (IV-11). The proposed procedure does not involve the launch vehicle model and the forcing
functions acting on the launch vehicle. Hence the entire process can
be implemented by the be implemented by the payload organization alone.

Although damping is not included in Eqs. (IV-11) and (IV-12), it will be incorporated later in the form of modal damping. Also for simplicity, it will be assumed at present that the payload is supported in a statically determinate manner such that 


$$
\left.\begin{array}{l}
{\left[k_{11}\right]=\left[{ }^{\phi_{R}}\right]^{\top}\left[k_{22}\right]\left[\phi_{R}\right]} \\
{\left[k_{21}\right]=-\left[\phi_{R}\right]^{\top}\left[k_{22}\right]=\left[k_{12}\right]^{\top}}
\end{array}\right\}
$$

where $\begin{aligned} {\left[\phi_{R}\right]=} & \text { payload A rigid body transformation matrix defined as } \\ & \text { the payload displacements due to unit displacement of }\end{aligned}$ the launch vehicle/payload interface DOF, $\left\{x_{I}\right\}$.

$\left\{x_{I}\right\}=$ launch vehicle/payload interface DOF corinecting payload to launch vehicle, a subset of the launch vehicle DOF $\left\{x_{1}\right\}$.

Next, the motion of the payload will be decomposed into two parts, namely, the rigid body motion and the elastic motion:

$$
\left\{x_{2}\right\}=\left[\phi_{R}\right]\left\{x_{I}\right\}+\left\{x_{e}\right\}
$$

The first term on the right-hand side of Eq. (IV-14) is the rigid-body motion. The second term $\left\{x_{e}\right\}$ is the elastic motiun, or relative motion with reference to the interface. It should be noted that only the elastic motion $\left\{x_{e}\right\}$ will generate internal loads in the structure. Using Eqs. (IV-13) and (IV-14), Eq. (IV-I1) can be transformed into the following form

$$
\left[\begin{array}{cc}
m_{1}+m_{r r} & \phi_{R} m_{2} \\
m_{2} \phi_{R} & m_{2}
\end{array}\right]\left\{\begin{array}{l}
\ddot{x}_{1} \\
\ddot{x}_{e}
\end{array}\right\}+\left[\begin{array}{ll}
k_{1} & 0 \\
0 & k_{22}
\end{array}\right]\left\{\begin{array}{l}
x_{1} \\
x_{e}
\end{array}\right\}=\left\{\begin{array}{c}
F(t) \\
0
\end{array}\right\}
$$

where

$$
\left[m_{r r}\right]=\left[\phi_{R}\right]^{\top}\left[m_{2}\right]\left[\phi_{R}\right]
$$

denoted as rigid-body mass of payload $A$. 
Similarly. Eq. (IV-12) can be transformed into the following form:

$$
\left[\begin{array}{cc}
m_{1}+\bar{m}_{r r} & \bar{\phi}_{R} \bar{m}_{2} \\
\bar{m}_{2} \ddot{\phi}_{R} & \bar{m}_{2}
\end{array}\right]\left\{\begin{array}{l}
\ddot{y}_{1} \\
\ddot{y}_{e}
\end{array}\right\}+\left[\begin{array}{cc}
k_{1} & 0 \\
0 & \bar{k}_{22}
\end{array}\right]\left\{\begin{array}{l}
y_{1} \\
y_{e}
\end{array}\right\}=\left\{\begin{array}{c}
F(t) \\
0
\end{array}\right\}
$$

where -

$\left[\bar{\phi}_{R}\right]=$ payload $B$ rigid-body transformation matrix defined similarly as for payload $A$.

$\left[\bar{m}_{r r}\right]=\left[\bar{\phi}_{R}\right]^{\top}\left[\bar{m}_{2}\right]\left[\bar{\phi}_{R}\right]$

denoted as rigid-body mass of payload $B$.

Also the motion of the payload $B$ is decomposed into two parts similar to that of payload A, Eq. (IV-14), as:

$$
\left\{y_{2}\right\}=\left[\bar{\phi}_{R}\right]\left\{y_{I}\right\}+\left\{y_{e}\right\}
$$

where $\left\{y_{I}\right\}$ is a subset of $\left\{y_{1}\right\}$ defined as the launch vehicle/payload interface DOF similar to that of $\left\{x_{I}\right\}$.

Using the basic mathematical formulations presented above, two different approaches for obtaining transient spacecraft responses using simplified methods will be discussed.

1. The Rigid Body Interface Acceleration Method

Since a significant coupling between the shuttle orbiter and the payloads exists, the launch vehicle organization will usually perform a dynamic analysis of the shuttle/payload system with a rigid payload model for the purpose of verifying the launch vehicle integrity. A method has been developed by which the launch vehicle/payload interface responses are modified such 
that the effect of payload elasticities are taken into consideration [55]. The payload responses and loads can then be obtained by applying the modified interface responses to the base of the payload. The advantage is that the entire procedure $c$ an be implemented within the payload organization such that timely design/analysis iteraition can be performed. However, the disadvantage is that only the analytical interface responses can be used, since it is unlikely that a rigid payload will be flown. Therefore, the measured flight data cannot be directly applied in the design/analysis process.

For a rigid payload, it is postulated that the stiffness of the payload is infinitely large, such that no elastic motion of the payload can be realized, i.e., $\left\{x_{e}\right\}=0$. Then the governing equation (IV=15) can be written as

$$
\left[m_{1}+m_{r r}\right]\left\{\ddot{x}_{1}\right\}+\left[k_{1}\right]\left\{x_{1}\right\}=\{F(t)\}
$$

Physically, $\left[m_{r r}\right]$ represents the distribution of rigid payload mass onto the interface degrees-of-freedom. Generally, for a typical payload, non-structural weights such as instrumentation, electronics, propellants, etc., constitute the major portion of the payload mass and the weight of the load carrying structure. is only a small portion of the total payload mass. Therefore, early in the project the payload rigid-body mass $\left[\mathrm{m}_{\mathrm{rr}}\right]$ can be estimated prior to the actual design since only the mass distribution and geometric configuration are required to establish $\left[m_{r r}\right]$ and $\left[\phi_{R}\right]$. It is a common practice that the payload organization will provide an estimated [ $\mathrm{m}_{\mathrm{rr}}$ ] to the launch vehicle organization early in the projeci such that the launch vehicle/rigid body payload composite model, i.e., Eq. (IV-18), can be constructed. The main purpose of such a model is the verification of the launch vehicle loading. Meanwhile the interface accelerations of the mocel can be obtained. 
The governing equation for the launch vehicle/rigid payload composite model, Eq. (IV-18) can be reduced to the generalized coordinate formulation as:

$$
\left\{\ddot{v}_{1}\right\}+2\left[\rho_{1}\right]\left[-^{-\omega_{1}}\right] \mid\left\{\dot{v}_{1}\right\}+\left[\omega_{1}^{2}\right]\left\{v_{1}\right\}=\{G(t)\}
$$

where

$$
\begin{aligned}
& \left.\begin{array}{l}
\left\{x_{1}\right\}=\left[\phi_{1}\right]\left\{v_{1}\right\} \\
G(t)\}=\left[\phi_{1}\right]^{\top}\{F(t)\}
\end{array}\right\} \\
& {\left[\phi_{1}\right]^{\top}\left[m_{1}+m_{r r}\right]\left[\phi_{1}\right]=\left[I_{-}\right]=\text {unity matrix }} \\
& {\left[\phi_{1}\right]^{\top}\left[k_{1}\right]\left[\phi_{1}\right]=\left[\begin{array}{c}
2 \\
\omega_{1}
\end{array}\right]}
\end{aligned}
$$


composite system 1$)^{2}$, the corresponding eigunvectors of the interface degrees-of-freedom, $\left[\phi_{1}\right]\left[\phi_{2}\right]$ which is a subset of $\left[\phi_{1}\right]$, and the modal damping $\left[\rho_{1}\right]$. The objective of the method is to use these data provided by the launch vehicle organization to caiculate the elastic payload responses and loads under the same dynamic events, without having to solve a new launch vehicle/elastic payload composite model similar to Eq. (IV-16).

First a transformation will be defined as

$$
\left\{\begin{array}{l}
y_{1} \\
y_{e}
\end{array}\right\}=\left[\begin{array}{ll}
\phi_{1} & 0 \\
0 & \Phi_{2}
\end{array}\right]\left\{\begin{array}{l}
u_{1} \\
u_{2}
\end{array}\right\}
$$

where $\left[\phi_{1}\right]$ are the eigenvectors of the launch vehicle/rigid payload system, Eq. (IV-2I), and $\left[\phi_{2}\right]$ are the eigenvectors of the elastic payload constrained at interface. $\left[\phi_{2}\right]$ satisfy the following orthogonality conditions:

$$
\begin{aligned}
& {\left[\phi_{2}\right]^{\top}\left[\bar{m}_{2}\right]\left[\phi_{2}\right]\left[\begin{array}{l}
\phi_{2} \\
\phi_{2}
\end{array}\right]=\text { unity matrix }} \\
& {\left[\phi_{2}\right]^{\top}\left[k_{22}\right]\left[\phi_{2}\right]=\left[\begin{array}{r}
2 \\
\omega_{2}
\end{array}\right]=\text { eigenvalues of elastic payload }}
\end{aligned}
$$

The governing Eq. (IV-16) can then be written as

$$
\left[\begin{array}{cc}
I & \Phi_{I}^{\top} m_{r e} \\
m_{e r} \phi_{I} & I
\end{array}\right]\left\{\begin{array}{l}
\ddot{u}_{1} \\
\ddot{U}_{2}
\end{array}\right\}+\left[\begin{array}{cc}
2 \rho_{1} \omega_{1} & 0 \\
0 & 2 \rho_{2} \omega_{2}
\end{array}\right]\left\{\begin{array}{l}
\dot{u}_{1} \\
\dot{U}_{2}
\end{array}\right\}+\left[\begin{array}{cc}
\omega_{1}^{2} & 0 \\
0 & \omega_{2}^{2}
\end{array}\right]\left\{\begin{array}{l}
u_{1} \\
u_{2}
\end{array}\right\}=\left\{\begin{array}{c}
G(t) \\
0
\end{array}\right\}
$$


where

$$
\begin{aligned}
& {\left[\mathrm{ln}_{\mathrm{e}}\right]=\left[\mathrm{m}_{\mathrm{re}}\right]^{\top}=\left[\phi_{2}\right]^{\top}\left[\bar{m}_{2}\right]\left[\bar{\Phi}_{\mathrm{R}}\right]} \\
& {\left[\mathrm{o}_{2}\right]=\text { payload modal damping }}
\end{aligned}
$$

With the information provided by the launch vehicle organization, Eq. (IV-24) can be constructed by the payload organization except the generalized forcing $G(t)$. To eliminate this difficulty, a modal response due to the launch vehicle/rigid payload interface acceleration will be defined as

$$
\left\{\ddot{v}_{2}\right\}+2\left[\rho_{2}\right]\left[\omega_{2},\right]\left\{\dot{v}_{2}\right\}+\left[\omega_{2}^{2}\right]\left\{v_{2}\right\}=-\left[m_{e r}\right]\left\{\ddot{x}_{I}\right\}=-\left[m_{e r}\right]\left[\phi_{I}\right]\left\{\ddot{v}_{1}\right\}
$$

$$
\begin{aligned}
& \text { It should be noted that }\left\{v_{2}\right\} \text { can be obtained once the } \\
& \text { interface accelerations }\left\{\ddot{x}_{I}\right\} \text { are available. Eqs. }(I V-19) \text { and } \\
& \text { (IV-25) can now be combined as } \\
& {\left[\begin{array}{cc}
I & 0 \\
m_{e r} \Phi_{1} & I
\end{array}\right]\left\{\begin{array}{c}
\ddot{v}_{1} \\
\ddot{V}_{2}
\end{array}\right\}+\left[\begin{array}{cc}
2 \rho_{1} \omega_{1} & 0 \\
0 & 2 \rho_{2} \omega_{2}
\end{array}\right]\left\{\begin{array}{l}
\dot{v}_{1} \\
\dot{v}_{2}
\end{array}\right\}+\left[\begin{array}{cc}
\omega_{1}^{2} & 0 \\
0 & \omega_{2}^{2}
\end{array}\right]\left\{\begin{array}{l}
v_{1} \\
v_{2}
\end{array}\right\}=\left\{\begin{array}{c}
G(t) \\
0
\end{array}\right\}}
\end{aligned}
$$

Then the solution to Eq. (IV-24) will be decomposed into two parts as

$$
\left\{\begin{array}{l}
u_{1} \\
u_{2}
\end{array}\right\}=\left\{\begin{array}{l}
v_{1} \\
v_{2}
\end{array}\right\}+\left\{\begin{array}{l}
w_{1} \\
w_{2}
\end{array}\right\}
$$


Upon substitution, the following equation can be obtained

$$
\left[\begin{array}{cc}
I & \phi_{I}^{\top} m_{r e} \\
m_{e r}{ }^{\phi} & I
\end{array}\right]\left\{\begin{array}{c}
\ddot{W}_{1} \\
\ddot{W}_{2}
\end{array}\right\}+\left[\begin{array}{cc}
2 \rho_{1} \omega_{1} & 0 \\
0 & 2 \rho_{2} \omega_{2}
\end{array}\right]\left\{\begin{array}{l}
\dot{\bar{W}}_{1} \\
\dot{\bar{W}}_{2}
\end{array}\right\}+\left[\begin{array}{cc}
\omega)_{1}^{2} & 0 \\
0 & \omega_{2}^{2}
\end{array}\right]\left\{\begin{array}{c}
\bar{W}_{1} \\
\bar{W}_{2}
\end{array}\right\}=\left\{\begin{array}{c}
-\phi_{I}^{\top} m_{r e} \ddot{V}_{2} \\
0
\end{array}\right\}
$$

In Eq. (IV-28), the generalized forcing function $G(t)$ has been replaced by $\ddot{V}_{2}(t)$ which in turn can be obtained from Eq. (IV-25) once the launch vehicle/rigid payload interface accelerations $x_{1}$ are available. Thus the payload responses $y_{e}$ can be obtained by the payload organization once Eqs. (IV-25) and (IV-28) are solved as follows

$$
\left\{y_{e}\right\}=\left[\Phi_{2}\right]\left\{u_{2}\right\}=\left[\Phi_{2}\right]\left(\left\{v_{2}\right\}+\left\{\bar{w}_{2}\right\}\right)
$$

The above describes a method by which a transient loads analysis $c$ an be performed within the payload organization. The method requires certain information from the launch vehicle organization including the launch vehicle/rigid payload composite frequencies, modal damping modal displacements for the interface degrees-of-freedom, and interface responses due to various events. The advantages of the method are the ability of the payload organization to perform complete a design/load analysis cycle independently, thus eliminating the costly and time consuming interfaces between the launch :chicle and payload organizations. The method developed above has no limitation regarding the relative size of the payload to launch vehicle or the type of forcing function used in the transient analysis.

The detailed mathematical derivation and the application of the method to a realistic problem can be found in Reference 55 . 
2. Recovered Transient Analys is

The objective of this method is to develop a procedure by which the interface accelerations of one launch vehicle/payload system, either analytically obtained or in measured flight, can be used directly in another launch vehicle/payload system design procedure, thus, the name "Recovered Transient Analysis." This effort should be especially beneficial for future payload designs using the shuttle as a launch vehicle. The payload dynamic loads can be obtained by performing a transient analysis of the payload model using the interface accelerations modified from another composite system, which consists of an identical launch vehicle, the shuttle, and a different payload, as forcing functions. In principle the proposed transient analys is recovers the interface accelerations for the unloaded launch vehicle and then modifies them to include the dynamic characteristics of the new payload. After a series of shuttle launches, the flight measured interface accelerations can be used to establish a payload forcing function data base for subsequent payload designs. The payload organization using the proposed loads analysis method can then perform payload loads analys is within the payload organization in a cost effective and timely rilanner.

In a recent article, [56], it was pointed out that the current dynamic analysis methods are unresponsive to the design process because of the long computational times and their associated costs. Their use is virtually precluded in the early design stages where frequent design changes are occurring. This method will not only simplify the analytical process thus reducing the cost, but also will provide results in a timely manner due to minimal interaction between the various oraanizations. Therefore, the rigor and potential accuracy of a systematic analytical procedure can be brought to bear on not only the design process in the early stages but a?so as a guide for the qualification testing in the later stages of the project. 
Since the objective is to utilize the results of the Composite System I to solve for the response of the Composite System II, as shown in the Fig. IV-4, the solution of Eq. (IV-15) which is the governing equation for the System I will be examined.

Let

$$
\left\{\begin{array}{l}
x_{1} \\
x_{e}
\end{array}\right\}=\left[\begin{array}{l}
\phi \\
\phi_{e}
\end{array}\right]\{q(t)\}
$$

where $[\phi]$ and $\left[\phi_{e}\right]$ are the eigenvectors of the $E q$. (IV-15) for the launch vehicle degrees of freedom (DOF) and payload elastic DOF, respectively, and $\{q(t)\}$ is the generalized coordinate vector. The eigenvectors satisfy the following orthogonality conditions:

$$
\begin{gathered}
{\left[\begin{array}{l}
\phi \\
\phi_{e}
\end{array}\right]^{\top}\left[\begin{array}{cc}
m_{1}+m_{r r} & \phi_{R^{T}}^{T} \\
m_{2} \phi_{R} & m_{2}
\end{array}\right]\left[\begin{array}{l}
\phi \\
\phi_{e}
\end{array}\right]=\left[\begin{array}{l}
1 \\
\phi_{e}
\end{array}\right]^{\top}\left[\begin{array}{ll}
k_{1} & 0 \\
0 & k_{22}
\end{array}\right]\left[\begin{array}{l}
\phi \\
\phi_{e}
\end{array}\right]=\left[\begin{array}{l}
\omega^{2} \\
\end{array}\right]}
\end{gathered}
$$

where $\left[\omega^{2}\right]$ is the composite system I eigenvalue matrix. From Eq. (IV-14), the complete eigenvectors for Payload A can be obtained as

$$
\left[\Phi_{S}\right]=\left[\phi_{R}\right]\left[\phi_{I}\right]+\left[\phi_{e}\right]
$$


where $\left[\phi_{I}\right]$ are the eigenvectors for the interface DOF, a subset of the eigenvectors for the launch vehicle DOF $[\phi]$.

By substituting Eq. (IV-30) into Eq. (IV-15) and using the orthogonality conditions as expressed in Eq. (IV-3I), one obtains the governing equations for the generalized coordinates $q(t)$.

$$
\{\ddot{q}\}+[2 p \omega]\{\dot{q}\}+\left[\omega^{2}\right]\{q\}=[\phi]^{\top}\{F(t)\}
$$

Note that modal damping, [-2pw.], has been included.

One other quantity, $\left[\mathrm{m}_{\mathrm{er}}\right]$, representing the inertia coupling effects between the launch vehicle and the payload is available from the analysis. It is defined as follows:

$$
\left[\bar{m}_{\mathrm{er}}\right]=\left[\phi_{S}\right]^{\top}\left[\mathrm{m}_{2}\right]\left[\phi_{R}\right]
$$

In summary, the following results from Composite System I will have to be made available to the payload organization,

1) The system eigenvalues $\left[\omega^{2},\right]$.

2) The system eigenvectors at interface DOF $\left[\phi_{I}\right]$.

3) Rigid-body mass and inertia coupling matrices, $\left[m_{r r}\right]$ and $\left[m_{e r}\right]$.

4) Time history of the generalized coordinates $\{q(t)\}$ or
$\{\ddot{q}(t)\}$. 
With this information, the responses of system II represented by Eq. (IV-16) will be sought. First, the external forcing functions $\{F(t)\}$ must be eliminated by combining Eqs. (IV-15) and $(I V-16)$.

$$
\left[\begin{array}{cc}
m_{1}+\bar{m}_{r r} & \bar{\phi}_{R}^{T} \bar{m}_{2} \\
\bar{m}_{2} \bar{\phi}_{R} & \bar{m}_{2}
\end{array}\right]\left\{\begin{array}{l}
\ddot{z}_{1} \\
\ddot{y}_{e}
\end{array}\right\}+\left[\begin{array}{cc}
k_{1} & 0 \\
0 & \bar{k}_{22}
\end{array}\right)\left\{\begin{array}{l}
z_{1} \\
y_{e}
\end{array}\right\}=\left[\begin{array}{c}
{\left[m_{e r}\right]^{T}-\left[m_{r r}\right]\left[\phi_{I}\right]} \\
-\left[\bar{m}_{2}\right]\left[\bar{\phi}_{R}\right]\left[\phi_{I}\right]
\end{array}\right]\{\ddot{q}(t)\}
$$

where

$$
\left\{z_{1}\right\}=\left\{y_{1}\right\}-\left\{x_{1}\right\},\left[\phi_{R}\right]\left\{x_{1}\right\}=\left[\phi_{R}\right]\left\{x_{I}\right\}
$$

In Eq. (IV-35), the external forcing function $\{F(t)\}$ has been $r \in p$ laced by the modal acceleration $\{\ddot{q}(t)\}$ which will be available to the payload organization. However, to solve for Eq. (IV-35), the eigenvalues and eigenvectors of system I are required. From Eq. (IV-35), it appears that the launch vehicle mass and stiffness matrices, $\left[m_{1}\right]$ and $\left[k_{1}\right]$, are needed which means the launch vehicle model is needed. Since it is an a priori assumption that the launch vehicle model will not be available, a method wil: be devised by which the required eigendata can be extracted without the use of the detailed launch vehicle model. Only the generalized, or modal launch vehicle model will be required. Basically, the method will first obtain the eigendata for an unloaded launch vehicle by removing Payload A from the Composite System I. Next, the unloaded launch vehicle will be coupled with Payload $B$ to obtain the eigendata for Composite system II. For reasons of mairix size compatibility, a system consisting of an unloaded launch vehicle and a cantilevered Payload $A$ will be studied. 


$$
\left[\begin{array}{cc}
m_{1} & 0 \\
0 & \cdots \\
m_{2}
\end{array}\right]\left\{\begin{array}{l}
\ddot{x}_{0} \\
\ddot{x}_{2}
\end{array}\right\}+\left[\begin{array}{ll}
k_{1} & 0 \\
0 & k_{22}
\end{array}\right]\left\{\begin{array}{l}
x_{0} \\
x_{2}
\end{array}\right\}=0
$$

It is obvicus that payload $A$ is not coupled to the launch vehicle, therefore the results from Eq. (IV-37) include the Payload $A$.

Let

$$
\left\{\begin{array}{l}
x_{0} \\
x_{2}
\end{array}\right\}=\left[\begin{array}{l}
\phi \\
\phi_{e}
\end{array}\right]\{u\}
$$

Substituting Eq. (IV-38) into Eq. (IV-37) and pre-multiplying by the transpose of the transformation matrix, one obtains

$$
\begin{aligned}
& {\left[\begin{array}{l}
\phi \\
\phi_{\mathrm{e}}
\end{array}\right]^{\top}\left(\left[\begin{array}{cc}
m_{1}+m_{r r} & \phi_{R}^{\top} m_{2} \\
m_{2} \phi_{R} & m_{2}
\end{array}\right]-\left[\begin{array}{cc}
m_{r r} & \phi_{R}^{\top} m_{2} \\
m_{2} \phi_{R} & 0
\end{array}\right]\right)\left[\begin{array}{c}
\phi \\
\phi_{e}
\end{array}\right]\{\ddot{u}\}} \\
& +\left[\begin{array}{l}
\phi \\
\phi \\
e
\end{array}\right]^{T}\left[\begin{array}{ll}
k_{1} & 0 \\
0 & k_{22}
\end{array}\right]\left[\begin{array}{l}
\phi \\
\phi \\
e
\end{array}\right]\{u\}=0
\end{aligned}
$$

Using the orthogonality relationship of Eq. (IV-31) and the relationship in Eq. (IV-32), Eq. (IV-39) can be reduced into the
form of

$$
\begin{array}{r}
\left(\left[{ }_{I}\right]+\left[\phi_{I}\right]^{\top}\left[m_{r r}\right]\left[\phi_{I}\right]-\left[\bar{m}_{e r}\right]\left[\phi_{I}\right]-\left[\phi_{I}\right]^{\top}\left[\bar{m}_{e r}\right]^{\top}\right)\{u ̈\} \\
+\left[\omega^{2}\right]\{u\}=0
\end{array}
$$


All the matrices in Eq. (IV-40) are available to the payload organization and they are in much simpler form than the launch vehicle inass and stiffness matrices. The eigenvalues and eigenvectors for Eq. (IV-40) will be denoted as $\left[\omega_{0}^{2}\right]$ and $[\psi]$, respectively. From Eq. (IV-38) the eigenvectors for the unloaded launch vehicle interface DOF will be

$$
\left[\phi_{O I}\right]=\left[\phi_{I}\right][\psi]
$$

As mentioned before, the eigenvalues and tre eiganvectors obtained from Eq. (IV-40) contain the effeci of the cantilevered Payload A. It must be identified and removed from the results. One way is to use the orthogonality condition to identify the payload modes.

Let

$$
\left[\Phi_{O S}\right]=\left[\Phi_{S}\right][\psi]
$$

From Eqs. (IV-38) and (IV-42), it is clear that the cantilevered payload modes are among the modes $\left[\phi_{0 S}\right]$. Since the payload modes are orthogonal modes with respect to the mass matrix, the following multiplication will ideally produce unit diagonal terms and zero off diagonal terms for those payload modes.

$$
\left[M_{g}\right]=\left[\phi_{O S}\right]^{\top}\left[m_{2}\right]\left[\phi_{O S}\right]
$$

Although truncation errors will contaminate the unit and zero terms, the errors should be small if sufficient modes are accounted for. Thus the matrix $\left[M_{g}\right]$ can be used to sort out the payload modes. 
After the eigendata of the unloaded launch vehicle are obtained, the eigendata for the new composite model, Eq. (IV-35) consisting of the identical launch vehicle and a new payload $B$ can be obtained.

Let

$$
\left\{\begin{array}{l}
z_{1} \\
y_{e}
\end{array}\right\}=\left[\begin{array}{ll}
\Phi_{0} & 0 \\
0 & \bar{\phi}_{2}
\end{array}\right]\left\{\begin{array}{l}
u_{1} \\
u_{2}
\end{array}\right\}
$$

where $\left[\phi_{0}\right]$ and $\left[\bar{\phi}_{2}\right]$ are the eigenvectors of the unloaded launch vehicle and the cantilevered $P$ ayload $B$, respectively. Note that the matrix $\left[\Phi_{O I}\right]$ is available from Eq. (IV-4I). Therefore the following orthogonality conditions are satisfied:

$$
\begin{aligned}
& \left.\begin{array}{l}
{\left[\phi_{0}\right]^{\top}\left[m_{1}\right]\left[\phi_{0}\right]=[I]} \\
{\left[\phi_{0}\right]^{\top}\left[k_{1}\right]\left[\phi_{0}\right]\left[\omega_{0}^{2}\right]}
\end{array}\right\} \\
& \left.\begin{array}{l}
{\left[\bar{\phi}_{2}\right]^{\top}\left[\bar{m}_{2}\right]\left[\bar{\phi}_{2}\right]=\left[\begin{array}{l}
1 \\
I
\end{array}\right]} \\
{\left[\bar{\Phi}_{2}\right]^{\top}\left[k_{22}\right]\left[\bar{\Phi}_{2}\right]=\left[\begin{array}{l}
\bar{\omega}_{2}^{2}
\end{array}\right]}
\end{array}\right\}
\end{aligned}
$$

where $\left[\omega_{0}^{2}\right]$ and $\left[\bar{\omega}_{2}^{2}\right]$ are the eigenvalues of the unloaded launch vehicle and the cantilevered Payload 3 , respectively. Using the transformation of Eq. (IV-44) the eigenproblem for the new composite model, Eq. (IV-35) can be rewritten as 


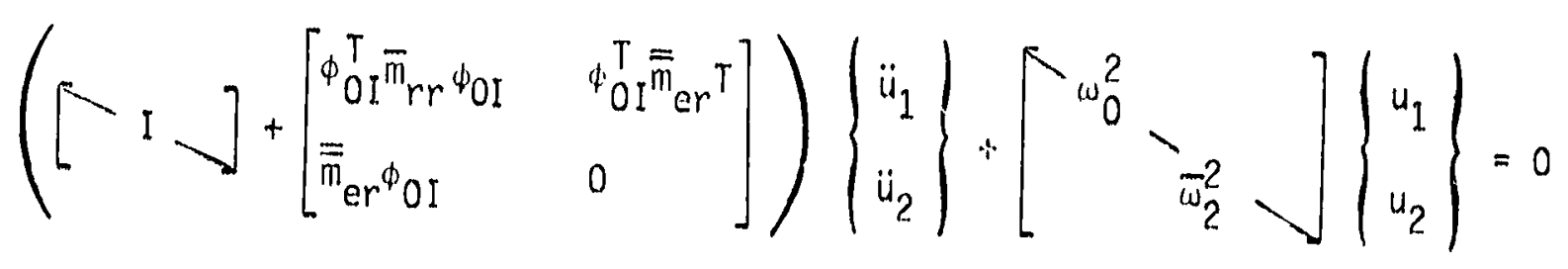
$($ IV -47$)$

where

$$
\left[\overline{\bar{m}}_{\mathrm{er}}\right]=\left[\bar{\phi}_{2}\right]^{\top}\left[\bar{m}_{2}\right]\left[\bar{\phi}_{R}\right]
$$

The elements in the coefficient matrices of $E$ Cl. (IV-47) are typically available either from the unloaded launch vehicle eigendata such as the $\left[\phi_{0 I}\right]$ and $\left[\omega_{0}^{2}\right]$ and from the cantilevered new payload eigendata such as the $\left[\bar{m}_{r r}\right],\left[\overline{\bar{m}}_{e r}\right]$ be calculated by the payload organization. They satisfy the following orthogonality conditions.

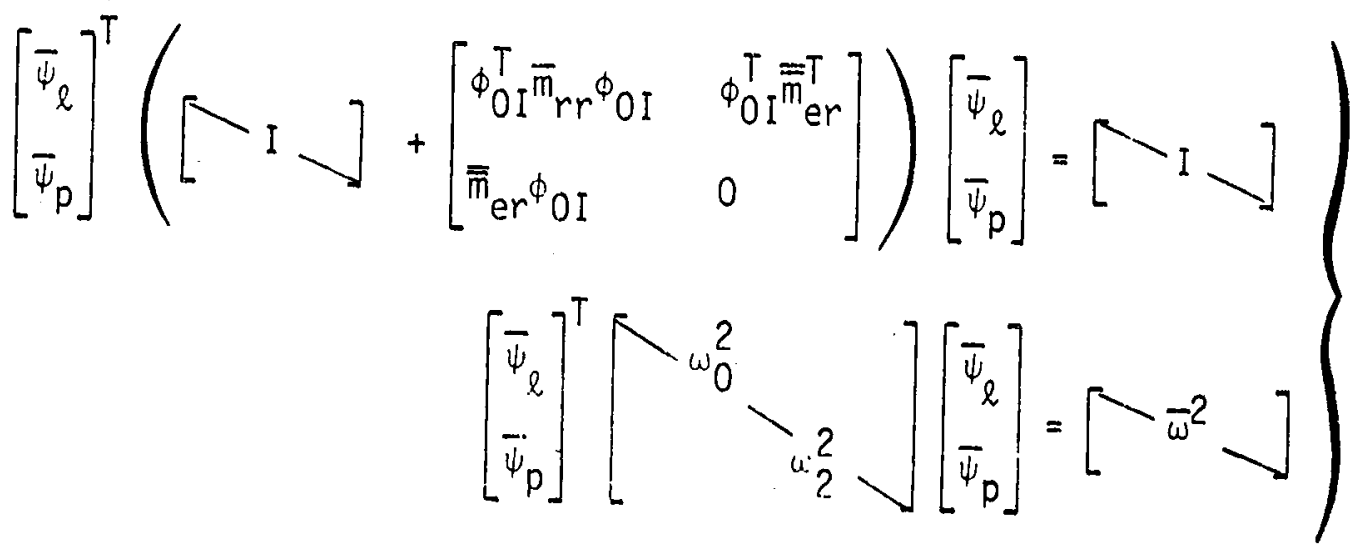

where $\left[\bar{\psi}_{\ell}\right],\left[\bar{\psi}_{p}\right]$ are the eigenvectors and $\left[\bar{\omega}_{2}\right]$ are the eigenvalues. The eigenvectors of the launch velicle/payload interface DOF are given as follows:

$$
\left[\bar{\phi}_{I}\right]=\left[\phi_{O I}\right]\left[\bar{\psi}_{\ell}\right]
$$


The responses of the composite model, Eq. (IV-35) will be solved by using the following transformation:

$$
\left\{\begin{array}{l}
z_{1} \\
y_{l}
\end{array}\right\}=\left[\begin{array}{ll}
\phi_{0} & 0 \\
0 & \phi_{2}
\end{array}\right]\left[\begin{array}{l}
\bar{\psi}_{l} \\
\bar{\psi}_{p}
\end{array}\right]\{\bar{q}(t)\}
$$

Then the unccupled modal equations can be obtained as

$\{\ddot{\bar{q}}\}+[2 \bar{\rho} \bar{\omega}]\{\dot{\bar{q}}\}+\left[\ddot{\omega}^{2}\right]\{\bar{q}\}=[G]\{\ddot{q}(t)\}$

where

$[G]=\left[\left[\bar{\phi}_{I}\right]^{\top}\left[\bar{m}_{e r}\right]^{\top}-\left[\bar{m}_{r r}\right]\left[\phi_{I}\right]-\left[\bar{\psi}_{\rho}\right]^{\top}\left[\bar{m}_{e r}\right]\left[\phi_{I}\right]\right]$

Since the quantities on the right hand side of $E q .(I V-52)$ are available to the payload organization, the modal response $q(t)$ can be obtained from the LV organization in a timely manner. It should be noted that modal damping $[2 \bar{p} \bar{w}]$ has been included in Eq. (IV-52).

The discrete payload accelerations of each DOF can be obtained by using Eqs. (IV-17), (IV-36) and (IV-5I) as follows:

$$
\begin{aligned}
& \left\{\ddot{y}_{2}\right\}=\left[\bar{\zeta}_{R}\right]\left\{\ddot{y}_{I}\right\}+\left\{\ddot{y}_{e}\right\} \\
& =\left[\Phi_{R}\right]\left(\left\{\ddot{z}_{I}\right\}+\left\{\ddot{x}_{I}\right\}\right)+\left\{\ddot{y}_{e}\right\} \\
& =\left[\bar{\Phi}_{R}\right]\left(\left[\Phi_{0 I}\right]\left[\bar{\psi}_{0}\right]\{\ddot{\bar{q}}(t)\}+\left\{\ddot{x}_{I}\right\}\right)+\left[\phi_{2}\right]\left[\bar{\psi}_{p}\right]\{\ddot{q}(t)\} \\
& =\left(\left[\bar{F}_{R}\right]\left[{ }^{*} 0 I\right]\left[\bar{\psi}_{t}\right]+\left[\Phi_{2}\right]\left[\bar{\psi}_{p}\right]\right)\{\ddot{\bar{q}}(t)\}+\left\{\ddot{x}_{I}\right\}
\end{aligned}
$$


The structural member loads, $\{p\}$, can be obtained from the following operations:

$$
|p|=[S]\left\{y_{e}\right\}=[S]\left[\bar{\Phi}_{2}\right]\left[\bar{\psi}_{p}\right]\{\bar{q}(t)\}
$$

where [S] is the loads coefficient matrix which relates the elastic deformation to the member loads. Typically, in a payload dynamic analysis, the product $[S]\left[\phi_{2}\right]$, rather that $[S]$ is obtained.

The described recovered transient analys is should theoretically provide the same results as that of the full scale transient analysis if the damping is absent. In view of the fact that generally only very light dampings are involved with the payload structural systems, good accuracy for the results can be expected. Anocher source of error is the modal truncation. One should expect similar exrors due to modal truncation just as any other dynamical system solved by the modal method. This method has been demonstrated by a realistic sample problem which can be found in Appendix $D$.

\section{Comparison of Load Estimation Methods to Transient Loads Methods}

Spacecraft members loads obtained by estimation methods, such as the generalized shock spectra/impedance method are by intent more conservative than those obtained by transient load analysis. It is, however, difficlit to quantify this conservatism analytically. One of the reasons for tinis difficulty is that in order to fully assess the conservatism a particular spacecraft structure would have to be designed by both metrinds; this implies several design and load analysis iterations. Such data is not available. Some limited data for realistic payload structural systems from past programs is available and will be discusied here to assess the-degree of 
conservatism of the load estimation methods. These comparisons should serve as an aid in the selection of loads methods for future projects.

The earlier version of the shock spectra method [49] was applied to the Viking Orbiter primary structure. The loads were then compared with the Viking design loads which were calculated by the full scale transient analysis on the system model. The results have been reported previously [57]. In evaluating this comparison it should again be remembered that the data presented is based on one load cycle using the shock spectra method for a spacecraft model designed by a system transient loads analysis. Thus this is not a comprehensive comparison of a structural system designed by the two methods.

Another type of comparative data is available from Voyager. This spacecraft structure was designed using the earlier version of the shock spectra method. The design loads were verified by transient analyses and found to be conservative. Flight instrumentation on b.oth Voyager spacecraft was used to reconstruct member flight loads. A detailed comparison of the design loads, verification loads and flight loads is contained in Reference 58.

A summary of the results of these two comparisons are shown in Tables IV-1 and VI-2. Structural members used for this comparison are primary truss slements, subjected to significant loading during the mission. Table IV-1 contains ratios of shock spectra loads to transient member loads for both Viking and Voyager primary truss members for two launch vehicle events, namely launch (or Stage 0 Ignition) and Stage I Burnout. This comparison shows that loads calculated by the early shock spectra method when compared for each event can be considerably more conservative than those obtained from transient analysis. For individual members the conservatism ranges 
from a favorable 26 percent to a very high 500 percent. The latter number is due to the assumed deleterious tuning between the launch vehicle and the spacecraft normal modes. A more meaningful comparison can be made by considering the design loads for the various members. Ratios of shock spectra design loads to transient design loads for both Viking and Voyager are shown in Table IV-2. The design loads are more meaningful since thay are more directly related to structural weight. The member design loads are obtained by considering all flight events, some of which do not lend themselves to a transient loads analys is such as the maximum $\alpha q$ event which is treated as a steady-state excitation.

For the Viking spacecraft, an estimate of the increase in the structural weight was made [57] using the design loads obtained by the shock spectra method. A minimum additional structural weight of 6.9 percent was estimated by using the actual viking orbiter primary structure capability determined by the test program, not the analysis, since this was the only available data.

In some cases, the tested capability was much greater than the analytically predicted values. If analytically predicted capabilities were used as a reference, as would be done in designing the structure, the weight increase would be larger. Since the conservatism in structural design is dictated by factors such as manufacturing considerations, handiing, and design load conditions that changed in the course of the project, a weight increase of up to 50 percent inight be possible. These considerations, as they arose on Viking, are reflected in an overall structural weight increase of only 6.9 percent using a single loads cycle and the shock spectra/ impedance meihod rather than the transient loads analysis method. Thus the values shown in Tables IV-I and IV-2 do not automatically result in a very heavy structure because:

1. The design process does not use all the computed loads but only a subset of the highest loads. 
Table IV-1. Comparlsom of Shock spoctra and Translont Loads for liwo livent:-

\begin{tabular}{|c|c|c|c|c|c|}
\hline \multicolumn{3}{|c|}{$\begin{array}{l}\text { Viking VLCA Truss } \\
\text { Ratio Shock Spectra/Transient }\end{array}$} & \multicolumn{3}{|c|}{$\begin{array}{l}\text { Voyager Mission Module Truss } \\
\text { Ratio Shock Spectra/Transtent }\end{array}$} \\
\hline Ilember & Launch & Stirge 1 BO & Momber & Launch & Stage 1 BO \\
\hline 750 & 2.66 & 2.70 & 6801 & 1.82 & 1.55 \\
\hline 751 & 3.64 & 2.15 & 6802 & 1.88 & 1.43 \\
\hline 752 & 4.65 & 1.66 & 6803 & 2.84 & 2.93 \\
\hline 753 & 3.53 & 1.90 & 6804 & 3.21 & 3.62 \\
\hline 754 & 2.05 & 2.25 & 6805 & 1.99 & 1.47 \\
\hline \multirow[t]{3}{*}{755} & 2.98 & 2.38 & 6306 & 1.88 & 1.26 \\
\hline & & & 6807 & 3.40 & 5.66 \\
\hline & & & 6808 & 2.85 & 3.27 \\
\hline
\end{tabular}

Table IV-2. Comparison of Shock Spectra and Transient Design Loads for Major Structural Elcments

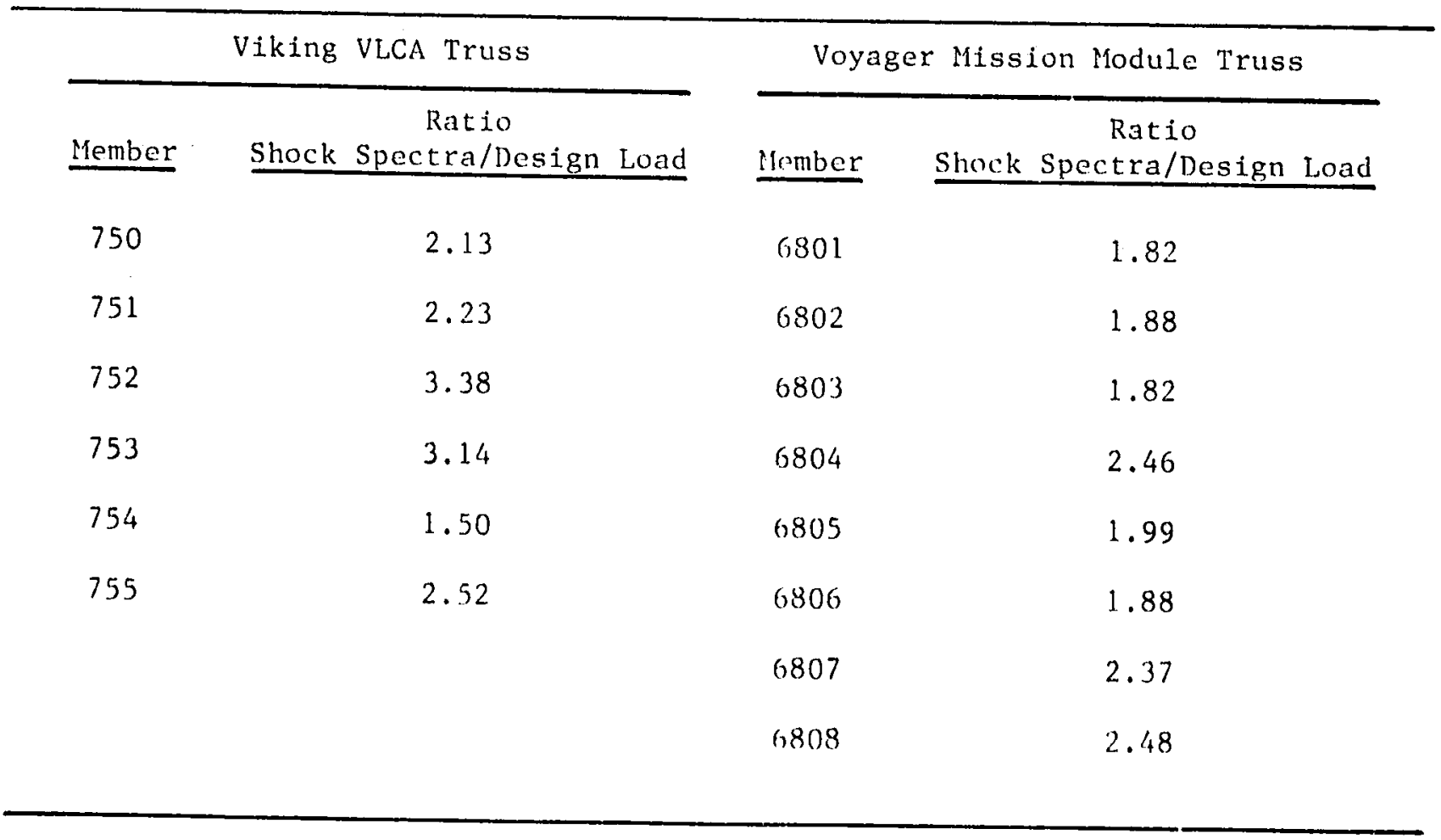


$-68-$

2. The shock spectra loads tend to equalize the loads in like members, make the loads less sensitive to directional effect and allow for deleierious tuning between launch vehicle modes and spacecraft modes.

3. The advantage of the transient analysis can rarely be fully exploited in design since tailoring member size to loads and degree of freedom, member by member, is not feasible in practice because of schedule and cost. In addition, design loads derived from transient analysis must be chosen higher than transient loads prediction in order to account for the deleterious tuning mentioned above.

Therefore, although the conservatism can be high the shock spectra method was found to be a cost effective loads approach. The data does not correspond to the shock spectra derivation of Section IV-A. The latter is currently being used for the design of the Galileo and the International Solar Polar Mission (ISPM) spacecraft. Tabie IV-3 shows the comparison of the ISPM spacecraft generalized shock spectra loads with those obtained by the recovered transient analysis. The comparison indicates that the loads are indeed very closed. 
Table TV-3. Comparison of Generalized Shock Spectra and Recovered Transient loads for ISPM

\begin{tabular}{cccc}
\hline Member & $\begin{array}{c}\text { Upper Bound } \\
\text { Load } \\
(\mathrm{N})\end{array}$ & $\begin{array}{c}\text { Maximum Load } \\
\text { From Recovered } \\
\text { Transient Analysis } \\
(\mathrm{N})\end{array}$ & $\begin{array}{c}\text { Ratio } \\
\text { Upper Bound } \\
\text { Transient }\end{array}$ \\
\hline 701 & 4020 & 2861 & 1.41 \\
702 & 10040 & 7968 & 1.26 \\
703 & 12200 & 10943 & 1.12 \\
704 & 7100 & 7692 & 0.92 \\
705 & 4380 & 3759 & $\ldots .17$ \\
706 & 10260 & 9430 & 1.09 \\
707 & 11500 & 12197 & 0.94 \\
703 & 7100 & 6891 & 1.03 \\
\hline
\end{tabular}


V. OTHER METHODS

Other aerospace organizations are actively involved in shuttle payload activities. In this section four different loads methods proposed by various companies will be briefly reviewed.

A. Time Uncorrelated Maxima and Minima

The Boeing Aerospace Company (BAC) has developed a simplified method [59] which aims at reducing the number of normal modes to be used in the evaluation of the time history of the member forces obtained from a transient analysis. For any event, the approach is, to first search for the absolute maxima of each coupled generalized coordinate $q(t)$. Second, the loads transformation row matrix (LTM) for each component is multiplied by the column of these maxima and the contribution to the total summation is noted and ordered by absolute maxima. Based on this ordering only those modes which are deemed important are selected. The selection criteria used can be varied but, in practice, those modes contributing less than a predetermined value, such as $0.1 \%$, to the total summation are discarded. Based on these criteria typically $50 \%$ of the modes are declared trivial. The computed time history for the force (or moment) component is now calculated using only the retained modes. It shculd be noted that each force component has a different set of retained modes. This method saves time and seems to be an interesting innovation for the time domain solution technique. There is as yet a lack of data to fully assess the coliservatism (or lack thereof) of this method. It should not be difficult to estimate the bound of the error. BAC experience indicates that for a cutoff criteria of discarding the $0.1 \%$ contributory modes, a saving in compulation time of 20 or $30 \%$ is achieved. For a $1 \%$ cutoff criteria the saving is approximately $75 \%$ in computation time. 
B. Impedance Technique for Determining Low Frequency Payload Environnents

Martin Marietta Aerospace (MMA) has developed an "impedance" method [60] which eliminates the necessity of creating detailed coupled models as well as decreasing the scope of an overall integration task. This approach corrects the response of the launch vehicle/payload interface to reflect feedback changes associated with changes of the payload. All calculations are made in the frequency domain. The approach eliminates the necessity of computing the final coupled eigensolutions. The final equations are reduced to simple complex transfer functions. Furthermore, the launch vehicle dynamic characteristics required to compute these transfer functions consist of unloaded interface free-free modal data. By obtaining a

"standard" set of launch vehicle models and input environmental data, the payload organizations should be able to calculate the expected low frequency environments at the launch vehicle/payload interface. This approach also reduces a large portion of the overall integration task. This approach was applied to the Long Duration Exposure Facility (LDEF) loads calculation for the STS environments. From the results, it was concluded that the frequency domain analysis was quice difficult to implement because of, among other things, the sensitivity to the damping. A comparison with the results of the time domain analysis also indicated that more meaningful information can be gained from the trarisient analysis in time domain.

C. Coupled Base Motion Response Analysis of Payload Structural Systems

The Marshall Space Flight Center (MSFC) has developed a simplified analytical approach for payload loads analysis [61]. This approach is similar in many respects to the recovered transient analysis described in section IV B.2. The main advantage of this approach is the avoidance of the reconstruction of the entire launch vehicle/payload composite model for each loads analysis cycle. This conceptual approach was further studied by other investigators using very simple examples [62]. It was concluded that the method gave good results even with modal truncation. 
D. Modification of Flight Vehicle Vibration Modes to Account for Design Changes.

As mentioned before, quite commonly, subsequent to the completion of a load cycle analysis, design modifications are made to the payload. A new load cycle is then required to assess the effects of these design changes on payload responses and loads. A technique has been developed by the Lockheed Missiles and Space Company (LMSC) that will bypass a portion of the new analys is cycle. The method is called mode modification [63], which consists of expressing the new composite modes in terms of the set of previous modes plus a set of constraint modes associated with the area of the composite system which is to be modified. An eigenvalue problem for the new modes is formulated within which the finite element mass and stiffness matrices in the area of modification are explicitly displayed and may be modified in any arbitrary manner. This method is not a perturbation method. Solution of the eigenvalue problem yields a set of new system modes of the modified composite system directly. This method was demonstrated using three sample problems with favorable results comparing them to the exact solutions. 
VI. CONCLUDING REMARKS

The state-of-the-art of load prediction for payloads launched by STS is presently reiying on very crude quasi-static load factors for preliminary analyses and complete STS/Payload or STS/IUS/Payload system transient load analyses for design and verification loads. The latter process is expensive and time consuming due to the complexity of the dynamic models and the many organizational interfaces. At the present time the accuracy of these analyses is questionable due to the lack of definition of the forcing functions and uncertainties in the model of a launch vehicle which has not yet been flown.

Over the last few years the problem of reducing the time and expenditure for the design/analysis cycle of payloads has been addressed. Design loads for the Voyager spacecraft were obtained in-house at JPL using upper bound loads obtained by the Shock Spectra/Impedance Method. The design loads were verified by a system transient analysis later in the program. A comparison of Voyager flight data with design data has shown that the design was more conservative than Viking, which was designed using transient analysis, at a substantial cost_reduction and some increase in structural weight.

Recently the shock spectra method has been improved and it is currently being used at JPL to design the Galileo (GLL) and the International Solar Polar Mission (ISPM) spacecraft. Designing spacecraft to be flown on STS to upper bound levels is appropriate due to the uncertainties of a yet not flown launch vehicle.

Recognizing the necessity of simplifying the transient loads analysis process JPL is also developing methods for decoupling the payload loads analysis process from the launch vehicle as much as possible. These methods are aimed at reducing the cost and improving the scheduie for transient load analyses. Ultimately, as flight data for the STS will become available it is expected that these simplified transient loads analysis methods will provide the most accurate loads prediction at reasonable cost. 
$-74-$

APPENDIX A

Comparison of Measured and Analytically

Predicted Member Forces

for Viking Orbiter

Both Viking spacecraft, Viking 1 and Viking 2, had strain gauges installed on the Viking Lander Capsule Adapter (VLCA) truss. These strain gauges measured the axial forces in each of the six members of the truss. Table A-1 shows the comparison of the flight data to pre-flight predictions. The final flight load prediction for Viking was made using the spacecraft structural modei verified by a test (Model VIII). Only those launch vehicle events considered critical were analyzed using this model. Other events, considered less critical were analyzed only early in the program using preliminary spacecraft models (Model I and IV). The predictions for the latter Models are not expected to be as good as for Model VIII. 
Table $4-1$. Comparison of VIfleg 1 and Viking 2 Mrasured VI,CA Forces to Preflight Analytical prodict fons

\begin{tabular}{|c|c|c|c|c|c|c|}
\hline \multirow[t]{2}{*}{ Member/Mcas. No. } & \multicolumn{3}{|c|}{ 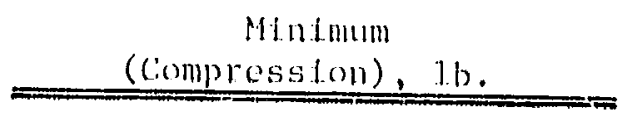 } & \multicolumn{3}{|c|}{$\begin{array}{r}\text { Maximum } \\
\text { (T'enston), 1b. } \\
\end{array}$} \\
\hline & Predicted & Viking 1 & Viking 2 & Prodicted & Viklng 1 & Viking 2 \\
\hline \multicolumn{7}{|c|}{ Stage 0 Ignition (Model VIII) } \\
\hline $\begin{array}{ll}750 / \mathrm{CY} & 186 \mathrm{~S} \\
751 / \mathrm{CY} & 187 \mathrm{~S} \\
752 / \mathrm{CY} & 188 \mathrm{~S} \\
753 / \mathrm{CY} & 189 \mathrm{~S} \\
754 / \mathrm{CY} & 190 \mathrm{~S} \\
755 / \mathrm{CY} & 191 \mathrm{~S}\end{array}$ & $\begin{array}{l}-2900 \\
-2700 \\
-2300 \\
-2900 \\
-2800 \\
-2800\end{array}$ & $\begin{array}{l}-2000 \\
-1600 \\
-2000 \\
-2500 \\
-2200 \\
-2200\end{array}$ & $\begin{array}{l}-2300 \\
-1300 \\
-2200 \\
-2800 \\
-1500 \\
-2300\end{array}$ & $\begin{array}{r}900 \\
1800 \\
400 \\
900 \\
1900 \\
800\end{array}$ & $\begin{array}{l}800 \\
800 \\
100 \\
200 \\
600 \\
200\end{array}$ & $\begin{array}{r}100 \\
1000 \\
0 \\
1100 \\
100 \\
200\end{array}$ \\
\hline \multicolumn{7}{|c|}{ (Iax a (Model VIII) } \\
\hline 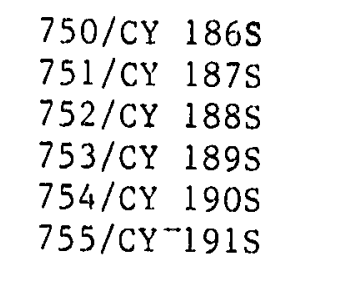 & $\begin{array}{l}-3200 \\
-2900 \\
-3400 \\
-3600 \\
-3000 \\
-3400\end{array}$ & $\begin{array}{l}-2000 \\
-1500 \\
-2100 \\
-1900 \\
-1500 \\
-1900\end{array}$ & $\begin{array}{l}-1900 \\
-1200 \\
-2100 \\
-2000 \\
-1400 \\
-2200\end{array}$ & $\begin{array}{l}1000 \\
1800 \\
1200 \\
1400 \\
2000 \\
1200\end{array}$ & $\begin{array}{r}-500 \\
300 \\
-400 \\
-300 \\
200 \\
-300\end{array}$ & $\begin{array}{r}-400 \\
200 \\
-300 \\
-300 \\
400 \\
-400\end{array}$ \\
\hline \multicolumn{7}{|c|}{ Stage I Ignition (Model I) } \\
\hline $\begin{array}{ll}750 / \mathrm{CY} & 186 \mathrm{~S} \\
751 / \mathrm{CY} & 187 \mathrm{~S} \\
752 / \mathrm{CY} & 188 \mathrm{~S} \\
753 / \mathrm{CY} & 189 \mathrm{~S} \\
754 / \mathrm{CY} & 190 \mathrm{~S} \\
755 / \mathrm{CY} & 191 \mathrm{~S}\end{array}$ & $\begin{array}{l}-1500 \\
-1200 \\
-2000 \\
-2100 \\
-1800 \\
-2000\end{array}$ & $\begin{array}{l}-1400 \\
-1200 \\
-2000 \\
-1800 \\
-1200 \\
-1900\end{array}$ & $\begin{array}{l}-1800 \\
-1200 \\
-1700 \\
-1800 \\
-1200 \\
-1900\end{array}$ & $\begin{array}{l}0 \\
0 \\
0 \\
0 \\
0 \\
0\end{array}$ & $\begin{array}{r}-800 \\
0 \\
-\quad 600 \\
-600 \\
0 \\
-\quad 500\end{array}$ & $\begin{array}{r}-800 \\
0 \\
-600 \\
-600 \\
-100 \\
-700\end{array}$ \\
\hline \multicolumn{7}{|c|}{ SRM Jettison (Mode1 I) } \\
\hline $\begin{array}{ll}750 / \mathrm{CY} & 186 \mathrm{~S} \\
751 / \mathrm{CY} & 187 \mathrm{~S} \\
752 / \mathrm{CY} & 188 \mathrm{~S} \\
753 / \mathrm{CY} & 189 \mathrm{~S} \\
754 / \mathrm{CY} & 190 \mathrm{~S} \\
755 / \mathrm{CY} & 191 \mathrm{~S}\end{array}$ & $\begin{array}{l}-1200 \\
-700 \\
-1500 \\
-1200 \\
-800 \\
-1400\end{array}$ & $\begin{array}{l}-1500 \\
-1000 \\
-1700 \\
-1400 \\
-900 \\
-1500\end{array}$ & $\begin{array}{l}-1600 \\
-1000 \\
-1700 \\
-1600 \\
-1100 \\
-1500\end{array}$ & $\begin{array}{l}0 \\
0 \\
0 \\
0 \\
0 \\
0\end{array}$ & $\begin{array}{r}-400 \\
200 \\
-500 \\
-100 \\
100 \\
-100\end{array}$ & $\begin{array}{r}-300 \\
300 \\
-\quad 200 \\
0 \\
200 \\
-\quad 300\end{array}$ \\
\hline \multicolumn{7}{|c|}{ Stage I Burn (lkodel VIII) } \\
\hline $\begin{array}{ll}750 / \mathrm{CY} & 186 \mathrm{~S} \\
751 / \mathrm{CY} & 187 \mathrm{~S} \\
752 / \mathrm{CY} & 188 \mathrm{~S} \\
753 / \mathrm{CY} & 189 \mathrm{~S} \\
754 / \mathrm{CY} & 190 \mathrm{~S} \\
755 / \mathrm{CY} & 191 \mathrm{~S}\end{array}$ & $\begin{array}{l}-4900 \\
-2500 \\
-5400 \\
-4500 \\
-2900 \\
-4500\end{array}$ & $\begin{array}{l}-2200 \\
-1100 \\
-2200 \\
-2300 \\
-1200 \\
-2300\end{array}$ & $\begin{array}{l}-2200 \\
-1000 \\
-2200 \\
-2300 \\
-1200 \\
-2400\end{array}$ & $\begin{array}{r}1000 \\
500 \\
1400 \\
600 \\
900 \\
1300\end{array}$ & $\begin{array}{l}-1600 \\
-800 \\
-1800 \\
-1200 \\
-600 \\
-1300\end{array}$ & $\begin{array}{l}-1600 \\
-800 \\
-1600 \\
-1500 \\
-600 \\
-1600\end{array}$ \\
\hline
\end{tabular}


Table $\Lambda-1$. Comparison of Viking 1 and Viking 2 Measured VLCA

lorees to preflight Analytical predtwions (Continued)

\begin{tabular}{|c|c|c|c|c|c|c|}
\hline \multirow[t]{3}{*}{ lember/Moas. No. } & \multicolumn{3}{|c|}{$\begin{array}{c}\text { Mintmum } \\
\text { (Compression), } 1 \mathrm{~b} .\end{array}$} & \multicolumn{3}{|c|}{$\begin{array}{c}\text { Maximum } \\
(\text { Tenston), lb. }\end{array}$} \\
\hline & Predicted & Viklng 1 & Viking 2 & Predicted & Viking 1 & Vik1ng 2 \\
\hline & \multicolumn{6}{|c|}{ Stage I Burnout/Stage II Ignition (Mode1 VIII) } \\
\hline $\begin{array}{ll}750 / \mathrm{CY} & 186 \mathrm{~S} \\
751 / \mathrm{CY} & 187 \mathrm{~S} \\
752 / \mathrm{CY} & 188 \mathrm{~S} \\
753 / \mathrm{CY} & 189 \mathrm{~S} \\
754 / \mathrm{CY} & 190 \mathrm{~S} \\
755 / \mathrm{CY} & 191 \mathrm{~S}\end{array}$ & $\begin{array}{l}-3100 \\
-2000 \\
-3100 \\
-3100 \\
-2200 \\
-3000\end{array}$ & $\begin{array}{l}-2600 \\
-1300 \\
-2700 \\
-2500 \\
-1400 \\
-2700\end{array}$ & $\begin{array}{l}-2500 \\
-1300 \\
-2500 \\
-2500 \\
-1300 \\
-2600\end{array}$ & $\begin{array}{l}2000 \\
1800 \\
2100 \\
1900 \\
2000 \\
2000\end{array}$ & $\begin{array}{l}300 \\
100 \\
300 \\
400 \\
300 \\
600\end{array}$ & $\begin{array}{l}300 \\
300 \\
600 \\
700 \\
300 \\
400\end{array}$ \\
\hline \multicolumn{7}{|c|}{ Stage II Burnout (Model IV) } \\
\hline $\begin{array}{ll}750 / \mathrm{CY} & 186 \mathrm{~S} \\
751 / \mathrm{CY} & 187 \mathrm{~S} \\
752 / \mathrm{CY} & 188 \mathrm{~S} \\
753 / \mathrm{CY} & 189 \mathrm{~S} \\
754 / \mathrm{CY} & 190 \mathrm{~S} \\
755 / \mathrm{CY} & 191 \mathrm{~S}\end{array}$ & $\begin{array}{l}-1500 \\
-600 \\
-2000 \\
-2400 \\
-1400 \\
-2400\end{array}$ & $\begin{array}{l}-1400 \\
-700 \\
-1400 \\
-1300 \\
-700 \\
-1400\end{array}$ & $\begin{array}{l}-1400 \\
-700 \\
-1400 \\
-1500 \\
-700 \\
-1600\end{array}$ & $\begin{array}{l}400 \\
400 \\
400 \\
400 \\
900 \\
900\end{array}$ & $\begin{array}{r}0 \\
-100 \\
-100 \\
0 \\
100 \\
100\end{array}$ & $\begin{array}{r}-100 \\
0 \\
0 \\
0 \\
100 \\
200\end{array}$ \\
\hline \multicolumn{7}{|c|}{ Centaur MES II (Model I) } \\
\hline 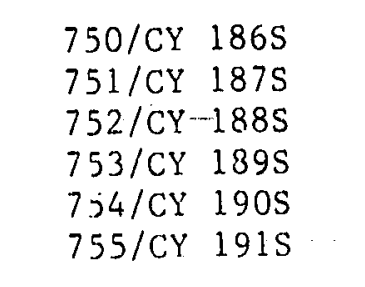 & $\begin{array}{l}-700 \\
-400 \\
-800 \\
-700 \\
-500 \\
-\quad 800\end{array}$ & $\begin{array}{l}-700 \\
-500 \\
-900 \\
-800 \\
-500 \\
=800\end{array}$ & $\begin{array}{l}-900 \\
-500 \\
-900 \\
-1000 \\
-500 \\
-1000\end{array}$ & $\begin{array}{r}0 \\
100 \\
0 \\
0 \\
0 \\
0\end{array}$ & $\begin{array}{r}0 \\
0 \\
0 \\
100 \\
0 \\
100\end{array}$ & $\begin{array}{l}200 \\
2 n 0 \\
200 \\
200 \\
200 \\
200\end{array}$ \\
\hline \multicolumn{7}{|c|}{ Centaur MECO II (Mode1 IV) } \\
\hline $\begin{array}{ll}750 / C Y & 186 \mathrm{~S} \\
751 / \mathrm{CY} & 187 \mathrm{~S} \\
752 / \mathrm{CY} & 188 \mathrm{~S} \\
753 / \mathrm{CY} & 189 \mathrm{~S} \\
754 / \mathrm{CY} & 190 \mathrm{~S} \\
755 / \mathrm{CY} & 191 \mathrm{~S}\end{array}$ & $\begin{array}{l}-1400 \\
-800 \\
-1900 \\
-2100 \\
-700 \\
-1500\end{array}$ & $\begin{array}{l}-1600 \\
-800 \\
-1600 \\
-1500 \\
-800 \\
-1700\end{array}$ & $\begin{array}{l}-1500 \\
-800 \\
-1600 \\
-1600 \\
-900 \\
-1900\end{array}$ & $\begin{array}{r}1300 \\
900 \\
1400 \\
1600 \\
900 \\
900\end{array}$ & $\begin{array}{l}400 \\
400 \\
600 \\
800 \\
300 \\
700\end{array}$ & $\begin{array}{r}500 \\
500 \\
700 \\
1000 \\
600 \\
900\end{array}$ \\
\hline
\end{tabular}

Note: Compression $=$ Negative $(-)$, Tension $=$ Positive $(+)$

A11 values in the above table have been rounded of to $\pm 100 \mathrm{lbs}$. 
APPENDIX B

Comparison of Measured and Ari... ir. inedicted
Member Forces for the Vova

Estimated flight loads for the Voyager spacecraft were obtained by applying the measured Launch Vehicle/Voyager interface accelerations to the base of the spacecraft analytical model. The resulting loads are comparable to those obtained from the launch vehicle/payload composite model under the corresponding environments.

Since the interface accelerations play a very prominent role in the shock spectra approach, the flight measurements will be compared with those obtained analytically from the transient analysis. Figure $B-1$ shows this comparison for the launch event. The analytical interface acceleration was obtained by applying the forcing function representing the lateral overpressure condition to the Launch Vehicle/Payload composite model. The amplitude of the analytical interface acceleration is somewhat higher than those of flight-measured values. However, due to different frequency content, it is not certain that the anal:, tical values will produce higher loads. Similarly, Figure B-2 shows the interface acceleration comparisons for the Stage I Burnout (STG I BO) event. Here not only the amplitudes of the analytical and flight data are similar but also the frequency contents are characteristically very close. It should be noted that some of the forcing functions used in the transient analysis are synthesized based on the experiences from the previous flights, and certain conservatism has been built into these forcing functions. Yet the resulting analytical interface acceleration is not much greater than that of the flight measurements.

Next, the flight loads will be compared with the corresponding design loads. Since only the Stage 0 Ignition (1aunch) and STG I BO events were considered in the loads analysis, the comparison will be made by first listing the shock spectra design loads for the two events, then listing the ratio of flight 


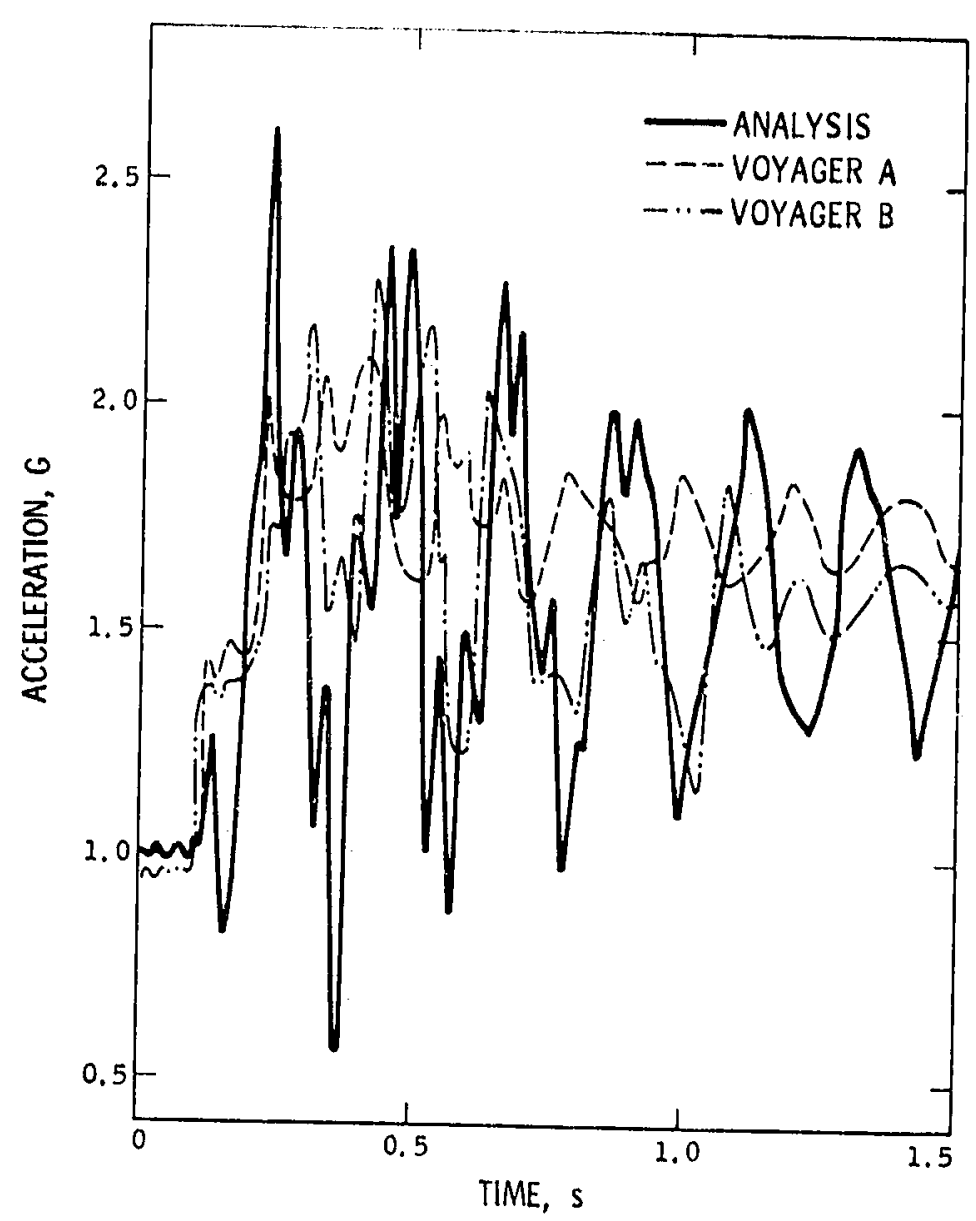

Figure $B-1$. Tnterface accelerations for launch

loads to the corresponding design loacs as shown in Table B-l. Most of the design loads are more than twice the flight loads (the flight to design load ratio is less than 0.5 ). This confirms the design postulations that the shock spectra approach will provide conservative loads and in view of the uncertainties, the conservatisni is reasonable. However, it must be emphasized that the comparisons are made for the launch and STG I BO events on?y. Similar comparisons are made for the transient analysis predicted loads as shown in Table B-2. In this comparison, the ratios of flight to predicter loads are much larger than the ones in the previous comparison. In fact, some members have the ratio greater than 1.0 which means that the fight loads are greater than the corresponding transient analysis predicted loads. One may observe that the transient load analys is indeed does provide more accurate loads prediction than that of the shork spectra approach, of course at a higher cost. It should also be noted here that the transient lcads analy'is 


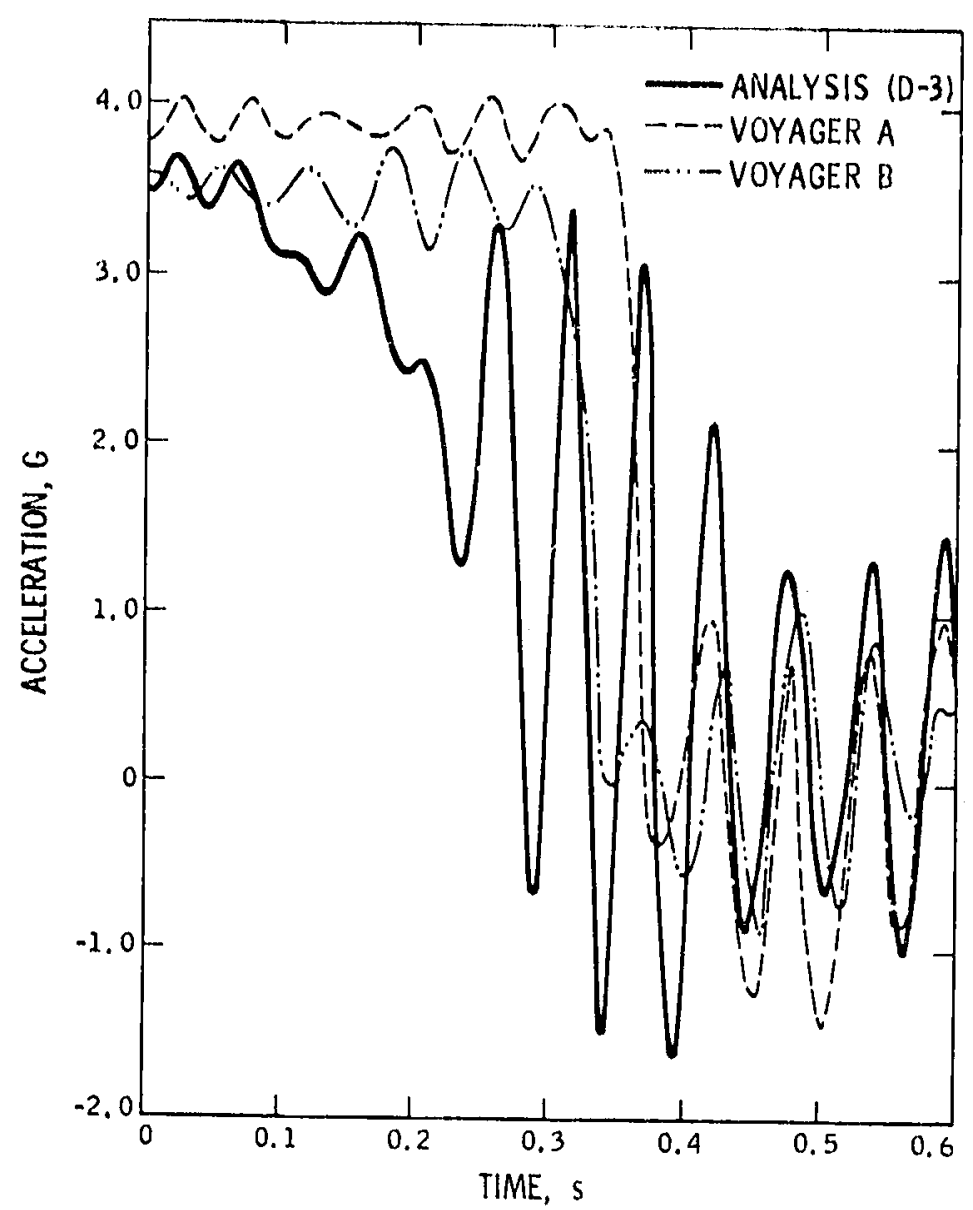

Figure B-2. Interface acelerations for Stage I burnout

Figure $B-2$.

for Voyager was performed not for the purpose of obtaining the design loads but rather for the verification of the shock spectra loads. Had the transient loads analysis been used for design purposes, a loads analys is factor would have been used to multiply the resulting loads to provide more conservative design loads. 
Tablo B-1. Comparison of Maximum Fleght and shock spectril Design loads

\begin{tabular}{|c|c|c|c|c|c|c|c|}
\hline & & & aunch & & & I Burn & \\
\hline & & Design & Fifsh & ign & Design & Fligh & sign \\
\hline & nber & $(1 b)$ & $\Lambda$ & B & (1b) & A & $B$ \\
\hline & 71917 & 1000.0 & 0.12 & 0.20 & 820.0 & 0.19 & 0.26 \\
\hline$=\stackrel{\text { s }}{z}$ & 71927 & 980.0 & 0.11 & 0.32 & 770.0 & 0.24 & 0.29 \\
\hline Tु & 71937 & 1020.0 & 0.16 & 0.35 & 850.0 & 0.31 & 0.23 \\
\hline 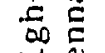 & 71947 & 1020.0 & 0.22 & 0.44 & 990.0 & 0.23 & 0.19 \\
\hline$I \stackrel{\Xi}{E}$ & 71957 & 730.0 & 0.27 & 0.43 & 810.0 & 0.25 & 0.22 \\
\hline & 71967 & 710.0 & 0.18 & 0.31 & 630.0 & 0.27 & 0.28 \\
\hline & 80017 & 790.0 & 0.34 & 0.49 & 620.0 & 0.77 & 0.67 \\
\hline$\Delta$ of & 80016 & 450.0 & 0.20 & 0.72 & 760.0 & 0.17 & 0.24 \\
\hline 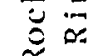 & 80106 & $410: 0$ & 0.30 & 0.42 & 460.0 & 0.37 & 0.40 \\
\hline$\tau \ddot{c}$ & 80107 & 700.0 & 0.47 & 0.61 & 900.0 & 0.64 & 0.58 \\
\hline $\overrightarrow{0}$ & 80177 & 670.0 & 0.48 & 0.61 & 740.0 & 0.74 & 0.69 \\
\hline & 80176 & 550.0 & 0.28 & 0.63 & 530.0 & 0.31 & 0.21 \\
\hline & 30007 & 1750.0 & 0.31 & 0.64 & 2400.0 & 0.36 & 0.34 \\
\hline si & 30017 & 1850.0 & 0.31 & 0.49 & 2.540 .0 & 0.35 & 0.34 \\
\hline$\underline{z}$ & 30027 & 570.0 & 0.12 & 0.21 & 140.0 & 0.28 & 0.34 \\
\hline$\div$ & 30047 & 1910.0 & 0.34 & 0.61 & 2650.0 & 0.37 & 0.35 \\
\hline$\stackrel{5}{3}$ & 30057 & 1900.0 & 0.29 & 0.46 & 2600.0 & 0.37 & 0.36 \\
\hline 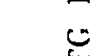 & 30067 & 1310.0 & 0.09 & 0.34 & 980.0 & 0.25 & 0.39 \\
\hline 2 & 30077 & 1320.0 & 0.19 & 0.46 & 1050.0 & 0.30 & 0.25 \\
\hline & 30087 & 450.0 & 0.12 & 0.27 & 200.0 & 0.28 & 0.42 \\
\hline
\end{tabular}


Table B-1. (cont funcd)

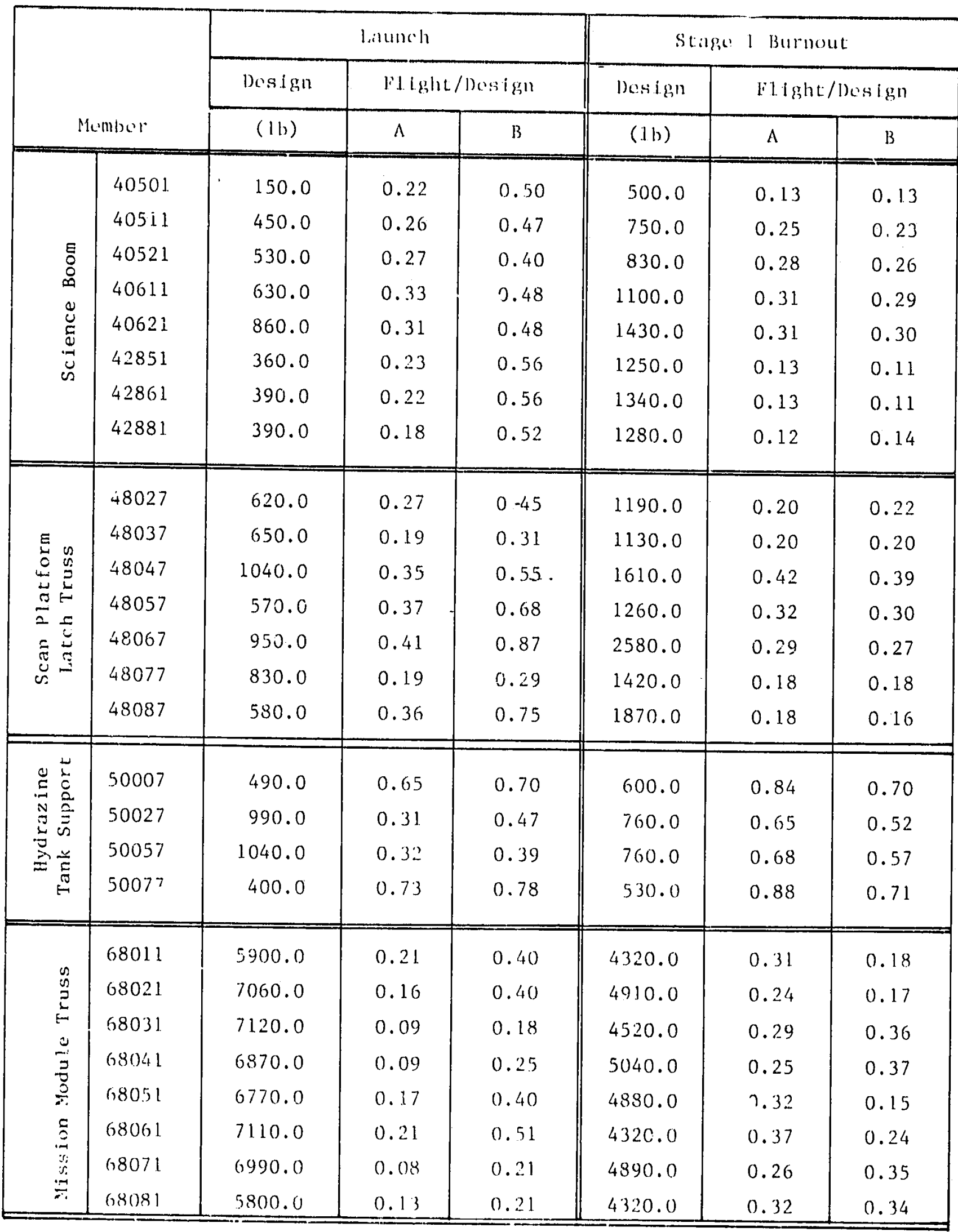


Table B-?. Compitrtson of Maximum Flight and Transident prodleted toonds

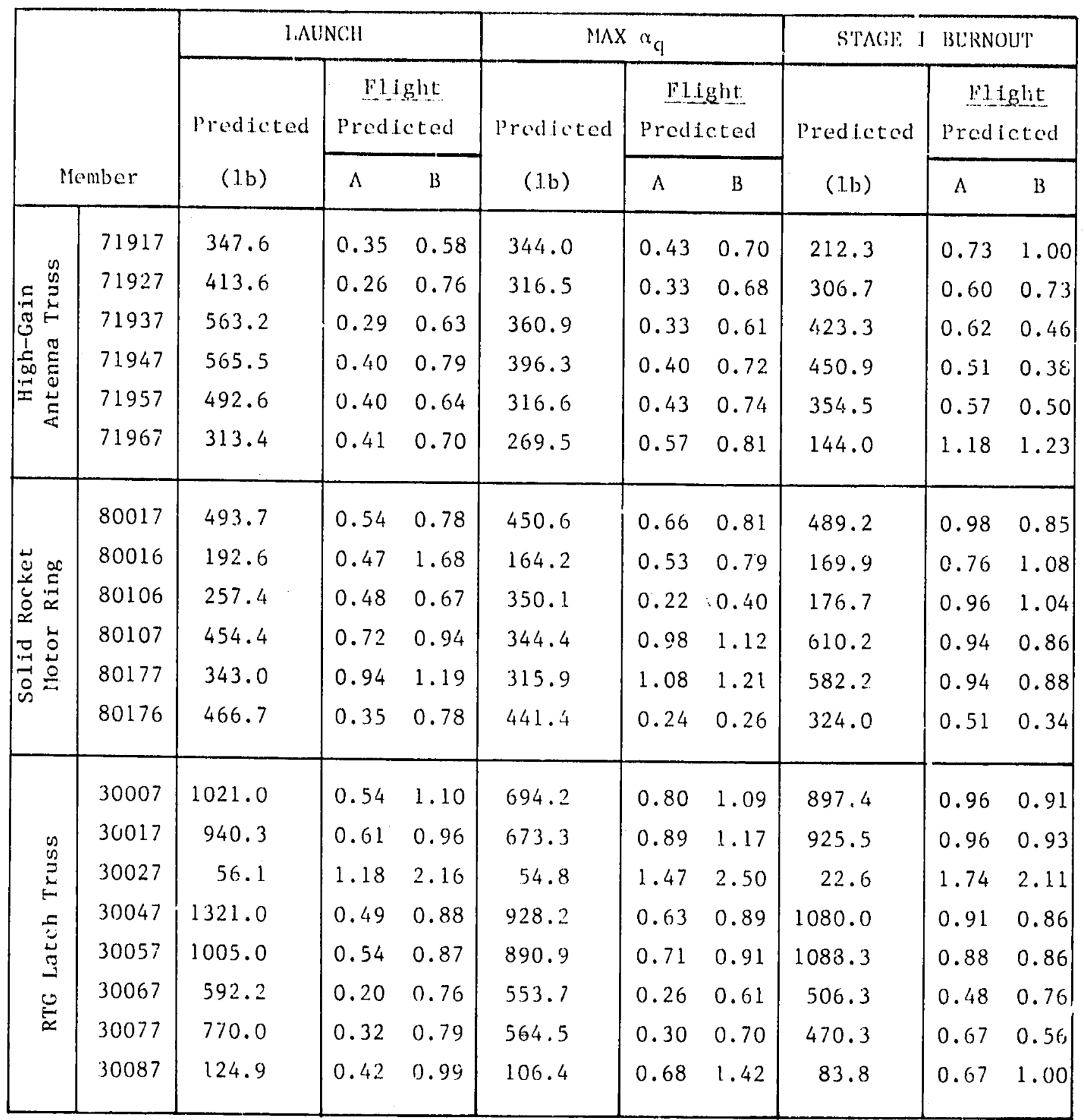


'lable B-2. (cont inued)

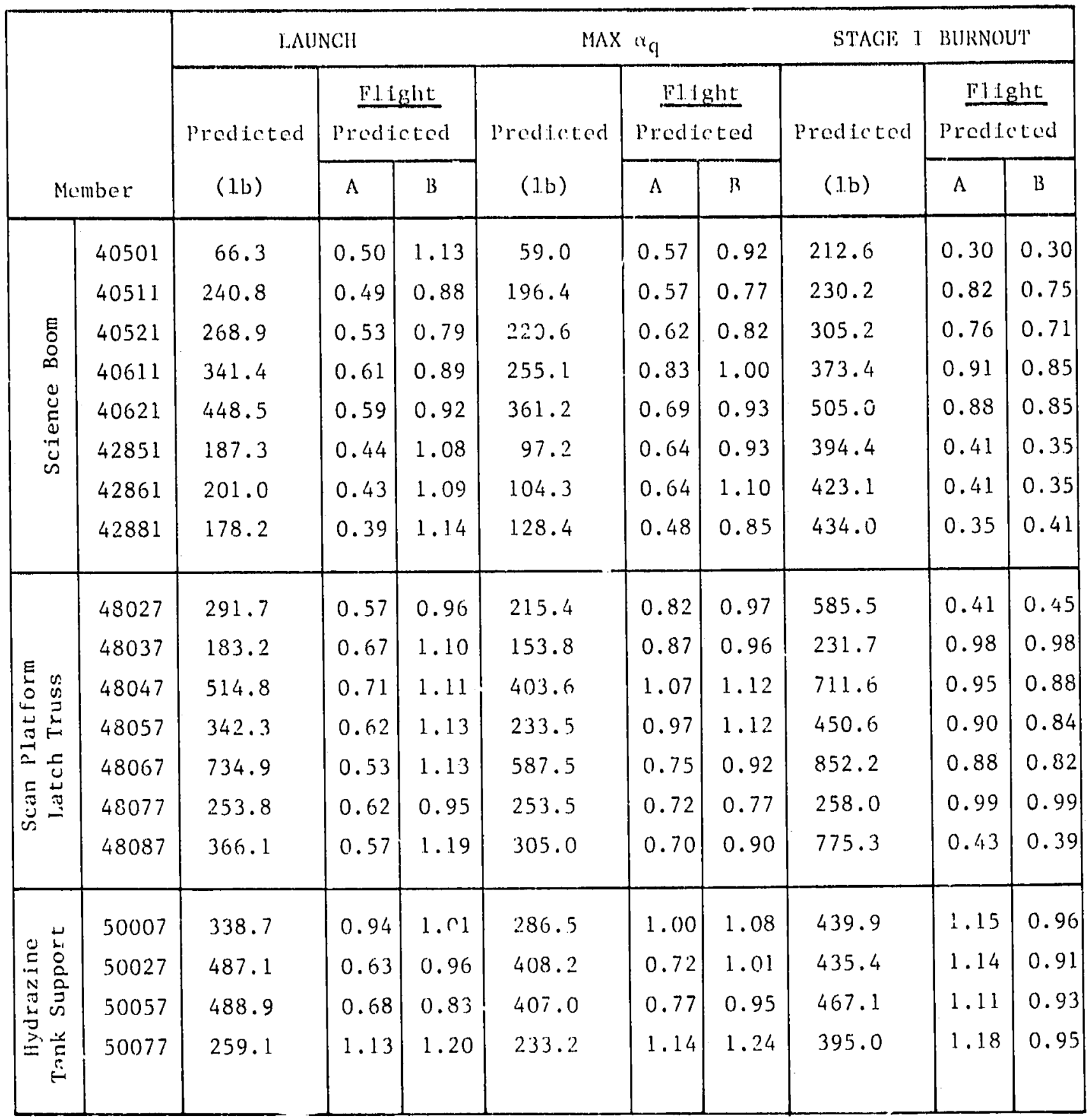


Pable B-2. (cont inued)

\begin{tabular}{|c|c|c|c|c|c|c|c|c|c|c|}
\hline & & \multicolumn{3}{|c|}{ I.AUNCII } & \multicolumn{3}{|c|}{$\operatorname{Mix} \mathrm{x}_{\mathrm{q}}$} & \multicolumn{3}{|c|}{ 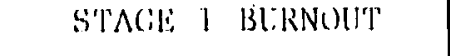 } \\
\hline & & \multirow{2}{*}{$\begin{array}{l}\text { Prodicted } \\
\text { (1.b) }\end{array}$} & \multicolumn{2}{|c|}{$\begin{array}{l}\text { Filght } \\
\text { Prodicted }\end{array}$} & \multirow{2}{*}{$\begin{array}{l}\text { Prodlcted } \\
\text { (1b) }\end{array}$} & \multicolumn{2}{|c|}{$\begin{array}{c}\text { Elight } \\
\text { Predicted }\end{array}$} & \multirow{2}{*}{$\begin{array}{l}\text { Precifcted } \\
(1 \mathrm{~b})\end{array}$} & \multicolumn{2}{|c|}{$\begin{array}{l}\text { Plight } \\
\text { Prodictod }\end{array}$} \\
\hline \multicolumn{2}{|c|}{ Member } & & $\Lambda$ & B & & $\Lambda$ & B & & $\Lambda$ & B \\
\hline \multirow{8}{*}{ 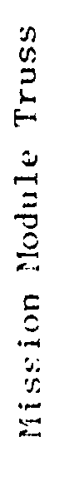 } & 68011 & 3234.0 & 0.38 & 0.73 & 2632.0 & 0.29 & 0.49 & 2784.8 & 0.48 & 0.28 \\
\hline & 68021 & 3753.0 & 0.30 & 0.75 & 3248.0 & 0.27 & 0.29 & 3432.7 & 0.34 & 0.24 \\
\hline & 68031 & 2.507 .0 & 0.26 & 0.51 & 2922.0 & 0.30 & 0.55 & 1543.0 & 0.85 & 1.05 \\
\hline & 68041 & 2143.0 & 0.29 & 0.80 & 2798.0 & 0.26 & 0.58 & 1393.0 & 0.90 & 1.34 \\
\hline & 68051 & 3398.0 & 0.34 & 0.80 & 3087.0 & 0.27 & 0.30 & 3321.9 & 0.47 & 0.22 \\
\hline & 68061 & 3774.0 & 0.40 & 0.96 & 3188.0 & 0.24 & 0.45 & 3434.0 & 0.47 & 0.30 \\
\hline & 68071 & $20 \leq 6.0$ & 0.27 & 0.7 .1 & 2944.0 & 0.23 & 0.56 & 864.3 & 1.47 & 1.98 \\
\hline & 68081 & $203 \varepsilon .0$ & 0.37 & 0.60 & 2335.0 & 0.35 & 0.57 & 1320.0 & 1.05 & 1.11 \\
\hline
\end{tabular}




\section{APPENDIX C}

\section{Compain ison of Acceleration Levels Obtained} Using the Generalized Shock Spectra Method To Those: Obtained From the Mass Acceleration Curve

Figure $\mathrm{C}-1$ shows the comparison of acceleration levels obtained from the mass acceleration curve to those obtained from the generalized shock spectra method for two spacecraft, Galileu (GLL) and the International Solar Polar Mission (ISPM) spacecraft. 
$-86-$

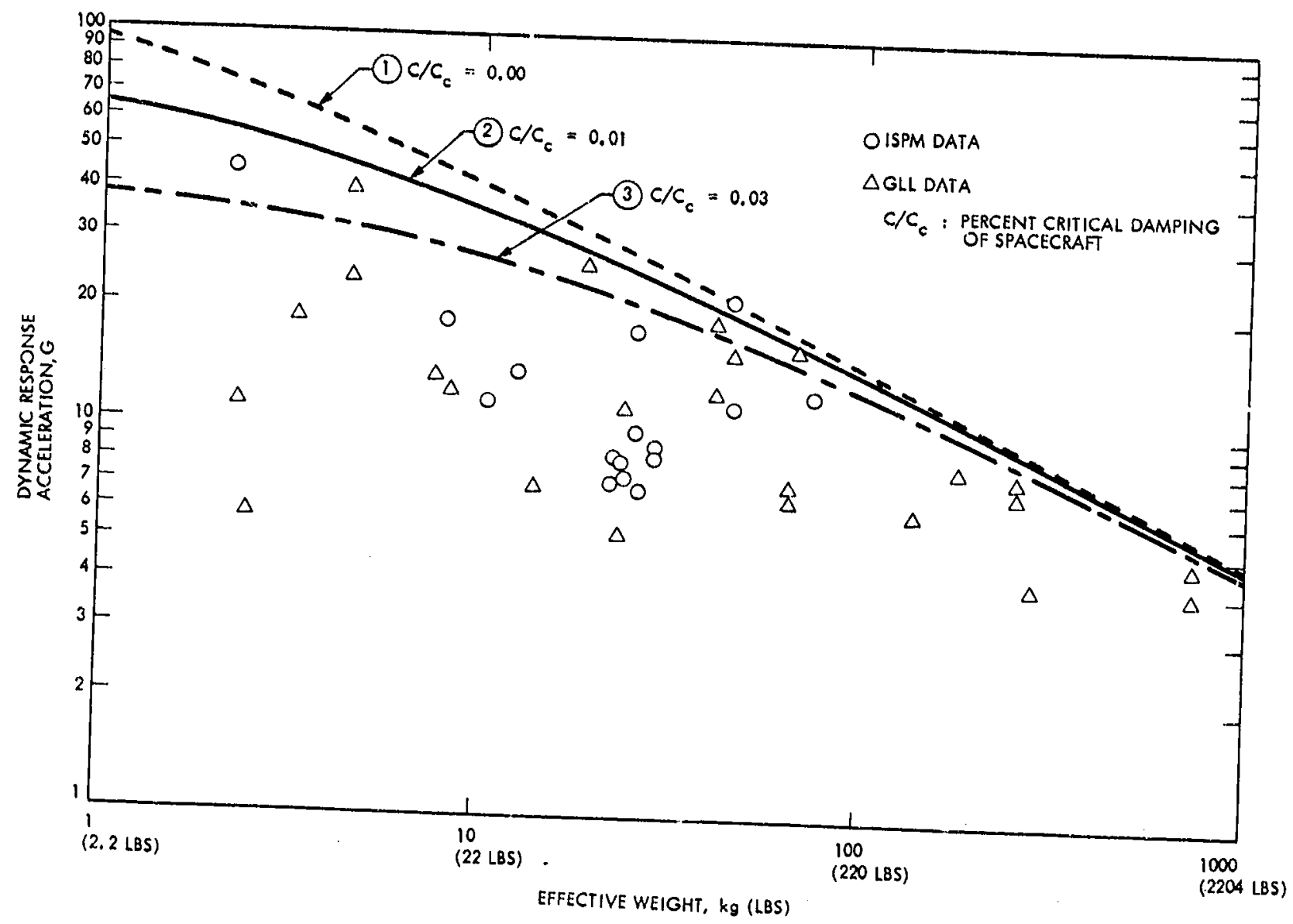

Figure $\mathrm{C}-1$. Compirison of accoleration levels 
APPENDIX D

A Sample Problem for the Recovered

Transient Analysis

The proposed payload transient analys is technique will be demonstrated on a realistic complex structural system, namely, the International Solar Polar Mission. (ISPM) spacecraft. The ISPM consists of two separate spacecraft, one sponsored by NASA and the other by the European Space Agency (ESA). Figure D-1 shows the schematic of the ISPM spacecraft with the major structural components identified. Table D-1 contains the descriptions of the mathematical model.

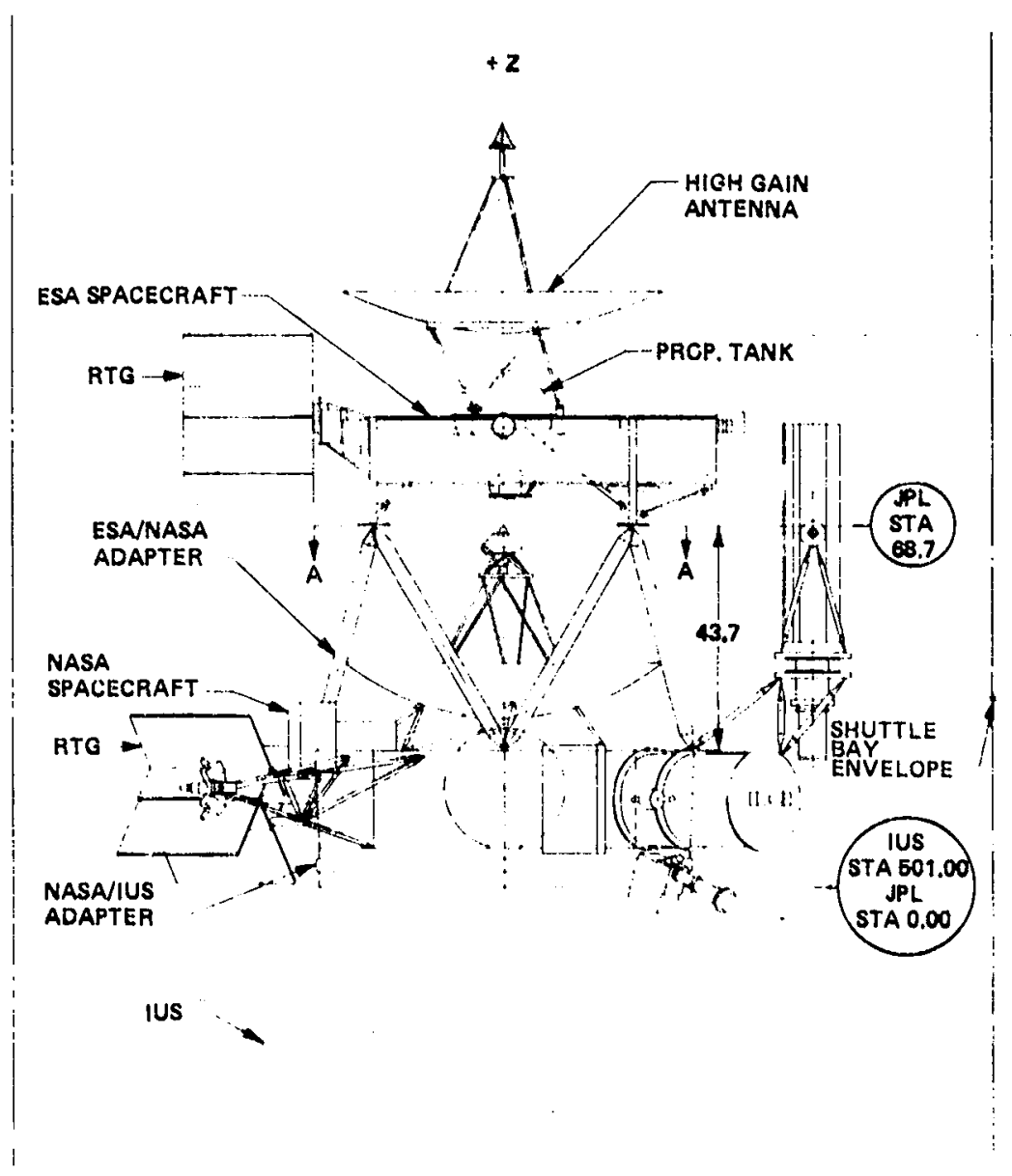

Figura D-1. 1Sl'M spacecraft 
iable b-1. ISPM Finte Element Model.

Number of Grid leotints

Number of: Static Degrees of Frecdom

Number of Finfte Elorients

Number of Dynamic Degrecs of Frecdom

Number of Vibration Modes of Interest

Number of Hodes Retained - Loads Analysis

\begin{tabular}{ccc} 
NASA S/C & ESA S/C & Tota1 \\
\hline 112 & 122 & 2.34 \\
400 & 430 & 830 \\
298 & 221 & 51.9 \\
1.50 & 87 & 237 \\
51 & 84 & 135 \\
& & 40 \\
& & $143 \mathrm{lz}$
\end{tabular}

The two spacecraft will be launched in tandem from a single shuttle/Inertial Upper Stage (IUS) in early 1983 to conduct scientific explorations in the Sun's polar orbit, approximately $90^{\circ}$ from the ecliptic plane. The space shuttla launch vehicle configuration consists of the orbiter, external oxygen, and hydrogen tank (ET), and two solid rocket boosters (SRBs). For interplanetary trajectories, an IUS is included for additional propulsion for payloads to reach distant planets. Figure D-2 shows the ISPM/Shuttle/IUS composite system in the lift-off corfiguration. The load conditions based on which the shuttle structural system is designed are numerous such as the lift-off, high of boost, SRB burn, SRB staging, orbiter main engine burn, orbiter main engine cutoff external tank jettison, space operation, entry and descent, TAEM (terminal area energy management), landing approach and various abort conditions. However, for the payload structure design it was found that the lift-off and abort landing events are of importance. In the sample problem on $; j$ the lift-off environment will be considered.

Prior to the ISPM project, another planetary spacecraft, Galileo (GLL.), has been designed to be launched by the identical Shuttle/IUS launch vehicle system. The Shuttle/IUS/Galileo composite model has been analyzed for the dynamic environments representing the lift-off and abort using a simplified GLL model. The results of the analys is will be used as described in Section IV.B.1 and IV.B.2 for the analysis of the Shuttle/IUS/ISPM system. The first 


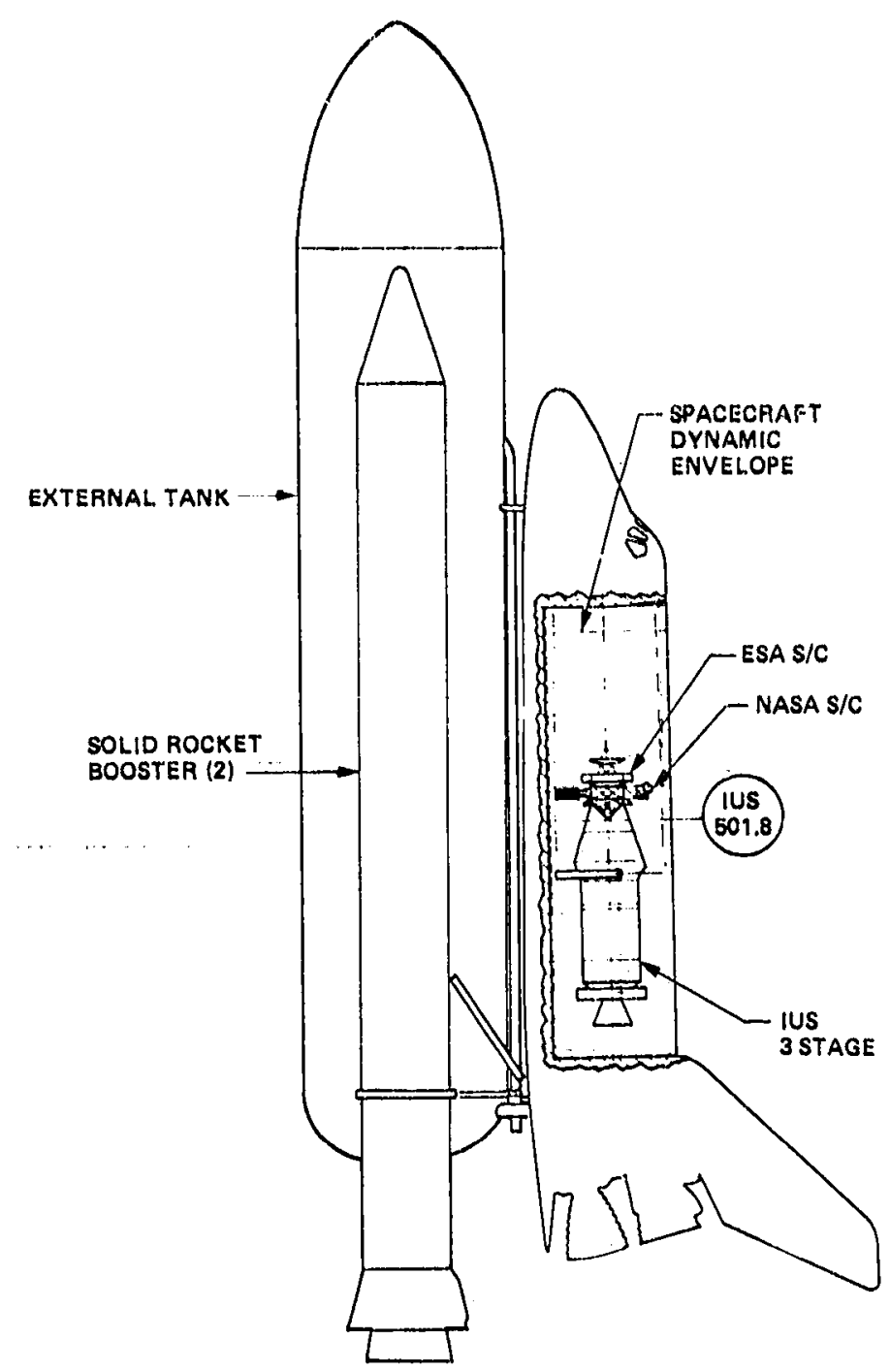

Figure D-2, STS/ILS with ISPM payload

composite system, Shuitle/IUS/ Galileo, is represented by 150 normal modes at the interface DOF and their corresponding frequencies, i.e., $\left[\phi_{1}\right]$ and $\left[\omega^{2}\right]$. The modal response time histories $\{q(t)\}$ were also available. The cantilevered ISPM model is represented by 40 normal modes and their 
corresponding frequencies, i.e., $\left[\bar{\Phi}_{2}\right]$ and $\left[\bar{u}_{2}^{2}\right]$. A constant modal damping cycle $c / c_{c}=0.01$ is assumed for all the modes. First, a mini loads analysis, in which the ISPM model will be subjected to a base motion obtained from the IUS/Galileo interface accelerations, will be performed. The mini loads analysis is similar to the rigid body interface acceleration method of Section IV.B.I without the correction term for the elasticity of the spacecraft. The results will be compared with the recovered transient analysis. The comparisons will be made on the member loads of the selected components.

Figure D-3 shows the IUS/Galileo interface acceleration for the lift-off condition. These accelerations have been used as forcing functions for the mini loads analysis. Since the ISPM spacecraft is in the same class as that of the Galileo spacecraft, the approximate dynamic environment for the ISPM can be estimated from Figure $D$ - 3 . In this case, approximately a three $G$ peak acceleration will be experienced at the base of the ISPM spacecraft in the longitudinal direction and two $G$ peak acceleration in the lateral direction. Table D-2 shows the loads obtained by the recovered transient method for the NASA/ES? spacecraft adapter truss. The comparison of these loads to those obtained by the mini loads analysis shows that reasonable agreement has been achieved. Since the spacecraft adapter truss consists of structural members connecting the two spacecraft, the loads are mainly derived from the low frequency motion of the interface. Therefore, it is not surprising that the mini loads analysis predicts the loads accurately. However, for the structural members dominated by the high frequency local motion, the discrepancies between the results of these two analyses can be substantial. Figure D-A shows the time histories of the loads obtained by a mini loads analysis and recovered transient analys is for a RCS thruster outrigger. These loads are order of magnitude different from each other. 


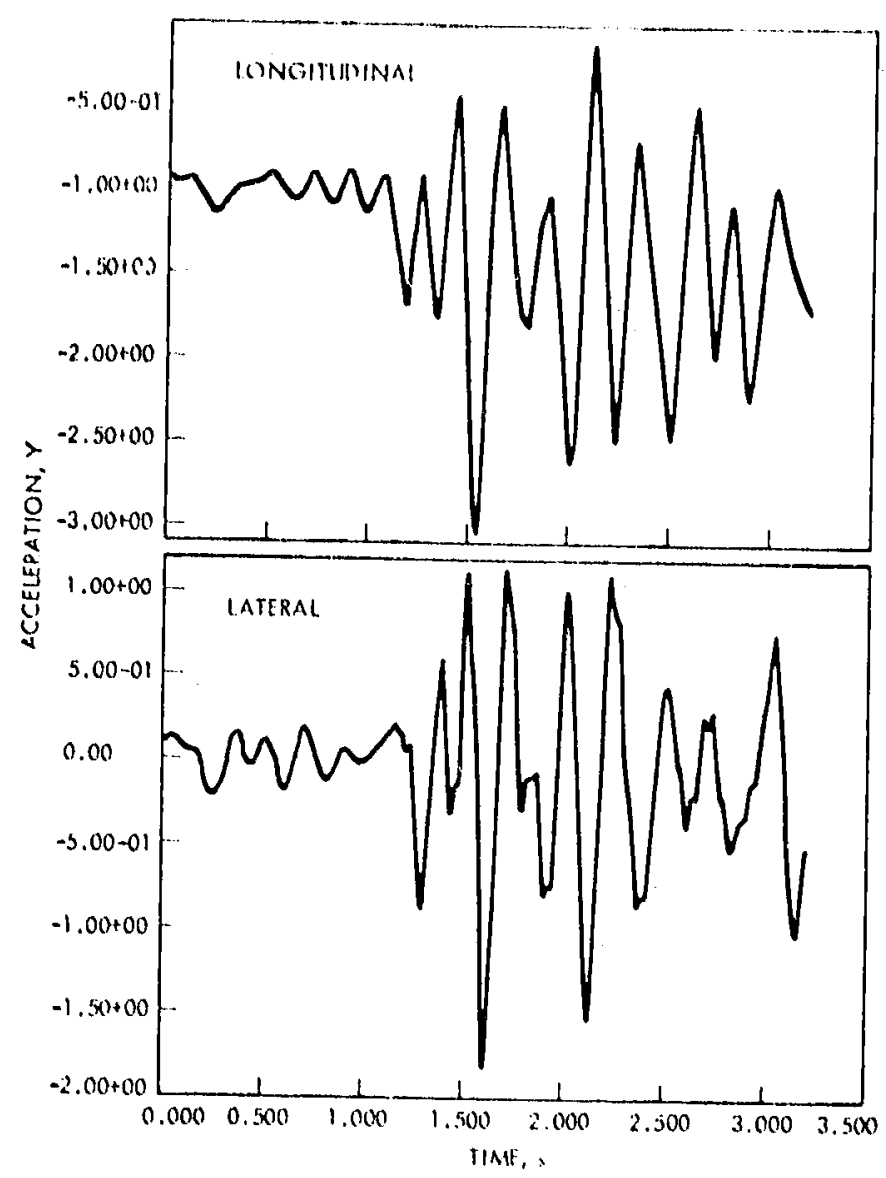

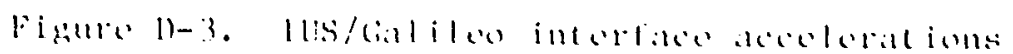

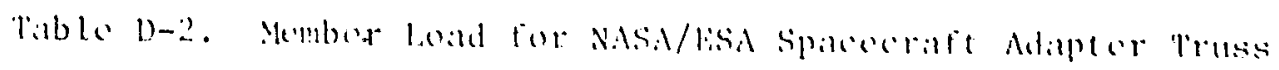

\begin{tabular}{|c|c|c|c|}
\hline Momber: & 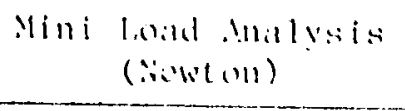 & licoovered & $\begin{array}{l}\text { 'rinlsiont Analysist } \\
\text { (Nowton) }\end{array}$ \\
\hline 701 & $4: 78$ & & $286:$ \\
\hline $70 ?$ & 11955 & & $79(18$ \\
\hline 703 & las'i & & 10943 \\
\hline 7014 & 903.4 & & 7642 \\
\hline 705 & 4720 & & 3759 \\
\hline 700 & $1: 3(19)$ & & 9430 \\
\hline 707 & 1.238 & & $1: 197$ \\
\hline 7018 & stois & & 0.391 \\
\hline
\end{tabular}


$-92-$

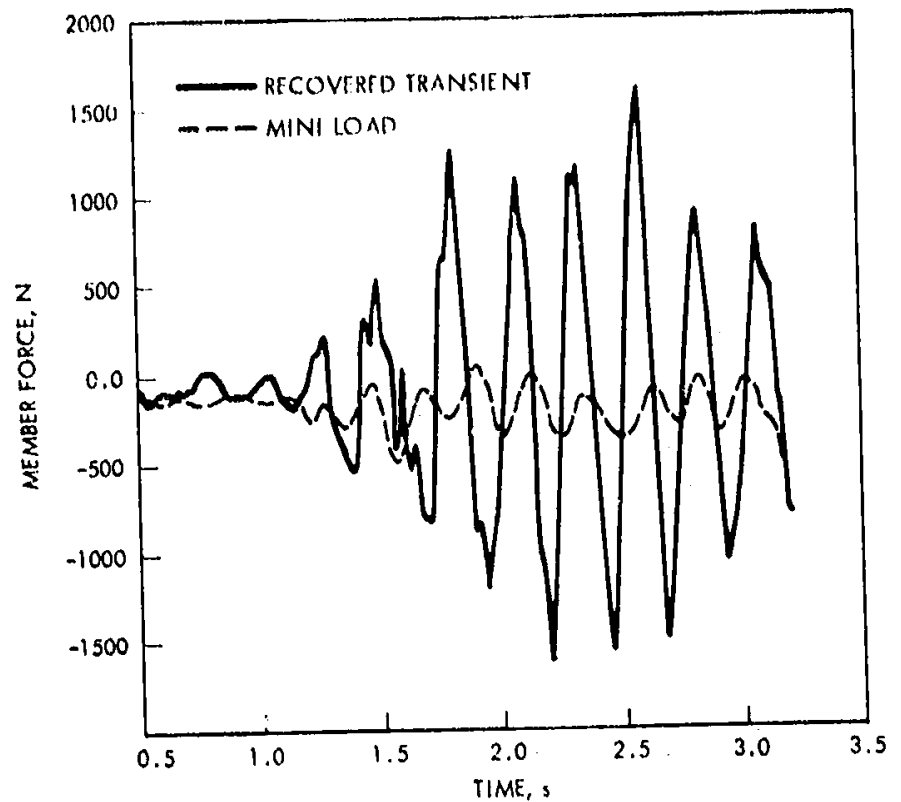

Figure 1-4. Load time history for RCS thruster outrigger 


\section{REFERENCES}

1. Project Manager's Guide for STS Payload Environmental Measurements, DATE Work ing Group, National Aeronautics and Space Administration, Washington, D.C., April 1973.

2. Project Plan for Dynamic Acoustic, Thermal Environments (DATE) Experiment, Goddard Space Fi ight Center, Greenbelt, Maryland, October 1979.

3. Schuett, R. H., Appleby, B. A., and Mart in, J. A., "Dynamic Loads Analysis of Space Vehicle Systems - Launch and Exit Phase," General Dynamics Convair Division, Report No. GDC-DDE66-012, San Diegn, Califorilia, June 1966.

4. Wada, B. K., Stiffness Matrix Structural Analysis, Technical Report 32-774, Jet Propulsion Laboratory, Pasadena, California, October 31, 1965.

5. Garba, J. A., Gayman, W. H., and Wada, B. K., Computation of Torsional Vibration Modes of Ranger and Surveyor Space Vehicles, Technical Temorandum 33-277, Jet Propulsion Laboratory, Pasadena, California, April 1, 1968 (JPi. internal document).

6. Trubert, M. R., A Fourier Transform Technique for the Prediction of Torsional Transients for a Spacecraft from Flight Data of Another Spacecraft using the Same Booster, Technical Memorandum 33-350, Jet Propulsion Laboratory, Pasadena, California, October 15, 1967.

7. Trubert, M. R., Use of Kanger Flight Data in the Synthes is of a Torsional Acceleration Transient for Surveyor Vibration Qualification Testing, Technical Memorandum 33-237, Jet Propulsion Laboratory, Pasadena, California, April 19, 1966.

3. Melosh, R. J., Diether, P. A., and Brennan, M., Structural Analys is and $i_{1}+r$ ix Interprative Systom (SAMIS) Prograin Report, Revision T, Technicil Memorandum 33-307, Jet Propulsion Laboratory, Pasadena, California, December $15,1966$.

9. Deitrich, R. E., and Jones, R. H., "Tnuchdown Dynamics Study" (Preliminary Report), Surveyor Spacecraft System, Report SSD 3030R, Space System Division, Hughes Aircraft Company, Cuiver City, Califorria, January 1963.

10. Alderson, R. G., and Wells, D. A., Final Report on Surveyor Lunar Touchdown Stability Study, Report MiM-66-19, Bendix Products Aerospace Division, South Bend, Indiana, July 3, 1966. 
11. Spe?:-1ing, F., and Garba, J., A Treatise on the Surveyor Lunar Landing Dynamics and an Evaluation of Pert inent Telemetry Data Returned by California. August. 15, 1967.

12. Harter, R. J. and switz, R. J., "Analytical and Experimental Techniques Used to Establish Structural Design Loads for the Surveyor Spacecraft During Lunar Landing," Shock and Vibration Bulletin No. 35, Naval Research Laboratory, Washington, D. C., January 1966.

13. Gayman, W. H., Trubert, M. R.,. and Garba, J. A., OGO-E Space Vehicle Response to Transient Loading at Atlas Booster Engine Cutoff, Report No. internal document).

14. Garba, J. A., and Simpson, R. D., Orbiting Astronomical Observatory A-2 Space Vehicle Response to Transient Loading at Atlas Bonster Engine (JPL internal document).

15. Gayman, W. H., Trubert, M. R., and Abbott, P. W., Measurement of Structural Transfer Functions Significant to Flight Stability of the Surveyor Spacecraft, Technical Memorandum No. 33-389, Jet Preputsion -aboratory, Pasadena, California, May $7,1969$.

16. Gayman, W. H., A Note on Boundary-Condition Simulation in the Dynamic Testing of Spacecraft Structures, Technical Report 32-938, Jet Proputsion Laboratory, Pasadena, California, April 15, 1966.

17. Hurty, W. C., Dynamic Analysis of Structural System by Component Mode Synthesis, Technical Report No, 32-530, Jet Propulsion Laboratory, Pasadena, California, January 15, 1964 .

18. Bamford, R. M., A Mrddi Combination Program for Dynamic Analys is of Structures, Technical Memorandim 33-290, Jet Propulsion Laboratory, Augist

19. Lang, T. E., Summary of the Functions and Capabilities of the Structural Analys is and Matrix Interpretive System Computer Program, Technical Rejort No. 32-1075, Jet Propulsion Laboratory, Pasadena, California,
April 1, 1967 .

20. Bamford, R. M., Application of Structural Analysis and Matrix Interpretive System, Technical Memorandum 33-399, Revision 1, Jet Propulsion Laboratory, Pasüdena, California, March 18, 1970.

21. Heer, E. and Trubert, M. R., Analys is of Space Vehicle Structures Using the Transfer-Function Concept, Technical Report No. 32-1367, Jet Propulsion Laboratory, Pasadena, California pril 1, 1969. 
22. Trubert, R. M., Chisholm, J. R., and Gayman, W. H., Use of Centaur/ Spacecraft Flight Data in the Synthes is of Forcing Functions a $i$ Centaur Main Engine Cutoff During Boost of Mariner 1969, OAO-II and AT'S Spacecraft: Analysis, Evaluation and Computer Plots, Technical Memorandum 33-487, Volumes I and II, Jet PropuTs ion Laboratory, Pasadena, California, June? $1,1971$.

23. Trubert, M. R., "A Practical Approach to Spacecraft Structural Dynamics Problenis" Journal of Spacecraft and Rockets, Vol. 9, No.11, November 1972 pp. 818-82.

24. Freeland, R. E., Mariner Mars 1971 Unique Structural Analys is and Tests, Report No. 610-176, Jet Propulsion Laboratory, Pasadena, California, March 26, 197:: (JPL internal document).

25. McCurmick, C. W. (Editor), "The NASTRAN User's Manual," NASA SP-222(01), Washington, U. C., May 1973.

26. Bamford, R., Wada, B. K., Garba, J. A., and Chrisholm, J., "Dynamic Analyses of Large Structural Systems, "Synthes is of Vibrating Systems, The American Society of Mechanical Engineers, New York, November 1971.

27. Wada, B. K., "Design of Space Payloads for Transient Environments, " paper presented at the ASME 1979 Winter Annual Meeting, December 2-7, 1979, New York, N.Y.

23. Wada, B. K., "Viking Orbiter - Dynamics Overview, "The Shock and Vibration Bulletin, Bulletin 44, Part 2, Naval Research Laboratory, Wajingtin, D. C., August 1974, pp. 25-39.

29. Wida, B. K, and Garba, J. A.: "Dynamic Analys is and Test Results of the Viking Orbiter," ASME 1975 Winter Annual Meeting, ASME paper 75-WA'Aero 7 , Houstinn, Texas, Nov. 30 - Dec. 4, 1975.

30. Garba, J. A., Wada, B. K., and Chen, J. C., "Experiences in Using Modal Synthes is with in Project Requirements," The Shock and Vibration Bullatin, Bullet in 46, part 5, Nav 11 Research Laboratory, Washington, 1. C., Aujust 1976 , pp. ?13-230.

31. Benfield, W. A., and Hruda, R. F., "Vibration Analyses of Structures by Component Mode Substitution," AIAA/ASNE 11 th Structures, Structural Dvnamics, and Materials Conference Proceedings, Denver, Colorado, April 2?-24, 1971).

32. Guyan, R. J., "Reduction of Stiffness and Mass Matrices," AIAA Journal, Vol. 3, No. 2, February 1965.

33. Bamford, R. M., Wada, B. K., and Gayman, W. H., Equivalent Mass System for Normal Modes, Technical Memorandum 33-380, Jet Propuls ion Laboratory, pasadena, California, February 1971. 
34. Wada, B. K., Bamford, R., and uarba, J. A., "Equivalent Spring Mass System: A Physical Interpretation, "The Shock and Vibration Bulletin, Bulletin 4?, Parts, Naval Research Laboratory, Washington, D. C., January 1972, pp. 215-225

35. Garba, J. A., "Viking Orbiter Member Load Est imates for the Transonic Flight Event," Project Document 611-100, Jet Propulsion Laboratory, Pasadena, California, April 1974 (JPL internal document).

36. Leppert, E. L., Wada, B. K., and Miyakawa, R., "Modal Test of the Viking Orbiter," The Shock and Vibration Bulletin, Bullet in 44, Part 2, Naval Research Laboratory, Washington, 0. C., pp. 165-175; also published as JPL. Technical Memorandum 33-688, July 15, 1974.

37. Wada, B. K., Garba, J. A., and Chen, J. C., "Development and Correlation: Viking Orbiter Analytical Dynamic Model with Modal Test," The Shock and Vibration Bulletin, Bullet in 44, Part 2, Naval Research Lahoratory, Washington, D. C., pp. 125-164, also published as JPL Technical Memorandum 33-690, June 1, 1974.

38. Gayman, W. H., "Fluid Dynamics Tests of the Viking Orbiter Propellant Tank Configuration," Project Document 900-711, Jet Propulsion Laboratory, Pasadena, California, July 1, 1975 (JPL internal document).

39. Chen, J. C., and Garba, J. A., "Determination of Propellant Effective Mass Properties Using Modal Test Data," The Shock and Vibration Bulletin, Bullet in 45, Part 3, Naval Research Laboratory, Washington, D. C., pp. 15-23.

40. Ugale, M., Volkert, K., and Fortenberry, J., Viking Orbiter 75 Test Report, Static Ult imate Type Approval Test, Jet Propuls ion Laboratory Project Document 611-117, Pasadena, California, October 11, 1974 (JPL internal document).

41. Fartenberry, J. and Brown lee, G., Viking Mars Lander 1975 Dynamic Test ivijel/Orb iter Developmental Test Model Forced Vibration Test: Summary Reprirt, Technical Memorandum 33-689, Jet Propulsion Laboratory, Pasadena, Calffornia, November 15, 1974.

42. Brownlee, G. R., Day, F. D., and Garba, J. A., "Analytical Prediction and Corrolation for the Orbiter During the Viking Spacecraft Sinusoidal Vibration Test," The Shock and Vibration Bulletin, Bulletin 45, Dart 3, Washington, D. C. June 1975, pp. 37-57.

43. Leondis, A., "Viking Dynamic Simulator - Vibration Testing and Analysis Method," The Shock and Vibration Bulletin, Bullet in 45, Part 3, Naval Research Laboratory, Washington, D. C., pp. 103-113.

44. Day, F. D., and Wada, B. K., "Unique Flight Instrumentation/Data Reduction Techniques Employed on the Viking Dynamic Simulator," The Shock and Vibration Bulletin, Bulletin 45, Part 3, Naval Research Laboratory, Wasilington, D. C., 1975, pp. 25-35. 
45. Day, F. D., and Wada, B. K., "Strain Gaged Struts and Data Reduction Techniques to Maximize Quality Data From Spacecraft Flight. Measurements," ? Ist International Instrumentation Procedures, Philadelphia, PA, 1975.

46. Trubert, M., and Eqwuatu, A., "Helios TC-2 Stage Zero Ignition Pulse Reconstruction for MJj 177 Load Analys is," Project Document 618-426, Jet Propulsion Laboratory, Pasadena, California, August 1976 (JPL internal document).

47. Garba, J. A., "Flight Data Obtained from Viking A During the Titan and Centaur Powered Flight," Project Document 611-126, Jet Propulsion Laboratory, Pasadena, California, Octoher 1975 (JPL internal document).

48. Garba, J. A., "Flight Data Obtained From Viking B During the Titan and Centaur Powered Flight," Project Document 611-128, Jet Propulsion Laboratory, Pasadena, California, November 1975 (JPL internal document).

49. Bamford, R., and Trubert, M. R., A Shock Spectra arid Impedance Method to Determine a Bound for Spacecraft Loads, Technical Memorandum No. 33-694, Jet Propuision Laboratory, Pasadena, California, September $1,197 i$.

50. Bamford, R. and Trubert, M. R., "A Shock Spectra and Impedance Miethod to Determine a Bound for Spacecraft Loads," AIAA paper No. 75-011, Denver,
Colo., May ?7-?9, 1975 .

51. Trubert, M., and Salama, M., A Generalizer! "ick Spectra Method for Spacecraft Loads Analys is, JPL Publicatic: $\frac{-2}{-2}$, Jet Propulsion Laboratory, Pasadena, California, March 15, 1979; to be published in AIAA Journal, Vol. 18, (Sept. 1980), and in the Journal of Spacecraft_and Rockets.

52. Chen, J. C. and Wada, B. K., "Matrix Perturbation for Structural Dynamic Analys is," AIAA Journal, Voi. 15, Aug. 1977, pp. 1095-1100.

53. Enen, J. C., Wada, B. K., and Garba, J. A., "Launch Vehicle Payload Interface Response," Journal of Spacecraft and Rockets, Vol. 15, No. 1, Jan-Feb 1373, pp. 7-11.

54. Wade, D. C., "Influence of Structural Dynamics on Space Shuttle Design," AIAA naper 77-436, AIAA/ASME 13th Structures, Structural Dynamics and Viaterials Conference, San Diego, Ca., March 21-23, 1977.

55. Chen, J. C., Garba, J. A. and Wada, B. K., "Estimation of Paylnad Loads Using Rigid-Body Interface Accelerations," Journal of Spacecraft and Rockets, Vol. 16, No. 2, March-April 1979, pp. 74-80.

56. Amos, A. K. and Goetz, R. C., "Research Needs in Aerospace Structural Dynamics," AIAA paper 79-0826, presented at the AIAA/ASME/ASCE/AHS 20 th Structures, Structural Dynamics, and Materials Conference, St. Louis, Mo.,
April 4-6, 1979 . 
57. Garba, J. A., Wada, B. K., Bamford, R. and Trubert, M. R., "Evaluation of a Cost-Effective Lnads Approach," Journal of Spacecraft and Rockets, Vol. 13, No. 11, Nov. 1976, pp. 675-683.

58. Chen, J. C., Garba, J. A. and Day, F. D., "Voyager Design and Flight Loads Comparison," Journal of Spacecraft and Rockets, Vol. 16, No. 1, Janmeb. 1979 , pp. $27-34$.

59. Chapman, J. M., "Technical Operating Report - Analytical Tool Descriptions - Structural Dynamics and Loads Methodology," Boeing Company Document D290-10228-7, April 27, 1979.

60. Payne, K. R., "An Impedance Technique for Determining Low Frequency Payload Environments," The Shock and Vibration Bulletin, No. 49, Sept. 1979, Part II, pp. 1-14.

61. Holland, W., "Methodology for Base Motion Response Analysis Using Incompatible Base Motion Excitation," Marshall Space Flight Center Internal Report; Feb. 1975.

62. Devers, A. D., Harcrow, H. and Kukreti, A. R., "Coupled Base Motion Response Analys is of Payload Structural Systems, " UCCE 75-2, Final Report, University of Colorado, April 1976.

63. Coal, -C. W. and White, M. R., "Modification of Flight Vehicle Vibration Modes to Account for Design Change, "presented at the 49 th Shock and Vibration Symposium, Washington, D. C., Oct. 17-19, 1978. 